\title{
Direct and Facile Synthesis of Acyl Isothiocyanates from Carboxylic Acids Using Trichloroisocyanuric Acid/Triphenylphosphine System
}

\author{
Najmeh Entezari, Batool Akhlaghinia, ${ }^{*}$ and Hamed Rouhi-Saadabad \\ Department of Chemistry, Faculty of Sciences, Ferdowsi University of Mashhad, Mashhad 9177948974, Iran
}

RECEIVED NOVEMBER 7, 2013; REVISED JUNE 3, 2014; ACCEPTED AUGUST 27, 2014

\begin{abstract}
A mild, efficient, and practical method for one-step synthesis of alkanoyl and aroyl isothiocyanates from carboxylic acids using a safe and inexpensive mixed reagent, trichloroisocyanuric acid/triphenylphosphine is described at room temperature. Availability of the reagents and easy workup of the reaction make this method attractive for organic chemists.
\end{abstract}

Keywords: acyl isothiocyanates, carboxylic acids, trichloroisocyanuric acid (TCCA), triphenylphosphine (TPP), potassium thiocyanate

\section{INTRODUCTION}

Acyl isothiocyanates have found wide application in the synthesis of various acyclic and heterocyclic compounds, including those possessing biological activity. ${ }^{1-3}$

The methods of preparation of isothiocyanates are limited. ${ }^{2}$ many methods have been described for the preparation of acyl isothiocyanates. ${ }^{4-14}$ which are mainly based on the reaction of acyl halides with thiocyanate ion. ${ }^{2,6}$ Acyl halides are not always easy to access or store. As acyl halides are highly sensitive to moisture and require care in handling, these methods need to anhydrous conditions and long reaction time. ${ }^{6}$ The reaction of carbonimidoyl dichloride with metal thiocyanate is also another reported method of preparation of acyl isothiocyanates, but the starting material is not easily available and the yield of the reaction is too low. ${ }^{15}$ There are few reports on the direct conversion of carboxylic acids to acyl isothiocyanates using acid activators such as $\mathrm{Ph}_{3} \mathrm{P}(\mathrm{SCN})_{2}$ (Ref. 16) and $\mathrm{PO}(\mathrm{NCS})_{3}$ (Ref. 17). Preparation of the reagents in these methods suffers from difficult procedures and the reactions take long time. Conversion of trialkylsilyl carboxylates to acyl isothiocyanates was also reported by using $\mathrm{Ph}_{3} \mathrm{P}(\mathrm{SCN})_{2}$ (Ref. 18). This methodology cannot be considered as a direct preparation of acyl isothiocyanates and also needs initial preparation of reagents.

By considering the activity of trichloroisocyanuric acid (TCCA) and $N$-chlorobenzotriazole (NCBT) towards triphenylphosphine, recently we reported direct preparation of acyl azides, esters, thioesters and sulfonyl azides from carboxylic acids and sulfonic acids under mild and neutral reaction conditions by using the above mentioned mixed reagents. ${ }^{19-21}$ Herein we wish to report a simplified, rapid and one-step method for the conversion of carboxylic acids to acyl isothiocyanates in the presence of TPP/TCCA as a mild, efficient and inexpensive reagent system at room temperature.

\section{EXPERIMENTAL}

\section{General}

The products were purified by column chromatography. The purity determinations of the products were accomplished by TLC on silica gel polygram STL G/UV 254 plates. The melting points of products were determined with an Electrothermal Type 9100 melting point apparatus. The FT-IR spectra were recorded on an Avatar 370 FT-IR Therma Nicolet spectrometer. The NMR spectra were provided on Brucker Avance 100 and 400 $\mathrm{MHz}$ instruments in $\mathrm{CDCl}_{3}$ and DMSO. Mass spectra were recorded with a $\mathrm{CH} 7 \mathrm{~A}$ Varianmat Bremem instrument at $70 \mathrm{eV}$; in $\mathrm{m} / \mathrm{z}$ (rel \%). Elemental analyses were performed using an Elementar, Vario EL III and Thermofinnigan Flash EA 1112 Series instrument. Most of the products were known compounds and characterized by the IR and comparison of their melting points with authentic samples. The structure of unknown products and some selected known products was further confirmed by ${ }^{1} \mathrm{H}$ NMR, ${ }^{13} \mathrm{C}$ NMR spectroscopy, mass spectrometry and elemental analysis.

\footnotetext{
* Author to whom correspondence should be addressed. (E-mail: akhlaghinia@um.ac.ir)
} 


\section{Preparation of Benzoyl Isothiocyanate from Benzoic Acid}

To a cold solution of triphenylphosphine $(0.262 \mathrm{~g}, 1 \mathrm{mmol})$ in toluene $(3 \mathrm{~mL})$, trichloroisocyanuric acid $(0.069 \mathrm{~g}$, $0.3 \mathrm{mmol}$ ) was added with continuous stirring. Benzoic acid $(0.097 \mathrm{~g}, 0.8 \mathrm{mmol})$ was added and stirring was continued for $15 \mathrm{~min}$. Potassium thiocyanate $(0.193 \mathrm{~g}$, $2 \mathrm{mmol}$ ) was added and the temperature was raised up to room temperature. Stirring was continued for $40 \mathrm{~min}$ at room temperature. The progress of the reaction was followed by TLC. Upon completion of the reaction, the concentrated residue passed through a short silicagel column using $n$-hexane / ethyl acetate mixture (vol. ratio: $60: 1$ ) as the eluent. Benzoyl isothiocyanate was obtained with $95 \%$ yield after removing the solvent under reduced pressure.

Benzoyl Isothiocyanate (Table 2, entry1)

Oil; $\mathrm{IR}^{22}$ (neat) $\bar{v}_{\max } / \mathrm{cm}^{-1}: 2964,2932,2876,1978$ $(\mathrm{N}=\mathrm{C}=\mathrm{S}), 1694(\mathrm{C}=\mathrm{O}), 1597,1451,1253,1239,1175$, 1083, 1067, 855, 693, 670, 648.

\section{4-Nitrobenzoyl Isothiocyanate (Table 2, entry2)}

Solid; m.p. 90-92 ${ }^{\circ} \mathrm{C}$ (Ref. 13) 92-93 ${ }^{\circ} \mathrm{C}$; IR (KBr) $\bar{v}_{\max } / \mathrm{cm}^{-1}: 3268,3096,3072,3039,1993(\mathrm{~N}=\mathrm{C}=\mathrm{S})$, 1956, $1690(\mathrm{C}=\mathrm{O}), 1601,1523,1346,1321,1270,1103$, 874, 839, 709, 669, 510; MS m/z: $206\left(\mathrm{M}^{+}, 5 \%\right) ; 149$ $\left(\mathrm{M}^{+}-\mathrm{NCS}, 72.5 \%\right) ; 121\left(\mathrm{M}^{+}-\mathrm{CONCS}, 7.5 \%\right) ; 75(\mathrm{Ph}$, $95 \%$; Anal. Calcd. mass fractions of elements, $\mathrm{w} / \%$, for $\mathrm{C}_{8} \mathrm{H}_{4} \mathrm{~N}_{2} \mathrm{O}_{3} \mathrm{~S}\left(M_{\mathrm{r}}=208.19\right)$ are: $\mathrm{C} 46.15, \mathrm{H} 1.94, \mathrm{~N} 13.46$, S 15.40; Found: C 46.36, H 1.66, N 14.08, S 16.05.

3-Nitrobenzoyl Isothiocyanate (Table 2, entry 3)

Solid; m.p. 94-95 ${ }^{\circ} \mathrm{C}$ (Ref. 23) $95-96{ }^{\circ} \mathrm{C}$; IR (KBr) $\bar{v}_{\max } / \mathrm{cm}^{-1}: 3370,3244,3092,3080,2929,2855,1991$ $(\mathrm{N}=\mathrm{C}=\mathrm{S}), 1723,1684(\mathrm{C}=\mathrm{O}), 1613,1537,1525,1351$, 1290, 1265, 1127, 927, 820, 709, 690; MS m/z: 206 $\left(\mathrm{M}^{+}, 15 \%\right) ; 149\left(\mathrm{M}^{+}-\mathrm{NCS}, 100 \%\right) ; 121\left(\mathrm{M}^{+}-\mathrm{CONCS}\right.$, $25 \%) ; 75$ (Ph, $80 \%)$; Anal. Calcd. mass fractions of elements, w/\%, for $\mathrm{C}_{8} \mathrm{H}_{4} \mathrm{~N}_{2} \mathrm{O}_{3} \mathrm{~S}\left(M_{\mathrm{r}}=208.19\right)$ are: C 46.15, H 1.94, N 13.46, S 15.40; Found: C 46.28, H 1.62, N 13.40, S 15.55 .

3,4-Dichlorobenzoyl Isothiocyanate (Table 2, entry 4) Oil; $\mathrm{IR}^{24}$ (neat) $\bar{v}_{\max } / \mathrm{cm}^{-1}: 3362,3166,3084,3060$, 2018, $1955(\mathrm{~N}=\mathrm{C}=\mathrm{S}), 1693(\mathrm{C}=\mathrm{O}), 1658,1583,1458$, 1383, 1266, 1232, 1106, 1030, 898, 837, 764, 734, 706, $681,547$.

2-Chlorobenzoyl Isothiocyanate (Table 2, entry 5) Oil; $\mathrm{IR}^{4}$ (neat) $\bar{v}_{\max } / \mathrm{cm}^{-1}: 3076,1981(\mathrm{~N}=\mathrm{C}=\mathrm{S}), 1948$, $1790(\mathrm{C}=\mathrm{O}), 1728,1691,1590,1473,1439,1319,1203$, 1132, 1077, 932, 997, 775, 742, 620, 477.

4-Chlorobenzoyl Isothiocyanate (Table 2, entry 6) Solid; m.p. $45-47{ }^{\circ} \mathrm{C}$ (Ref. 25) $46-47{ }^{\circ} \mathrm{C}$; IR (KBr) $\bar{v}_{\max } / \mathrm{cm}^{-1}: 3088,2961,2925,2851,1988(\mathrm{~N}=\mathrm{C}=\mathrm{S})$, 1927, $1692(\mathrm{C}=\mathrm{O}), 1590,1485,1400,1255,1171,1090$,
1012, 861, 840, 738, 666, 532; MS m/z: $197\left(\mathrm{M}^{+}, 2.5 \%\right)$; $138\left(\mathrm{M}^{+}-\mathrm{NCS}, 100 \%\right) ; 110\left(\mathrm{M}^{+}-\mathrm{CONCS}, 92.5 \%\right) ; 75$ (Ph, $95 \%)$.

4-Bromobenzoyl Isothiocyanate (Table 2, entry 7)

Solid; m.p. $53-55{ }^{\circ} \mathrm{C}$ (Ref. 26) $54-55{ }^{\circ} \mathrm{C}$; IR (KBr) $\bar{v}_{\max } / \mathrm{cm}^{-1}:$ 3088, 2197, 2039, $1985(\mathrm{~N}=\mathrm{C}=\mathrm{S}), 1687$ $(\mathrm{C}=\mathrm{O}), 1587,1482,1397,1269,1172,1100,1066$, 1010, 860, 837, 734, 665, 510, 459; ${ }^{1} \mathrm{H}$ NMR (400 $\mathrm{MHz}, \mathrm{CDCl}_{3}$ ) $\delta /$ ppm: 7.67 (d, 2H, $\left.J=8.8 \mathrm{~Hz}, \mathrm{ArH}\right)$, $7.94(\mathrm{~d}, 2 \mathrm{H}, J=8.8 \mathrm{~Hz}, \mathrm{ArH}) ;{ }^{13} \mathrm{C}$ NMR $(100 \mathrm{MHz}$, $\left.\mathrm{CDCl}_{3}\right) \delta / \mathrm{ppm}: 161.4(\underline{\mathrm{C}}=\mathrm{O}), 149.1(\mathrm{~N}=\underline{\mathrm{C}}=\mathrm{S}), 132.4$, $131.8,130.7,129.8,129.7$; $\mathrm{MS} m / z: 243\left(\mathrm{M}^{+}+2\right.$, $25 \%) ; 241\left(\mathrm{M}^{+}, 25 \%\right) ; 183\left(\mathrm{M}^{+}-\mathrm{NCS}, 100 \%\right) ; 155$ $\left(\mathrm{M}^{+}-\mathrm{CONCS}, 85 \%\right)$.

4-Methylbenzoyl Isothiocyanate (Table 2, entry 8) Oil; IR ${ }^{27}$ (neat) $\bar{v}_{\max } / \mathrm{cm}^{-1}: 3043,2986,2913,2847$, $1974(\mathrm{~N}=\mathrm{C}=\mathrm{S}), 1931,1696(\mathrm{C}=\mathrm{O}), 1607,1511,1446$, 1405, 1256, 1175, 1082, 861, 785, 747, 677, 597.

3,5-Dimethylbenzoyl Isothiocyanate (Table 2, entry 9) Oil; $\mathrm{IR}^{6}$ (neat) $\bar{v}_{\max } / \mathrm{cm}^{-1}: 3015,2925,2864,1973$ $(\mathrm{N}=\mathrm{C}=\mathrm{S}), 1697(\mathrm{C}=\mathrm{O}), 1606,1453,1379,1301,1182$, 1164, 1100, 937, 865, 762, 735, 669, 547, 449; ${ }^{1}$ HNMR $\left(400 \mathrm{MHz}, \mathrm{CDCl}_{3}\right) \delta / \mathrm{ppm}: 2.41\left(\mathrm{~s}, 6 \mathrm{H}, 2 \mathrm{CH}_{3}\right), 7.30(\mathrm{~d}$, $1 \mathrm{H}, J=10 \mathrm{~Hz}, \mathrm{ArH}), 7.69$ (s, 2H, ArH); ${ }^{13} \mathrm{C}$ NMR (100 $\left.\mathrm{MHz}, \mathrm{CDCl}_{3}\right) \delta / \mathrm{ppm}: 161.9(\underline{\mathrm{C}}=\mathrm{O}), 147.40(\mathrm{~N}=\underline{\mathrm{C}}=\mathrm{S})$, $138.8,138.3,136.9,136.2,133.7,130.7,128.3,126.2$, 125.2, 21.3, 21.2.

4-Methoxybenzoyl isothiocyanate (Table 2, entry 10) Oil; IR ${ }^{4}$ (neat) $\bar{v}_{\max } / \mathrm{cm}^{-1}: 2961,2932,2839,2160,1973$ $(\mathrm{N}=\mathrm{C}=\mathrm{S}), 1930,1690(\mathrm{C}=\mathrm{O}), 1603,1577,1506,1423$, 1330, 1250, 1164, 1085, 1023, 863, 785, 750, 681, 599.

4-(Isothiocyanatocarbonyl) phenyl acetate (Table 2, entry 11)

Oil; IR(neat) $\bar{v}_{\max } / \mathrm{cm}^{-1}: 2956,2916,2848,1981$ $(\mathrm{N}=\mathrm{C}=\mathrm{S}), 1936,1774(\mathrm{C}=\mathrm{O}), 1703,1598,1503,1417$, 1370, 1249, 1198, 1161, 1017, 910, 882, 850, 681, 645, 592; ${ }^{1} \mathrm{H}$ NMR (400 MHz, DMSO-d6) $\delta / \mathrm{ppm}: 2.26$ (s, $3 \mathrm{H}, \mathrm{Me}), 7.22$ (d, 2H, $J=8.4 \mathrm{~Hz}, \mathrm{ArH}), 7.95$ (d, 2H, $J=$ $8.4 \mathrm{~Hz}, \mathrm{ArH}) ;{ }^{13} \mathrm{C}$ NMR (100 MHz, DMSO-d6) $\delta / \mathrm{ppm}$ : $161.9(\mathrm{O}-\mathrm{C}=\mathrm{O}), 161.4(\mathrm{~N}-\mathrm{C}=\mathrm{O}), 148.2(\mathrm{~N}=\mathrm{C}=\mathrm{S}), 133.2$, 132.4, 132.2, 129.9, 22.3; MS m/z: $221\left(\mathrm{M}^{+}, 5 \%\right) ; 163$ $\left(\mathrm{M}^{+}-\mathrm{NCS}, 8 \%\right) ; 104$ (PhCO, $\left.100 \%\right)$; Anal. Calcd. mass fractions of elements, w/\%, for $\mathrm{C}_{10} \mathrm{H}_{7} \mathrm{NO}_{3} \mathrm{~S}\left(M_{\mathrm{r}}=\right.$ 221.23) are: C 54.29, H 3.19, N 6.33, S 14.49; Found: C 54.08, H 3.29, N 6.48, S 14.92.

4-Acetamidobenzoyl Isothiocyanate (Table 2, entry 12) Oil; IR ${ }^{28}$ (neat) $\bar{v}_{\max } / \mathrm{cm}^{-1}: 3460,3264,3182,3096$, 2953, 2921, 2851, $1989(\mathrm{~N}=\mathrm{C}=\mathrm{S}), 1697(\mathrm{C}=\mathrm{O}), 1594$, 1536, 1413, 1315, 1253, 1170, 1021, 955, 869, 751, 677.

Cinnamoyl Isothiocyanate (Table 2, entry 13)

Solid; m.p. $41-43{ }^{\circ} \mathrm{C}$ (Ref. 27) $40-43{ }^{\circ} \mathrm{C}$; IR (KBr) $\bar{v}_{\max } / \mathrm{cm}^{-1}:$ 3059, 3022, 2018, $1972(\mathrm{~N}=\mathrm{C}=\mathrm{S}), 1678$ 
$(\mathrm{C}=\mathrm{O}), 1624,1449,1263,1229,1200,764,657 ;{ }^{1} \mathrm{H}$ NMR $\left(100 \mathrm{MHz}, \mathrm{CDCl}_{3}\right) \delta / \mathrm{ppm}: 6.5(\mathrm{~d}, 1 \mathrm{H}, J=20 \mathrm{~Hz}$, $\mathrm{PhCH}=\mathrm{CHCO}), 7.31-7.65(\mathrm{~m}, 5 \mathrm{H}, \mathrm{ArH}), 7.8(\mathrm{~d}, 1 \mathrm{H}, J=$ $20 \mathrm{~Hz}, \mathrm{PhCH}=\mathrm{CHCO}) ; \mathrm{MS} \mathrm{m} / z: 189\left(\mathrm{M}^{+}, 5 \%\right) ; 130$ $\left(\mathrm{M}^{+}-\mathrm{NCS}, 100 \%\right) ; 102\left(\mathrm{M}^{+}-\mathrm{CONCS}, 92 \%\right) ; 77(\mathrm{Ph}$, $87.5 \%)$.

(E)-3-(3-Nitrophenyl) Acryloyl Isothiocyanate (Table 2, entry 14)

Solid; m.p. $118-119^{\circ} \mathrm{C}$ (Ref. 29) $116-119^{\circ} \mathrm{C}$; IR (KBr) $\bar{v}_{\max } / \mathrm{cm}^{-1}: 3080,3035,2022,1974(\mathrm{~N}=\mathrm{C}=\mathrm{S}), 1672$ $(\mathrm{C}=\mathrm{O}), 1634,1613,1536,1525,1474,1442,1353$, 1264, 1245, 1204, 980, 874, 824, 808, 737, 656, 592; ${ }^{1} \mathrm{H}$ NMR (400 MHz, $\left.\mathrm{CDCl}_{3}\right) \delta / \mathrm{ppm}: 6.65$ (d, 1H, $J=16$ $\mathrm{Hz}, \mathrm{PhCH}=\mathrm{CHCO}), 7.67(\mathrm{t}, 1 \mathrm{H}, J=8 \mathrm{~Hz}, \mathrm{ArH}), 7.83$ $(\mathrm{d}, 1 \mathrm{H}, J=16, \mathrm{PhCH}=\mathrm{CHCO}), 7.90(\mathrm{~d}, 1 \mathrm{H}, J=7.6 \mathrm{~Hz}$, ArH), 8.33 (dd, $1 \mathrm{H}, J=8.4 \mathrm{~Hz}, J=0.8 \mathrm{~Hz}, \mathrm{ArH}), 8.45$ (s, $1 \mathrm{H}, \mathrm{ArH}) ;{ }^{13} \mathrm{C} \mathrm{NMR}\left(100 \mathrm{MHz}, \mathrm{CDCl}_{3}\right) \delta / \mathrm{ppm}$ : $160.8(\underline{\mathrm{C}}=\mathrm{O}), 145.9 \quad(\mathrm{~N}=\mathrm{C}=\mathrm{S}), 135.1,134.1,130.3$, 125.7, 123.2; MS m/z: $233\left(\mathrm{M}^{+}, 3 \%\right) ; 175\left(\mathrm{M}^{+}-\mathrm{NCS}, 77\right.$ \%); $148\left(\mathrm{M}^{+}\right.$-CONCS, $\left.40 \%\right)$; $102(\mathrm{PhCH}=\mathrm{CH}, 85 \%)$.

(E)-3-(4-Chlorophenyl) Acryloyl Isothiocyanate (Table 2, entry 15)

Solid; m.p. $118-119^{\circ} \mathrm{C}$ (Ref. 30) $116-119^{\circ} \mathrm{C}$; IR (KBr) $\bar{v}_{\max } / \mathrm{cm}^{-1}:$ 3060, 3031, 2032, 1981( $\left.\mathrm{N}=\mathrm{C}=\mathrm{S}\right), 1677$ $(\mathrm{C}=\mathrm{O}), 1623$, 1589, 1495, 1406, 1262, 1244, 1203, 1090, 991, 821, 694, 632, 493; MS $m / z: 179\left(\mathrm{M}^{+}-\mathrm{C}=\mathrm{S}\right)$; $165\left(\mathrm{M}^{+}-\mathrm{NCS}, 92.5 \%\right), 137\left(\mathrm{M}^{+}-\mathrm{CONCS}, 22.5 \%\right)$, $111(\mathrm{PhCl}, 12.5 \%)$; Anal. Calcd. mass fractions of elements, $\mathrm{w} / \%$, for $\mathrm{C}_{10} \mathrm{H}_{6} \mathrm{ClNOS}\left(M_{\mathrm{r}}=223.68\right)$ are: C 53.70, H 2.70, N 6.26, S 14.34; Found: C 53.65, H 2.95, N 6.25, S 14.29.

2-Phenylacetyl Isothiocyanate (Table 2, entry 16) Oil; $\mathrm{IR}^{31}$ (neat) $\bar{v}_{\max } / \mathrm{cm}^{-1}: 3358,3182,3064,3031$, 2925, 2859, $1966(\mathrm{~N}=\mathrm{C}=\mathrm{S}), 1716(\mathrm{C}=\mathrm{O}), 1646,1499$, 1217, 1104, 1025, 713, 694, 522.

2, 2-Diphenylacetyl Isothiocyanate (Table 2, entry 17) Oil; $\mathrm{IR}^{6}$ (neat) $\bar{v}_{\max } / \mathrm{cm}^{-1}: 3088,3060,3031,1966$ $(\mathrm{N}=\mathrm{C}=\mathrm{S}), 1721(\mathrm{C}=\mathrm{O}), 1495,1453,1180,1121,984$, 792, 742, 698, 617 .

2-(4-Methoxyphenyl) Acetyl Isothiocyanate (Table 2, entry 18)

Oil; IR ${ }^{6}$ (neat) $\bar{v}_{\max } / \mathrm{cm}^{-1}: 3031,2956,2931,2839,1979$ $(\mathrm{N}=\mathrm{C}=\mathrm{S}), 1731(\mathrm{C}=\mathrm{O}), 1612,1513,1463,1301,1250$, 1178, 1118, 1033, 959, 816, 784, 522.

2-(2,4-Dichlorophenoxy) Ethanoyl Isothiocyanate (Table 2, entry 19)

Oil; IR(neat) $\bar{v}_{\max } / \mathrm{cm}^{-1}: \quad 3072,2978,2892,1956$ $(\mathrm{N}=\mathrm{C}=\mathrm{S}), 1731(\mathrm{C}=\mathrm{O}), 1589,1477,1311,1234,1090$, 910, 796, 718, 641; ${ }^{1} \mathrm{H}$ NMR (400 MHz, $\left.\mathrm{CDCl}_{3}\right)$ $\delta /$ ppm: 2.35 (s, 2H, $\left.\mathrm{CH}_{2}\right), 8.15-8.17$ (m, 3H, ArH) $;{ }^{13} \mathrm{C}$ NMR (100 MHz, $\left.\mathrm{CDCl}_{3}\right) \delta /$ ppm: $162.5(\underline{\mathrm{C}}=\mathrm{O}), 154.1$ $(\mathrm{N}=\underline{\mathrm{C}}=\mathrm{S}), 136.4,131.8,131.2,128.5,121.5,115.2$,
21.1; $\mathrm{MS} m / z$ : $264\left(\mathrm{M}^{+}+4,5 \%\right) ; 262\left(\mathrm{M}^{+}+2,10 \%\right)$, $260\left(\mathrm{M}^{+}, 18 \%\right) ; 174\left(\mathrm{M}^{+}-\mathrm{CONCS}, 10 \%\right) 147\left(\mathrm{PhCl}_{2}\right.$, $100 \%$ ). 91 (PhO, $98 \%)$; Anal. Calcd. mass fractions of elements, w/\%, for $\mathrm{C}_{9} \mathrm{H}_{5} \mathrm{Cl}_{2} \mathrm{NO}_{2} \mathrm{~S}\left(M_{\mathrm{r}}=262.11\right)$ are: $\mathrm{C} 41.24, \mathrm{H}$ 1.92, N 5.34, S 12.23; Found: C 41.38, H 1.81, N 5.43, S 12.34.

Stearoyl Isothiocyanate (Table 2, entry 20)

Oil; $\mathrm{IR}^{17}$ (neat) $\bar{v}_{\max } / \mathrm{cm}^{-1}: 3053,2926,2854,2684$, 2304, $1974(\mathrm{~N}=\mathrm{C}=\mathrm{S}), 1731(\mathrm{C}=\mathrm{O}), 1466,1264,1106$, $894,746,705$.

\section{RESULTS AND DISCUSSION}

In this article we report a more simplified one-step method for the conversion of carboxylic acids to acyl isothiocyanates (Scheme 1).

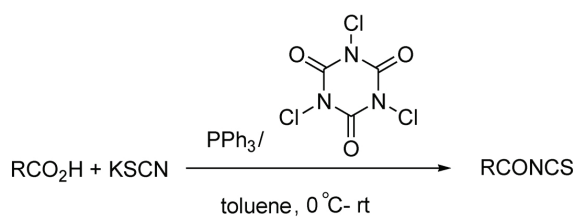

$\mathrm{R}=\mathrm{C}_{6} \mathrm{H}_{5}, 4-\mathrm{NO}_{2} \mathrm{C}_{6} \mathrm{H} 4,3-\mathrm{NO}_{2} \mathrm{C}_{6} \mathrm{H}_{4}, 3,4-\mathrm{Cl}_{2} \mathrm{C}_{6} \mathrm{H}_{3}, 2-\mathrm{ClC}_{6} \mathrm{H}_{4}, 4-\mathrm{ClC}_{6} \mathrm{H}_{4}, 4-\mathrm{BrC}_{6} \mathrm{H}_{4}$ $4-\mathrm{CH}_{3} \mathrm{C}_{6} \mathrm{H}_{4}, 3,5-\left(\mathrm{CH}_{3}\right)_{2} \mathrm{C}_{6} \mathrm{H}_{3}, \quad 4-\mathrm{CH}_{3} \mathrm{OC}_{6} \mathrm{H}_{4}, \mathrm{CH}_{3} \mathrm{CONHC}_{6} \mathrm{H}_{4}, \mathrm{C}_{6} \mathrm{H}_{5} \mathrm{CH}=\mathrm{CH}$, 3- $\mathrm{NO}_{2} \mathrm{C}_{6} \mathrm{H}_{4} \mathrm{CH}=\mathrm{CH}, 4-\mathrm{ClC}_{6} \mathrm{H}_{4} \mathrm{CH}=\mathrm{CH}, \mathrm{C}_{6} \mathrm{H}_{5} \mathrm{CH}_{2},\left(\mathrm{C}_{6} \mathrm{H}_{5}\right)_{2} \mathrm{CH}, 4-\mathrm{CH}_{3} \mathrm{OC}_{6} \mathrm{H}_{4} \mathrm{CH}_{2}$, $\mathrm{CH}_{3}\left(\mathrm{CH}_{2}\right)_{15} \mathrm{CH}_{2}$

Scheme 1.

The optimization of the reaction conditions was carried out for the direct preparation of benzoyl isothiocyanate from benzoic acid in the presence of TPP/ TCCA system at room temperature in different solvents and by using various molar ratios of TPP/TCCA/ $\mathrm{RCO}_{2} \mathrm{H} / \mathrm{KSCN}$ in order to achieve the maximum chemical yield at the lowest reaction time.

The representative results are shown in Table 1 . There is not any tendency between benzoic acid and thiocyanate ion to react in the absence of TCCA and TPP (Table 1, entries 1-3). Benzoic acid was converted to benzoyl isothiocyanate completely by applying $1 / 1 / 1 / 1$ molar ratio of TPP/TCCA/ $\mathrm{RCO}_{2} \mathrm{H} / \mathrm{KSCN}$ in $\mathrm{CH}_{3} \mathrm{CN}$ (Table 1, entry 4). Increasing the molar ratio of $\mathrm{KSCN}$ reduces the reaction time considerably (Table 1, entries 5-7). The lower reaction time was obtained when the reaction was carried out by using $1 / 1 / 0.8 / 2.5$ molar ratio of $\mathrm{TPP} / \mathrm{TCCA} / \mathrm{RCO}_{2} \mathrm{H} / \mathrm{KSCN}$ (Table 1, entries 8). Surprisingly, there is no any difference between the rate of reaction in $\mathrm{CH}_{3} \mathrm{CN}$ and $\mathrm{CH}_{2} \mathrm{Cl}_{2}$ by applying the same reaction conditions (Table 1, compare entry 8 and 9). Because of economic consideration $\mathrm{CH}_{2} \mathrm{Cl}_{2}$ was chosen for further experiments. In $\mathrm{CH}_{2} \mathrm{Cl}_{2}$, increasing the molar ratio of $\mathrm{KSCN}$ has not any influence on the reaction time (Table1, entry 10). As one equivalent of TCCA (contains three $\mathrm{N}-\mathrm{Cl}$ bonds) can react with 3 equivalents of TPP, using the lower ratios 
of TCCA has not any effect on the reaction rate (Table 1, entries 11-12). Replacement of KSCN by $\mathrm{NH}_{4} \mathrm{SCN}$ in optimized reaction conditions produces benzoyl isothiocyanate in longer reaction time (Table 1, entry 13). The optimized molar ratio of TPP/TCCA/ $\mathrm{RCO}_{2} \mathrm{H} / \mathrm{KSCN}(1 / 0.3 / 0.8 / 2.5)$ was examined in other solvents such as THF, $\mathrm{CHCl}_{3}, 1,4$-dioxane, acetone, toluene and hexane (Table 1, entries 14-19). Best result was obtained when the optimized reaction conditions were applied in toluene (Table 1, entry 14), but in other solvents the desired product was produced in longer reaction time. Complete conversion of benzoic acid was obtained in $40 \mathrm{~min}$ when the isothiocyanation reaction was examined in toluene by using $1 / 0.3 / 0.8 / 2$ molar ratio of TPP/TCCA/ $/ \mathrm{RCO}_{2} \mathrm{H} / \mathrm{KSCN}$ (Table 1 , entry 20 ).

By using the optimized reaction conditions ( $1 / 0.3 /$ $0.8 / 2$ molar ratio of TPP/TCCA/ $\mathrm{RCO}_{2} \mathrm{H} / \mathrm{KSCN}$ in toluene) different structurally acyl isothiocyanates were obtained from different carboxylic acids (aromatic and aliphatic) at room temperature in high yields (80-95\%). The representative data are shown in Table 2. Electronwithdrawing substituents on aromatic rings accelerate the reactions of aromatic carboxylic acids with TPP/ TCCA/KSCN system (Table 2, entries 2-7). The reac-

Table 1. Conversion of benzoic acid to benzoyl isothiocyanate by using TPP/TCCA/KSCN system under different reaction conditions

\begin{tabular}{|c|c|c|c|c|}
\hline Entry & Solvent & $\begin{array}{c}\text { Molar Ratio } \\
\text { TPP / TCCA/ } \\
\mathrm{RCO}_{2} \mathrm{H} / \mathrm{KSCN}\end{array}$ & Time $/ \mathrm{h}$ & $\begin{array}{c}\text { Conversion } \\
\%\end{array}$ \\
\hline 1 & $\mathrm{CH}_{3} \mathrm{CN}$ & $0 / 0 / 1 / 1$ & 5 & 0 \\
\hline 2 & $\mathrm{CH}_{3} \mathrm{CN}$ & $1 / 0 / 1 / 1$ & 5 & 0 \\
\hline 3 & $\mathrm{CH}_{3} \mathrm{CN}$ & $0 / 1 / 1 / 1$ & 5 & 0 \\
\hline 4 & $\mathrm{CH}_{3} \mathrm{CN}$ & $1 / 1 / 1 / 1$ & 18 & 100 \\
\hline 5 & $\mathrm{CH}_{3} \mathrm{CN}$ & $1 / 1 / 1 / 1.5$ & 12 & 100 \\
\hline 6 & $\mathrm{CH}_{3} \mathrm{CN}$ & $1 / 1 / 1 / 2$ & 4 & 100 \\
\hline 7 & $\mathrm{CH}_{3} \mathrm{CN}$ & $1 / 1 / 1 / 2.5$ & 2 & 100 \\
\hline 8 & $\mathrm{CH}_{3} \mathrm{CN}$ & $1 / 1 / 0.8 / 2.5$ & $55 \mathrm{~min}$ & 100 \\
\hline 9 & $\mathrm{CH}_{2} \mathrm{Cl}_{2}$ & $1 / 1 / 0.8 / 2.5$ & $55 \mathrm{~min}$ & 100 \\
\hline 10 & $\mathrm{CH}_{2} \mathrm{Cl}_{2}$ & $1 / 1 / 0.8 / 3$ & $55 \mathrm{~min}$ & 100 \\
\hline 11 & $\mathrm{CH}_{2} \mathrm{Cl}_{2}$ & $1 / 0.5 / 0.8 / 2.5$ & $55 \mathrm{~min}$ & 100 \\
\hline 12 & $\mathrm{CH}_{2} \mathrm{Cl}_{2}$ & $1 / 0.3 / 0.8 / 2.5$ & $55 \mathrm{~min}$ & 100 \\
\hline $13^{(\mathrm{a})}$ & $\mathrm{CH}_{2} \mathrm{Cl}_{2}$ & $1 / 0.3 / 0.8 / 2.5$ & 2 & 100 \\
\hline 14 & toluene & $1 / 0.3 / 0.8 / 2.5$ & $40 \mathrm{~min}$ & 100 \\
\hline 15 & THF & $1 / 0.3 / 0.8 / 2.5$ & 6 & 100 \\
\hline 16 & $\mathrm{CHCl}_{3}$ & $1 / 0.3 / 0.8 / 2.5$ & 7 & 100 \\
\hline 17 & 1,4-dioxane & $1 / 0.3 / 0.8 / 2.5$ & 1.5 & 100 \\
\hline 18 & acetone & $1 / 0.3 / 0.8 / 2.5$ & 1.5 & 100 \\
\hline 19 & hexane & $1 / 0.3 / 0.8 / 2.5$ & 24 & 70 \\
\hline 20 & toluene & $1 / 0.3 / 0.8 / 2$ & $40 \mathrm{~min}$ & 100 \\
\hline
\end{tabular}

(a) $\mathrm{KSCN}$ was replaced by $\mathrm{NH}_{4} \mathrm{SCN}$. tion of aromatic carboxylic acids bearing electrondonating substituents, with TPP/TCCA/KSCN system was completed in longer reaction time (50-90 $\mathrm{min}$ ) than the above mentioned acids (e.g. compare entries 2-7 with 8-12). This novel direct isothiocyanation method can be applied efficiently for the conversion of cinnamic acid, substituted cinnamic acids and aliphatic carboxylic acids to the corresponding acyl isothiocyanates (Table 2 , entries 13-20). The isothiocyanation of aliphatic carboxylic acids was completed in longer reaction time than the aromatic carboxylic acids. According to the results obtained from Table 2, we can conclude that electronic effects of substituents on aromatic rings have an essential influence on the reaction rate of isothiocyanation.

The results of Table 2, demonstrate that TPP/ TCCA/KSCN system was found to be compatible with different functional groups and isothiocyanation proceeded smoothly with carboxylic acids bearing electron withdrawing as well as electron donating substituents. Also, carboxylic acids with sensitive functional groups such as alkyl, ether, amide and ester wherein the previously described protocols would not work, can be converted efficiently to corresponding acyl isothiocyanates (Table 2, entries 8, 9, 10, 11, 12, 18, 19, 20).

In our experiments, the completion of the reaction was confirmed by the disappearance of the carboxylic acid on TLC followed by the disappearance of $\mathrm{OH}$ stretching frequency at $3400-2400 \mathrm{~cm}^{-1}$ in FTIR spectra. Also absorption bands at 2150-1800 and 1780-1620 $\mathrm{cm}^{-1}$ due to $\mathrm{N}=\mathrm{C}=\mathrm{S}$ and carbonyl group of acyl isothiocyanate in FTIR spectra confirmed product formation. In ${ }^{13} \mathrm{C}$ NMR a signal at $162.5-160.8$ and 154.1-145.9 ppm is assigned to the quaternary carbonyl and $-\mathrm{N}=\underline{\mathrm{C}}=\mathrm{S}$ carbon.

Acyl isothiocyanates (Table 2) are pale yellow oil or crystalline substances. They were characterized by IR spectroscopy and comparison of their melting points with the known compounds. The structures of selected products were further confirmed by ${ }^{1} \mathrm{H},{ }^{13} \mathrm{C}$ NMR spectroscopy and mass spectrometry.

The proposed mechanism of isothiocyanation of carboxylic acid by using TPP/TCCA/KSCN system was shown in Scheme 2.

The initial nucleophilic attack of TPP at the halogen of TCCA affords the halogen-phosphonium salt (I). The reaction of I with carboxylic acid yields II and $[1,3,5]$ triazine-2,4,6-triol (III), which is in equilibrium with [1,3,5]triazinane-2,4,6-trione (IV; Scheme 2). A rapid reaction of II with potassium thiocyanate yields triphenylphosphine oxide and the corresponding acyl isothiocyanate (at room temperature).

On the basis of the results obtained from Table 2 and proposed mechanism in Scheme 2, II was formed in the rate determining step of the thiocyanation reaction. 
Table 2. Synthesis of different structurally acyl isothiocyanates by using TPP/TCCA/ $\mathrm{RCO}_{2} \mathrm{H} / \mathrm{KSCN}$ system.

(s)

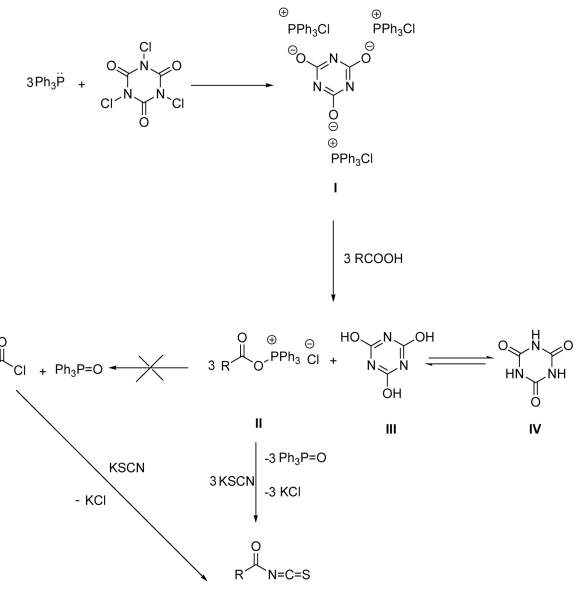

Scheme 2.

Formation of II was accelerated with electron-withdrawing substituents on the aromatic rings (e.g. compare entries 1 with 2 ). In the other words, electronwithdrawing substituents increase the activity of carboxyl functional groups towards nucleophiles, which leads to an easier formation of II. Benzoic acid is converted to benzoyl isothiocyanate more slowly than $p$-nitro benzoic acid and faster than $p$-methyl benzoic acid and $p$-methoxy benzoic acid respectively.

\section{CONCLUSION}

We have demonstrated a facile, new, inexpensive, and convenient procedure for one-pot conversion of aliphatic and aromatic carboxylic acids to their corresponding alkanoyl and aroyl isothiocyanates under neutral condition. The excellent yields, short reaction time, and mild reaction conditions make this procedure a useful and attractive alternative to the currently available methods of preparation of acyl isothiocyanates. In contrast to the reported methods the present protocol avoids the use of toxic and corrosive reagents. All reagents in the present method (TPP, TCCA and KSCN) are highly stable and commercially available.

Acknowledgements. The authors gratefully acknowledge the partial support of this study by Ferdowsi University of Mashhad Research Council (Grant no. p/3/24168).

\section{REFERENCES}

1. A. E. Dixon and J. Taylor, J. Chem. Soc., Trans. 93 (1908) 684-700.

2. A. K. Mukerjee and R. Ashare, Chem. Rev. 91 (1991) 1-24.

3. A. J. Pearson and W. J. Roush, Activating Agents and Protecting Groups, $1^{\text {st }}$ edn., Wiley, New York, 1999.

4. W. P. Reeves, A. Jr. Simmons, J. A. Rudis, and T. C. Bothwell, Synth. Commun. 11 (1981) 781-785.

5. G. Cainelli, and F. Manescalchi, Synthesis 2 (1979) 141-144.

6. P. A. S. Smith, and R. O. Kan, J. Org. Chem. 29 (1964) 2261-2265. 
7. M. Lipp, F. Dallacker, and G. Koenen, Chem. Ber. 91 (1958) 1660-1664.

8. Zh. M. Ivanova, N. A. Kirsanova, and C. I. Derkach, Zh. Org. Khim. 1 (1965) 2186.

9. W. P. Reeves, A. Jr. Simmons, and K. Keller, Synth. Commun. 10 (1980) 633-636

10. W. Taibao, and Ch. Jichou, NONGYAO 34 (1995) 12.

11. A. J. Speziale, L. R. Smith, and J. E. Fedder, J. Org. Chem. 30 (1965) 4306-4307.

12. A. J. Speziale and L. R. Smith, Org. Synth. 46 (1966) 16-17.

13. K. A. Nuridzhanyan, Russ. Chem. Rev. 39 (1970) 130-139.

14. M. Z. Deng, p. Caubere, J. P. Senet, S. Lecolier, Tetrahedron 44 (1988) 6079-6086.

15. S. Tanaka, S. Uemura, and M. Okano, Bull. Chem. Soc. Jpn. 50 (1977) $722-725$.

16. Y. Tamura, T. Kawasaki, M. Tanio, M. Adachi, and Y. Kita, Tetrahedron Lett. 18 (1977) 4417-4420.

17. L. Kniezo, and J. Bernat, Synth. Commun. 20 (1990) 509-513.

18. N. Iranpoor, H. Firouzabadi, and H. R. Shaterian, Synth. Commun. 32 (2002) 3653-3657.

19. H. Rouhi-Saadabad, and B. Akhlaghinia, J. Braz. Chem. Soc. 25 (2014) 253-263.
20. B. Akhlaghinia, and H. Rouhi-Saadabad, Can. J. Chem. 91 (2013) 181-185.

21. A. Kiani, B. Akhlaghinia, H. Rouhi-Saadabad, and M. Bakavoli, J. Sulfur Chem. 35 (2014) 119-127.

22. A. Gaber, M. Aly, and A. Atalla, Collect. Czech. Chem. Commun. 56 (1991) 2183-2187.

23. W. M. Bruce, J. Am. Chem. Soc. 26 (1904) 449-464.

24. C. Christpphersen, Acta Chem. Scand. 25 (1971) 1160-1162.

25. P. Kristlan, O. Hritzova, and P. Talan, Collect. Czech. Chem. Commun. 42 (1977) 671-677.

26. M. N. Basyouni, and A. M. El-Khamry, Bull. Chem. Soc. Jpn. 52 (1979) 3728-3732.

27. J. Imrich, P. Kristian, D. Podhradsky, and M. Dzurill, Collect. Czech. Chem. Commun. 45 (1980) 2334-2342.

28. L. Poitout, V. Brault, C. Sacku, P. Roubert, and P. Plas, United States Patent Application 00565179 A1, 2005.03.24.

29. M. Dzurilla, P. Kristian, and P. Kutschy, Chem. Zvesti. 23 (1969) 173-180.

30. M. Dzurilla, and P. Kristian, Collect. Czech. Chem. Commun. 41 (1976) 1388-1395.

31. H. Ogura, H. Takahashi, and K. Takeda, Chem. Pharm. Bull. 29 (1981) 1832-1837. 


\title{
Supplementary data
}

\section{Direct and facile synthesis of acyl isothiocyanates from carboxylic acids using trichloroisocyanuric acid/triphenylphosphine system}

\author{
Najmeh Entezari, Batool Akhlaghinia*, Hamed Rouhi-Saadabad \\ Department of Chemistry, Faculty of Sciences, Ferdowsi University of Mashhad, Mashhad \\ 9177948974, Iran
}

\section{General}

The products were purified by column chromatography. The purity determinations of the products were accomplished by TLC on silica gel polygram STL G/UV 254 plates. The melting points of products were determined with an Electrothermal Type 9100 melting point apparatus. The FT-IR spectra were recorded on an Avatar 370 FT-IR Therma Nicolet spectrometer. The NMR spectra were provided on Brucker Avance 100 and $400 \mathrm{MHz}$ instruments in $\mathrm{CDCl}_{3}$ and DMSO. Mass spectra were recorded with a CH7A Varianmat Bremem instrument at $70 \mathrm{eV}$; in $\mathrm{m} / \mathrm{z}$ (rel \%). Elemental analyses were performed using an Elementar, Vario EL III and Thermofinnigan Flash EA 1112 Series instrument. Most of the products were known compounds and characterized by the IR and comparison of their melting points with authentic samples. The structure of unknown products and some selected known products was further confirmed by ${ }^{1} \mathrm{H}$ NMR, ${ }^{13} \mathrm{CNMR}$ spectroscopy, mass spectrometry and elemental analysis. 


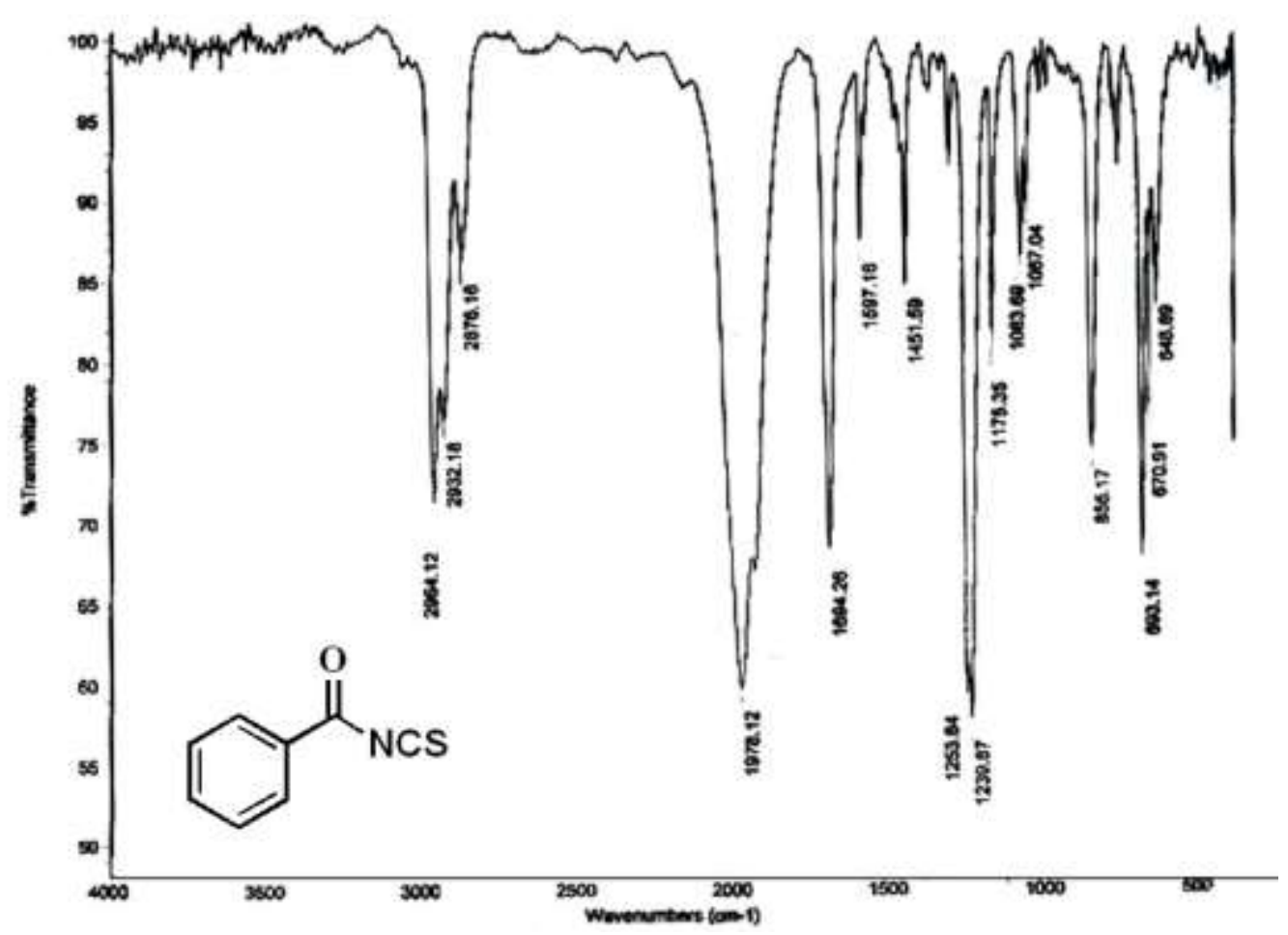

Figure S1-A: FT-IR (neat) spectrum of benzoyl isothiocyanate (Table 2, entry1)

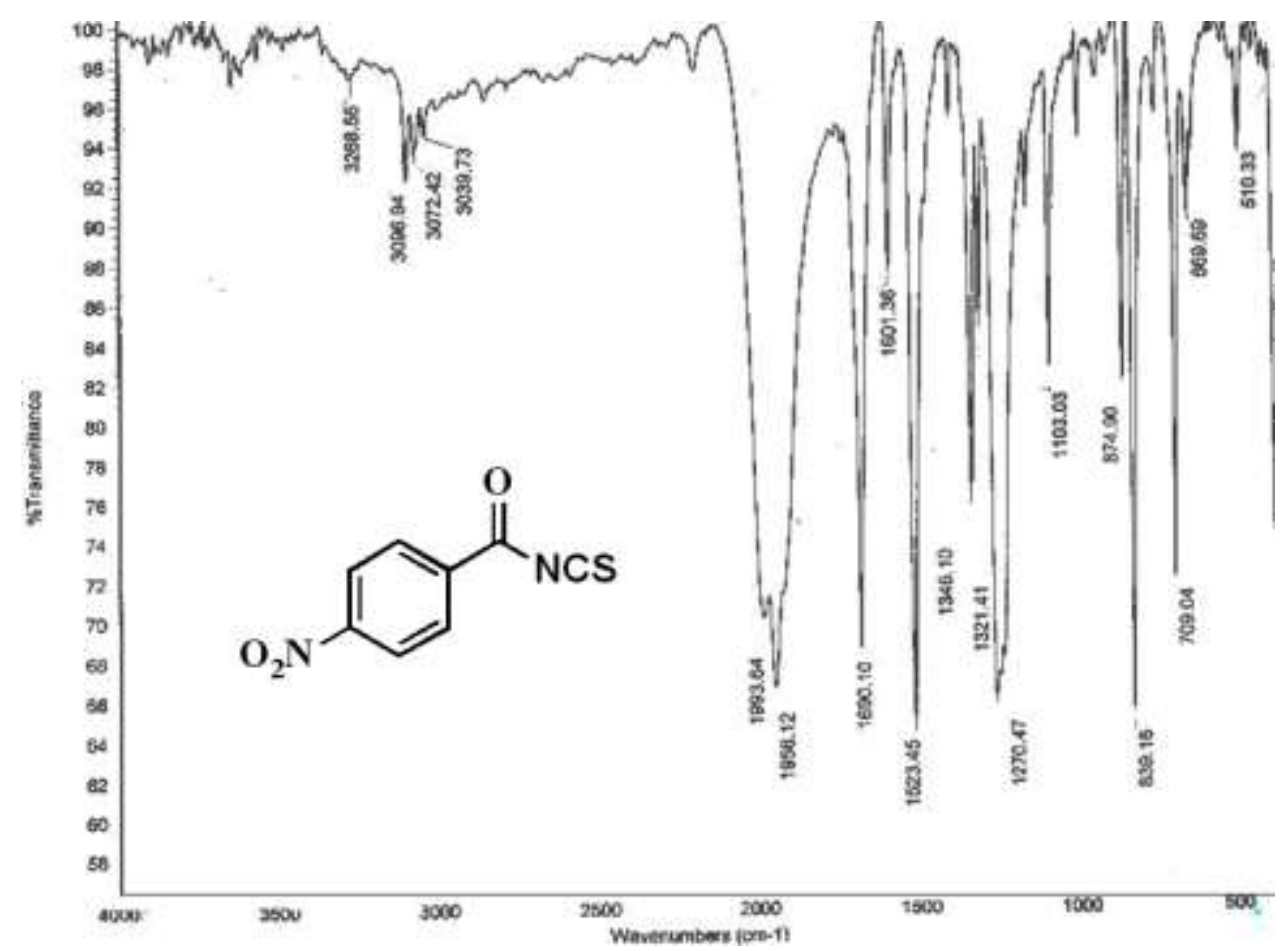

Figure S2-A: FT-IR (KBr) spectrum of 4-nitrobenzoyl isothiocyanate (Table 2, entry 2) 


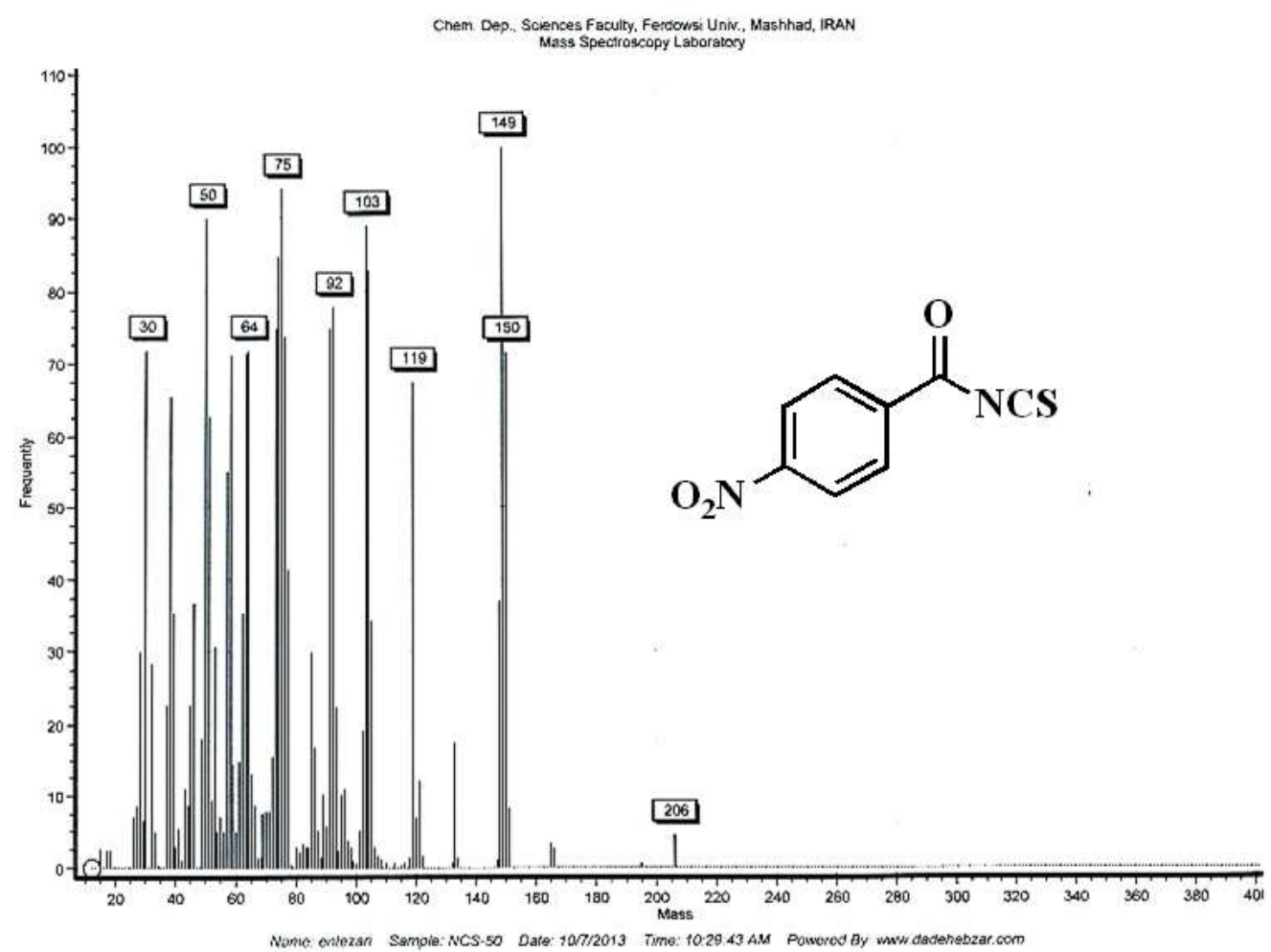

Figure S2-B: Mass spectrum of 4-nitrobenzoyl isothiocyanate (Table 2, entry 2)

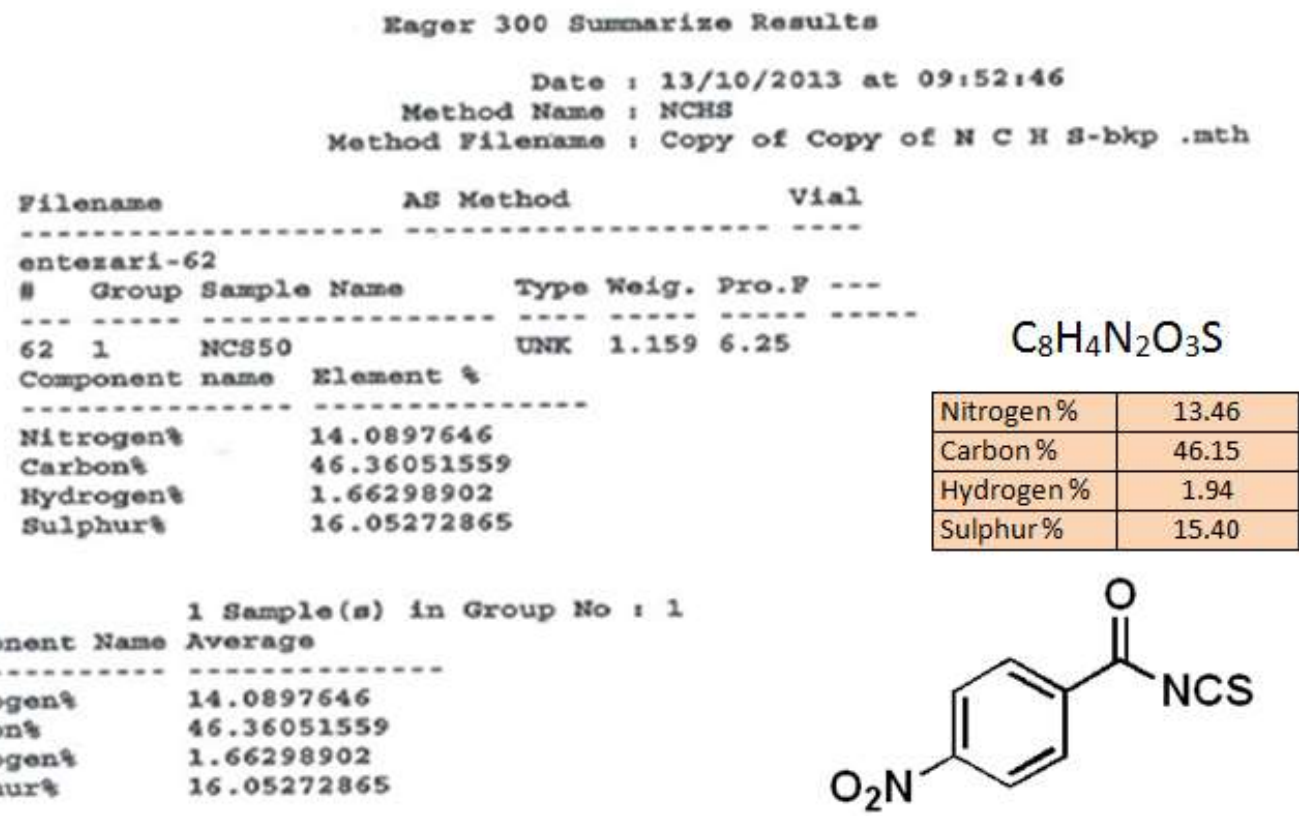

Figure S2-C: Elemental analysis data of 4-nitrobenzoyl isothiocyanate (Table 2, entry 2) 


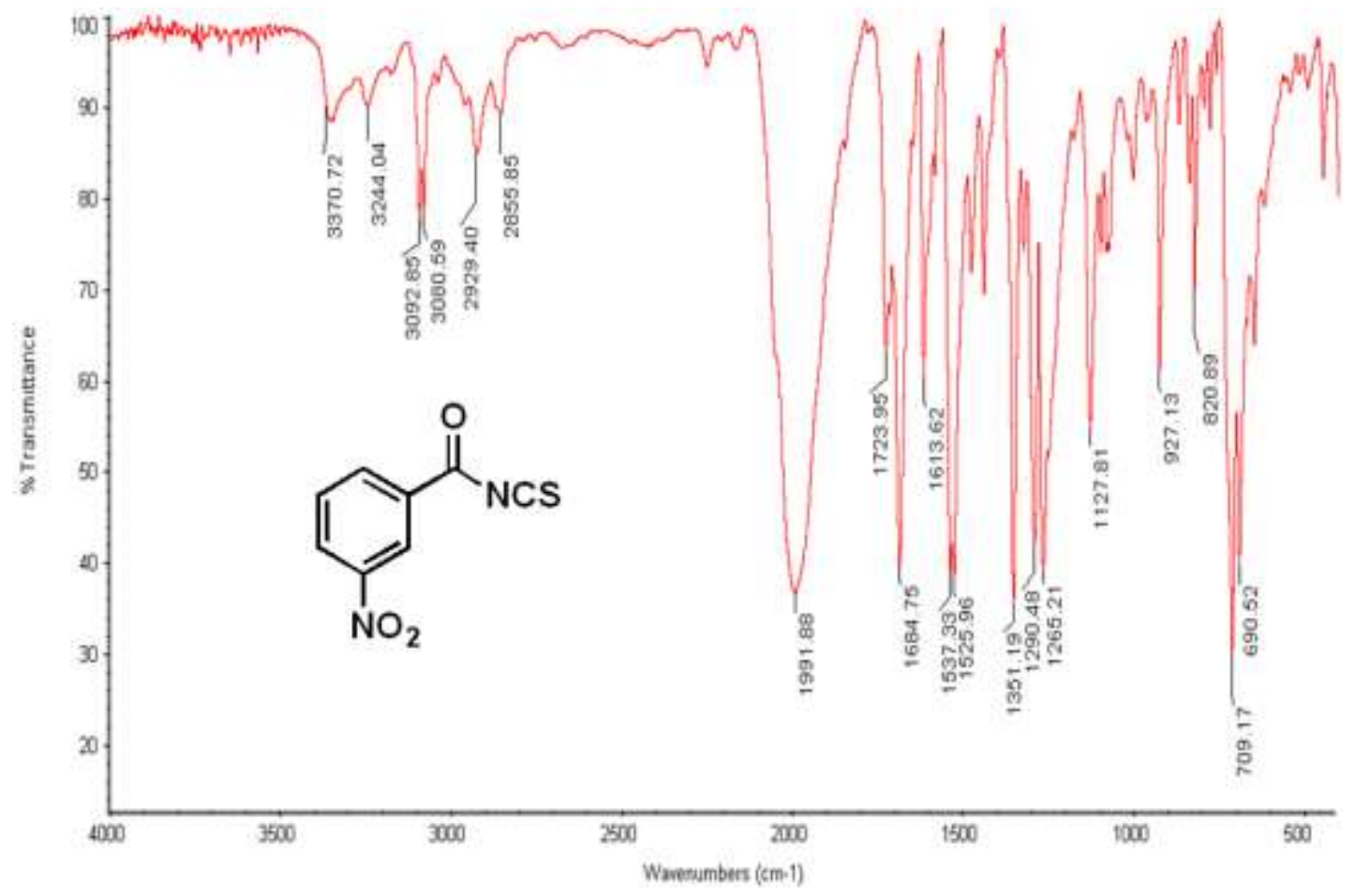

Figure S3-A: FT-IR (KBr) spectrum of 3-nitrobenzoyl isothiocyanate (Table 2, entry 3)

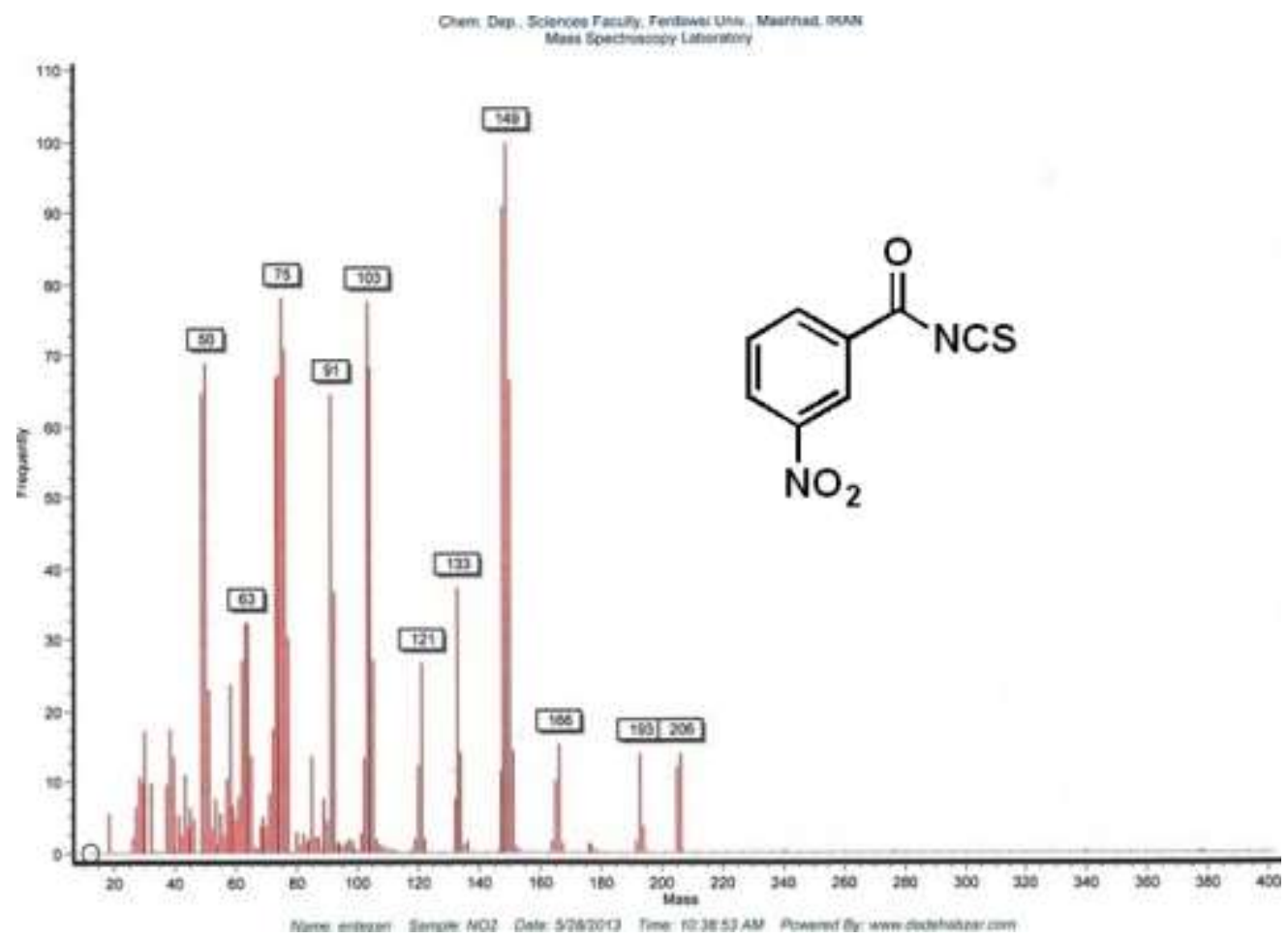

Figure S3-B: Mass spectrum of 3-nitrobenzoyl isothiocyanate (Table 2, entry 3) 
rager 300 sumar1zo Rosulto

Date : 03/11/2013 at 09:14:51

Method Name : NCHS

Nethod pilename : Copy of Copy of $\mathrm{N}$ C $\mathrm{B}$ s-bkp .mth

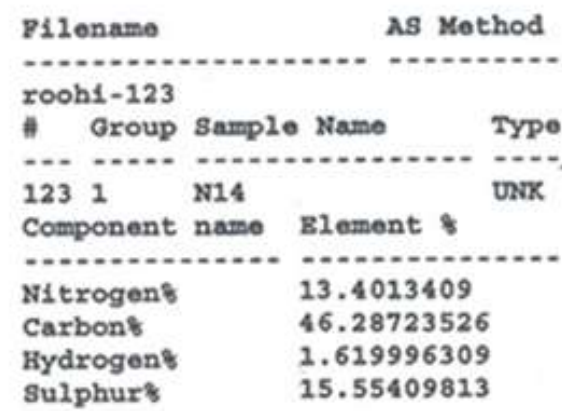

V1a1

Yype Weig. Pro.P

.........

$\mathrm{C}_{8} \mathrm{H}_{4} \mathrm{~N}_{2} \mathrm{O}_{3} \mathrm{~S}$

\begin{tabular}{|l|c|}
\hline Nitrogen \% & 13.46 \\
\hline Carbon \% & 46.15 \\
\hline Hydrogen \% & 1.94 \\
\hline Sulphur \% & 15.40 \\
\hline
\end{tabular}

1 Sample(s) in Group No : 1

Componenv Name Average

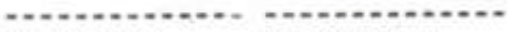

Nitrogens $\quad 13.4013409$

Carbons $\quad 46.28723526$

Hydrogent $\quad 1.619996309$

Sulphurs $\quad 15.55409813$<smiles>CN(S)C(=O)c1cccc([N+](=O)[O-])c1</smiles>

Figure S3-C: Elemental analysis data of 3-nitrobenzoyl isothiocyanate (Table 2, entry 3)

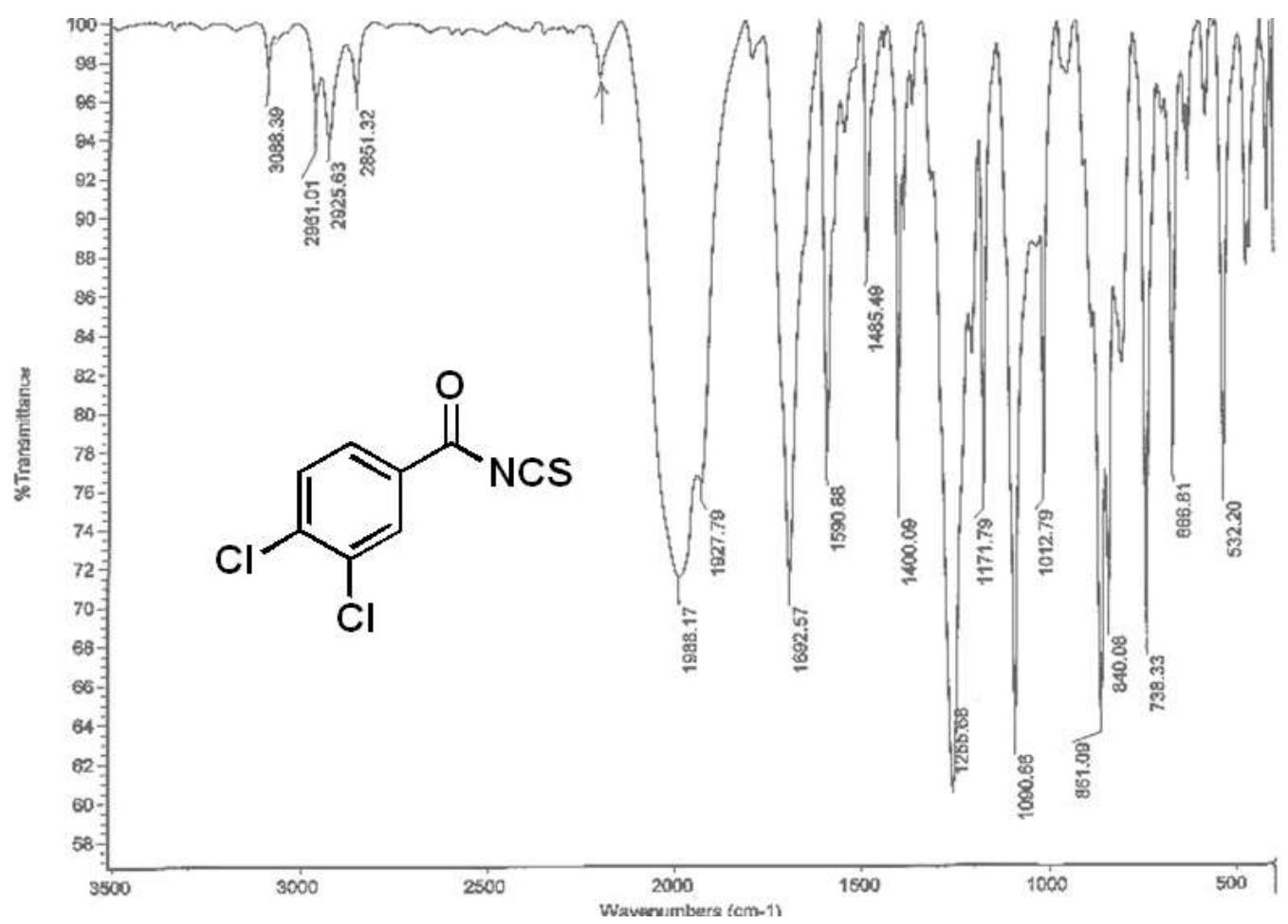

Figure S4-A: FT-IR (neat) spectrum of 3,4-dichlorobenzoyl isothiocyanate (Table 2, entry 4) 


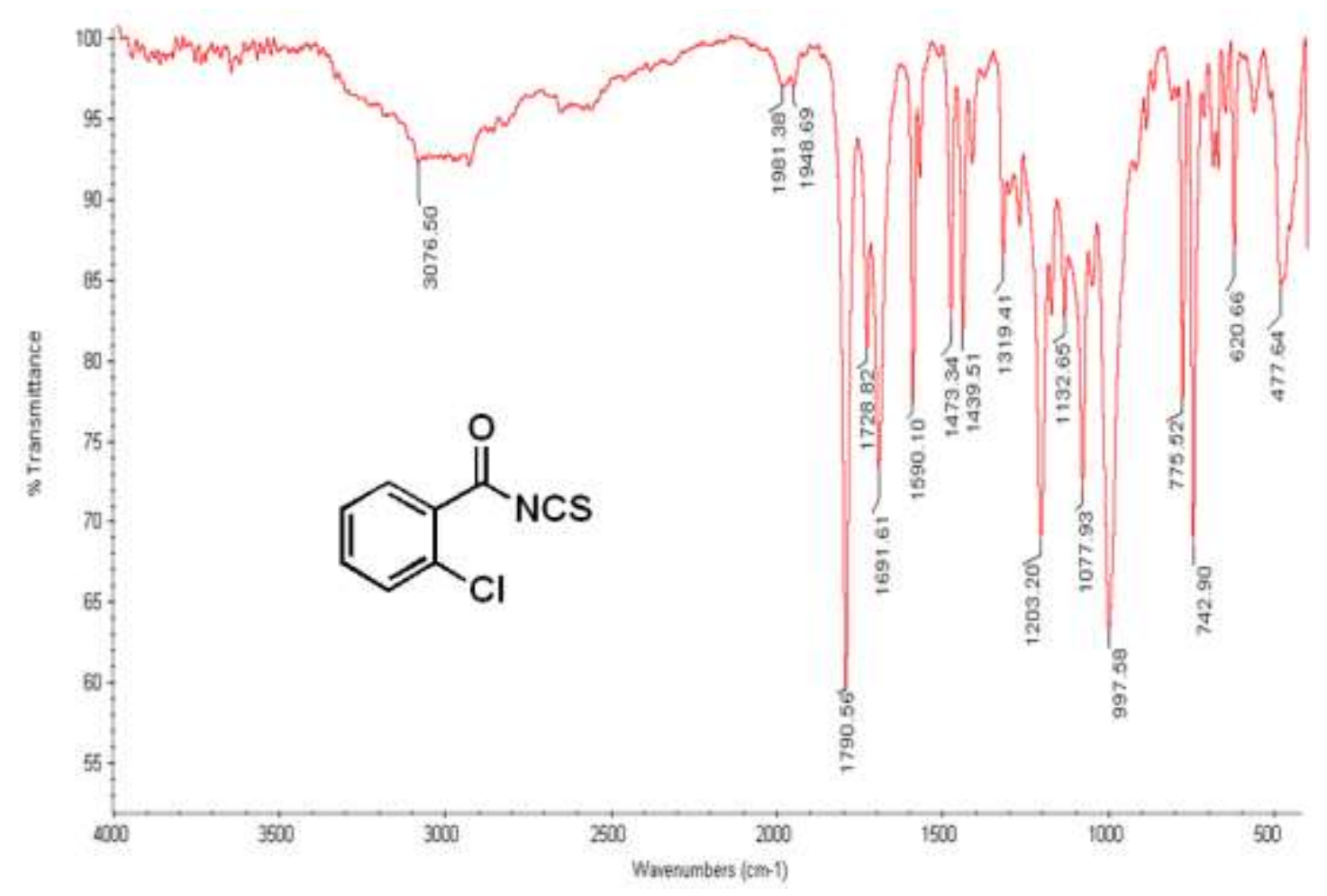

Figure S5-A: FT-IR (neat) spectrum of 2-chlorobenzoyl isothiocyanate (Table 2, entry 5)

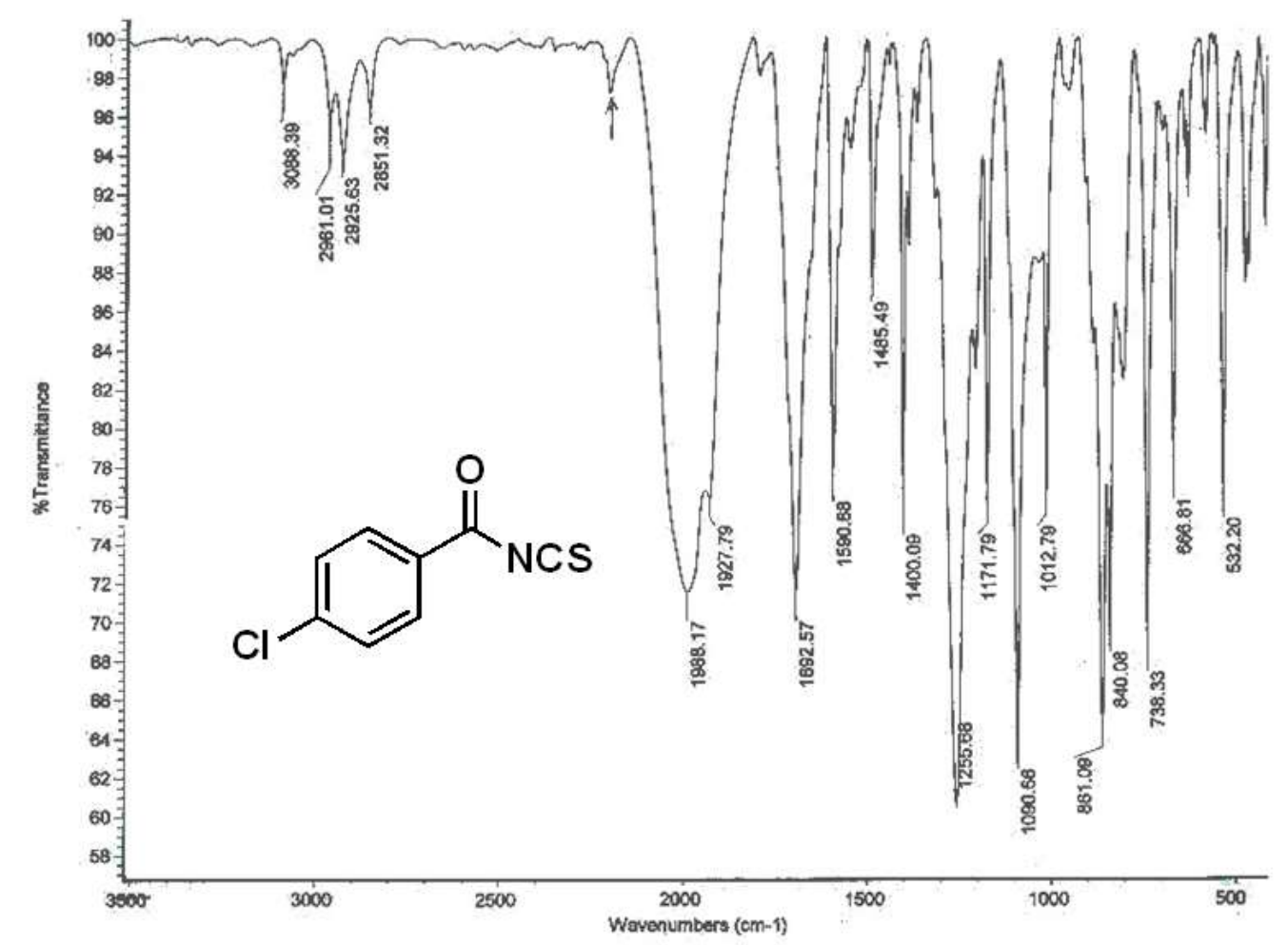

Figure S6-A: FT-IR (KBr) spectrum of 4-chlorobenzoyl isothiocyanate (Table 2, entry 6) 


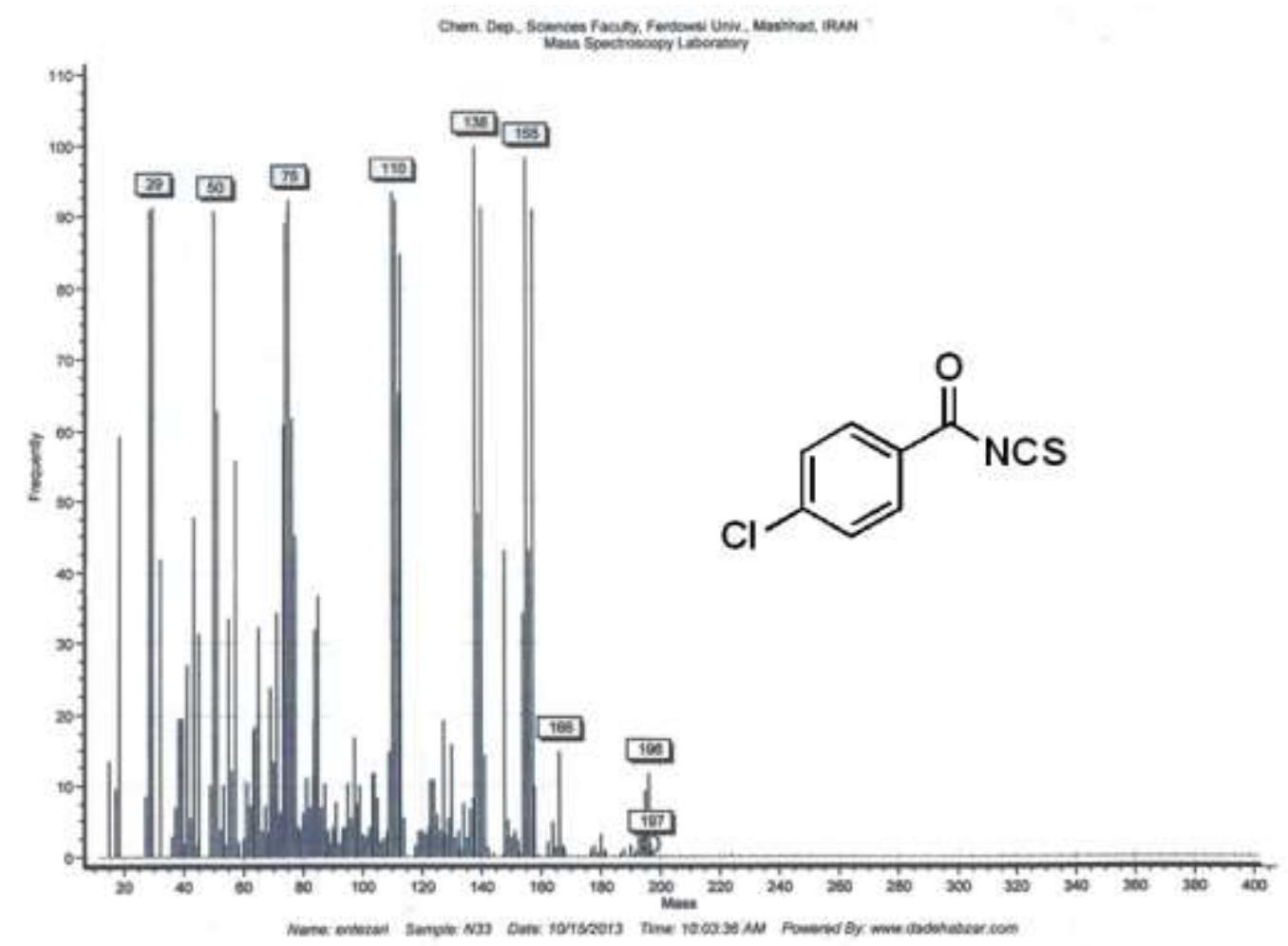

Figure S6-B: Mass spectrum of 4-chlorobenzoyl isothiocyanate (Table 2, entry 6)

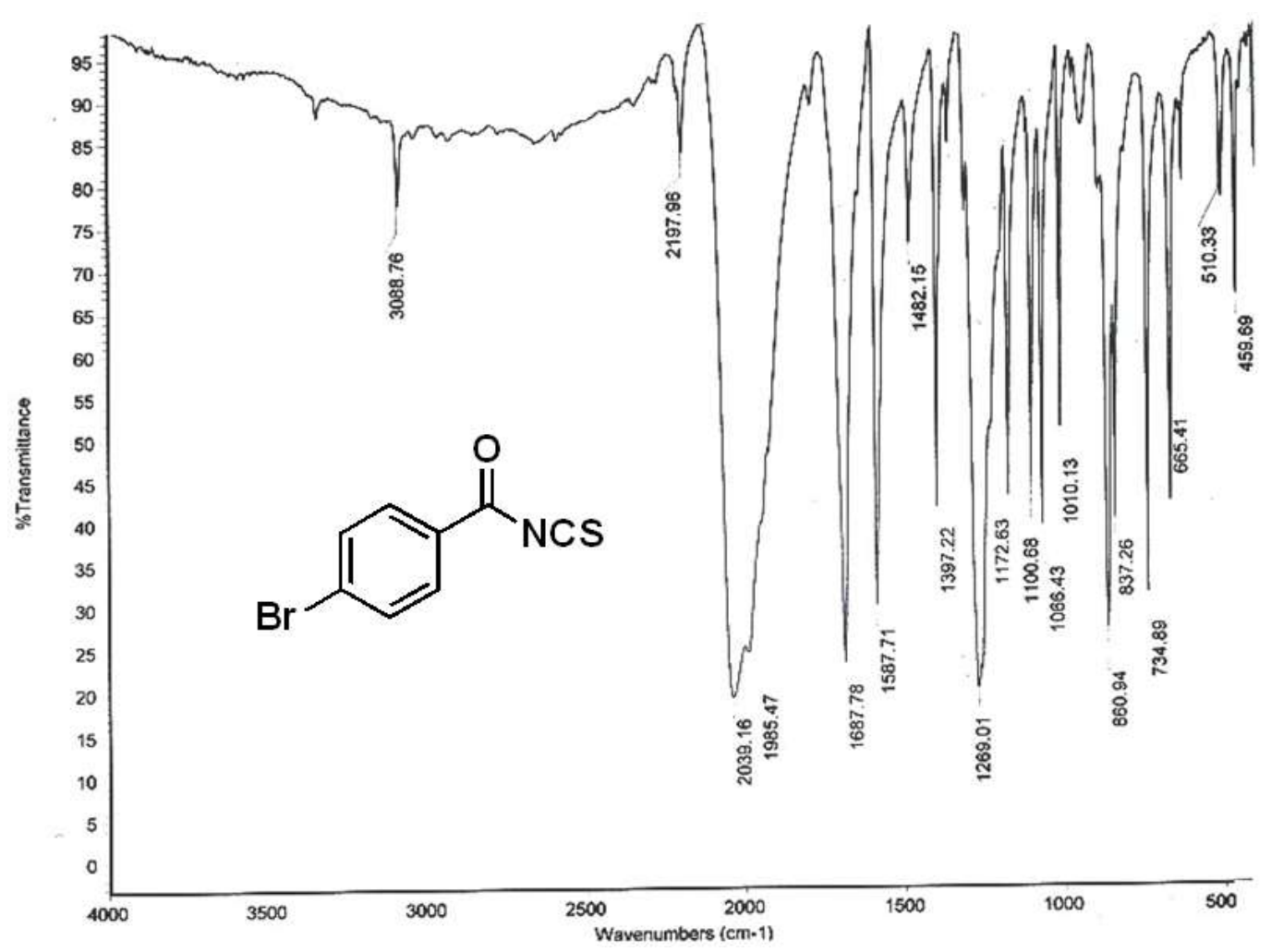

Figure S7-A: FT-IR (KBr) spectrum of 4-bromobenzoyl isothiocyanate (Table 2, entry7) 


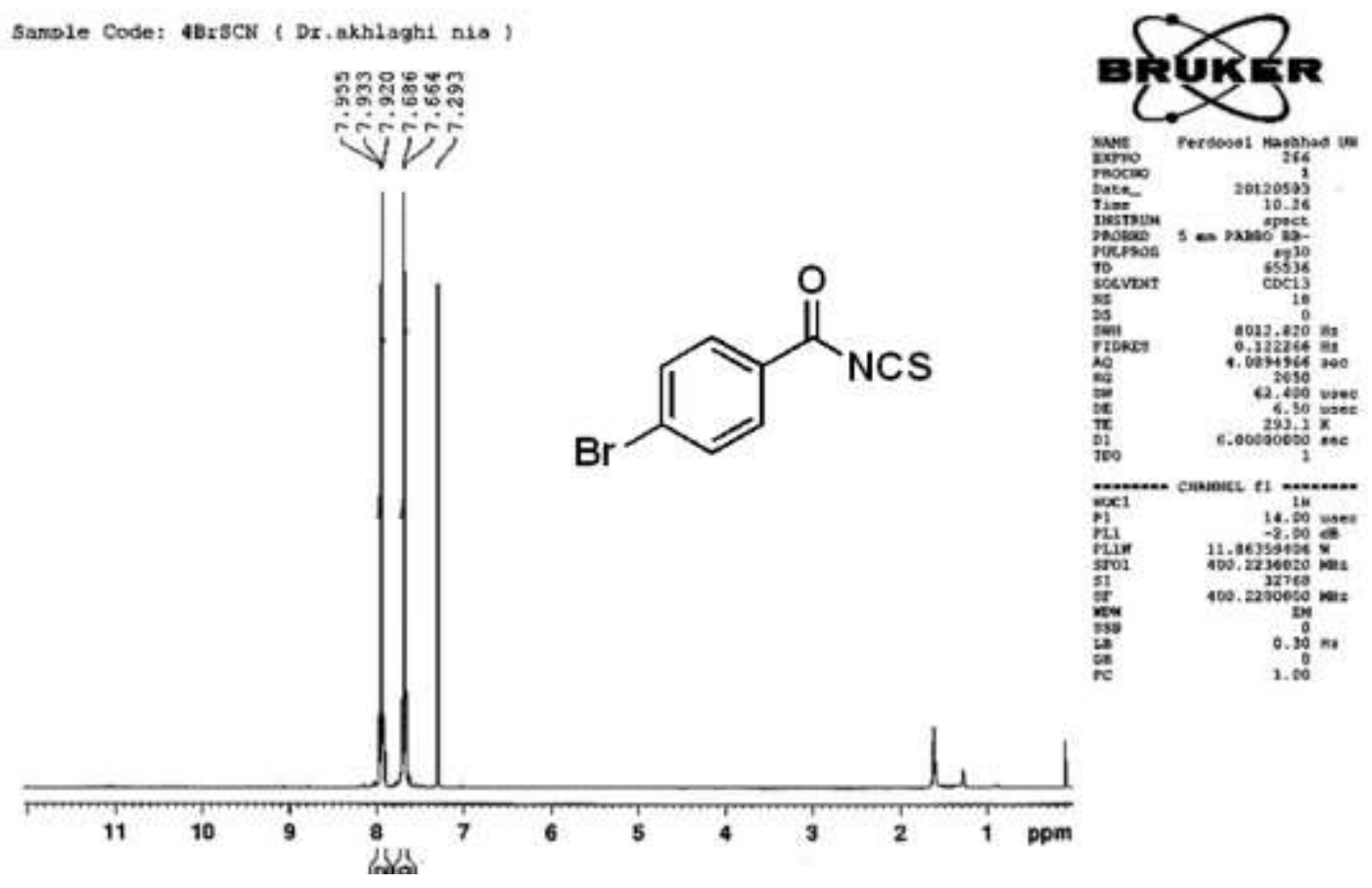

Figure S7-B: ${ }^{1} \mathrm{H}$ NMR (400 MHz, $\mathrm{CDCl}_{3}$ ) spectrum of 4-bromobenzoyl isothiocyanate (Table 2, entry7)

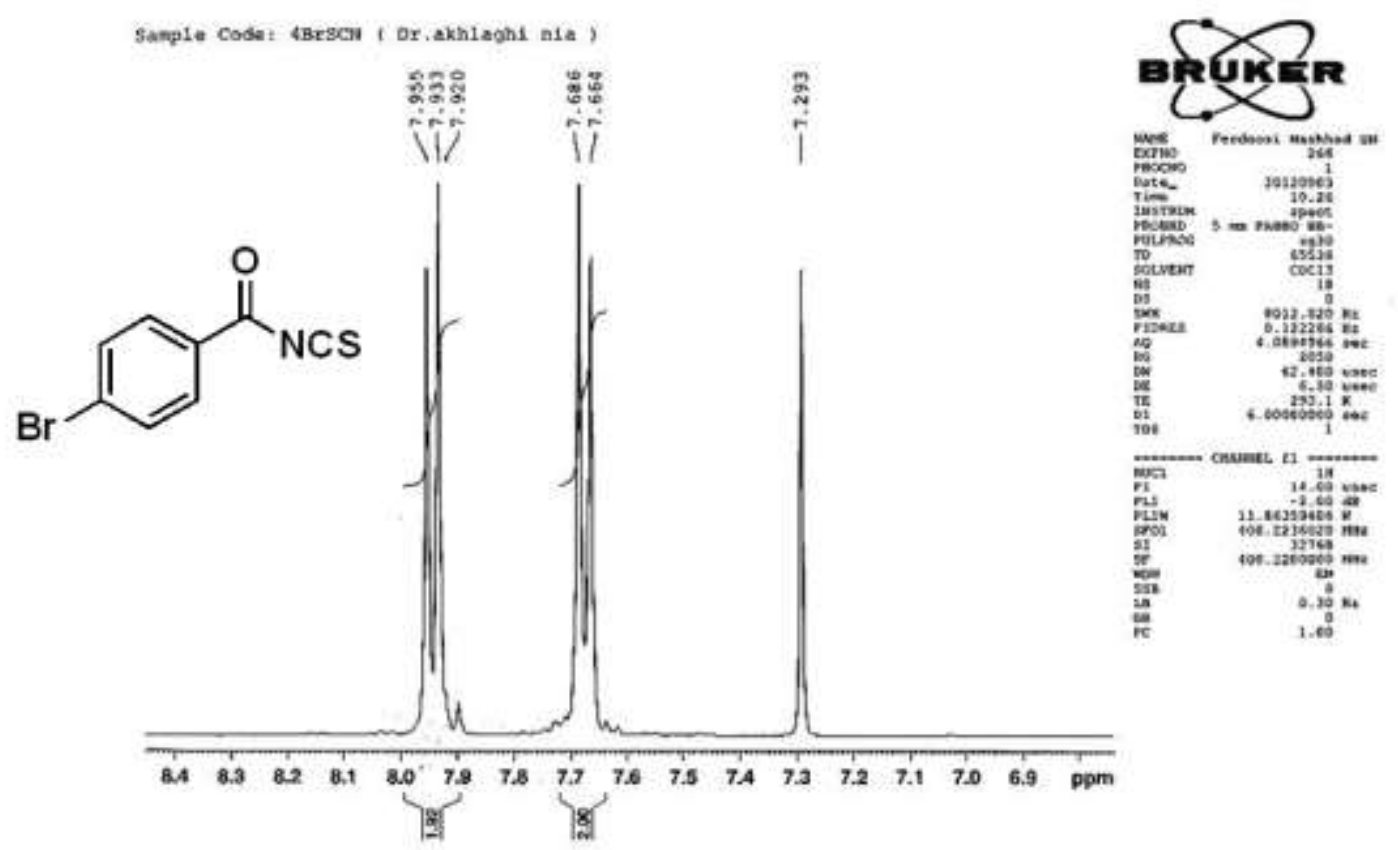

Figure S7-B $\mathbf{a}:{ }^{1} \mathrm{H}$ NMR (400 MHz, $\mathrm{CDCl}_{3}$ ) spectrum of 4-bromobenzoyl isothiocyanate (Table 2, entry7) 


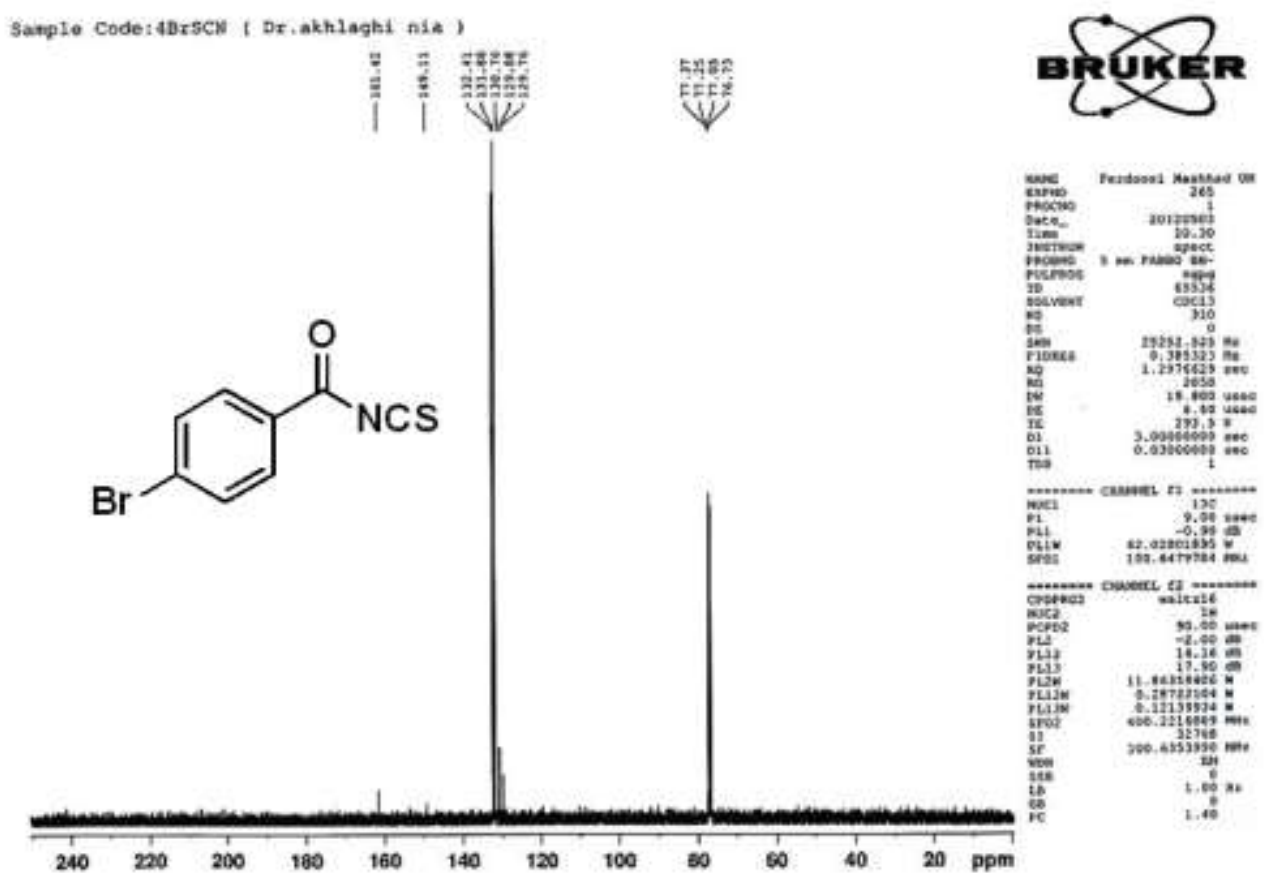

Figure S7-C. ${ }^{13} \mathrm{C}$ NMR (100 MHz, $\mathrm{CDCl}_{3}$ ) spectrum of 4-bromobenzoyl isothiocyanate (Table 2, entry7)

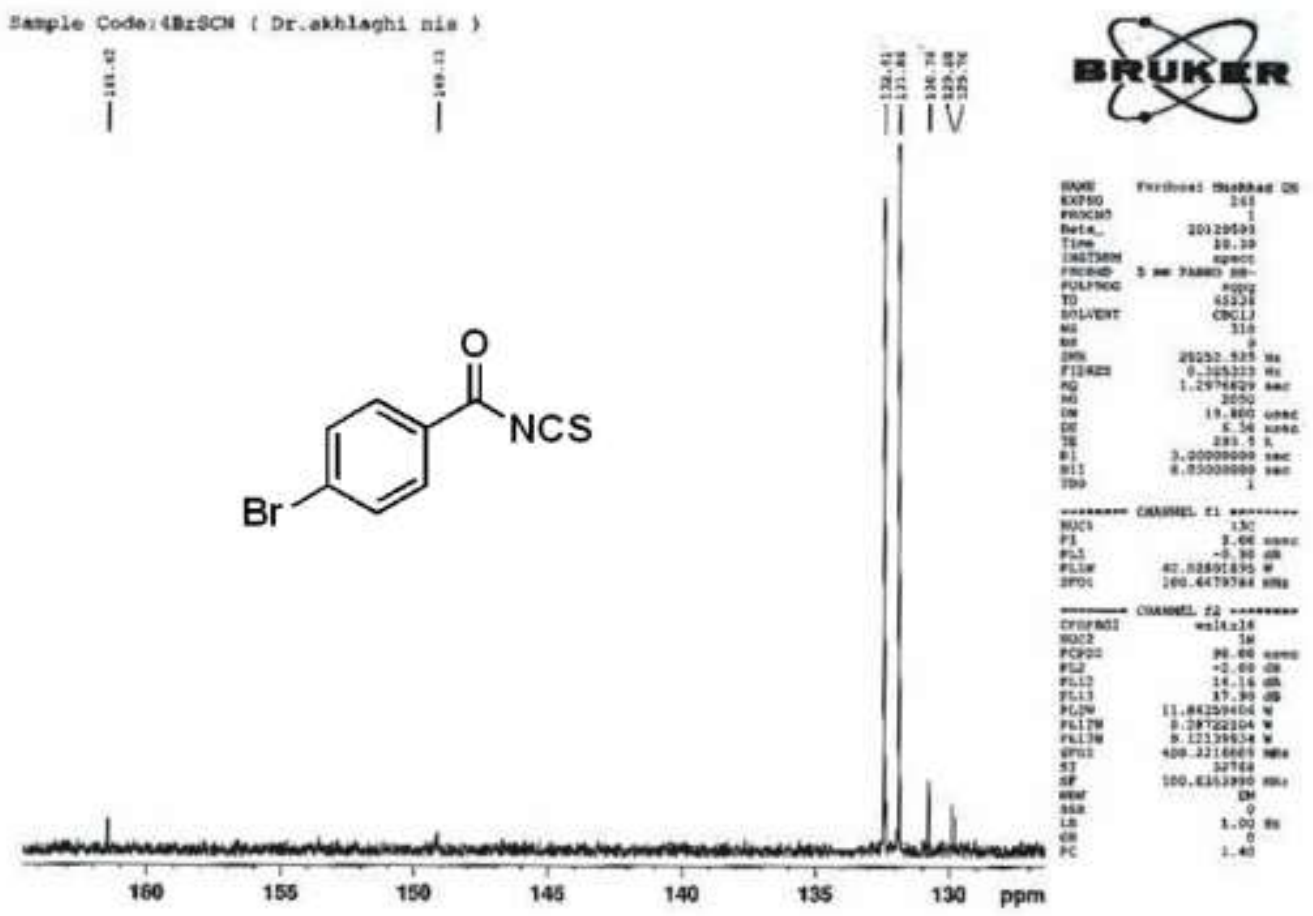

Figure $\mathbf{S 7}-\mathbf{C}_{\mathbf{a}}:{ }^{13} \mathrm{C}$ NMR $\left(100 \mathrm{MHz}, \mathrm{CDCl}_{3}\right)$ spectrum of 4-bromobenzoyl isothiocyanate (Table 2, entry7) 


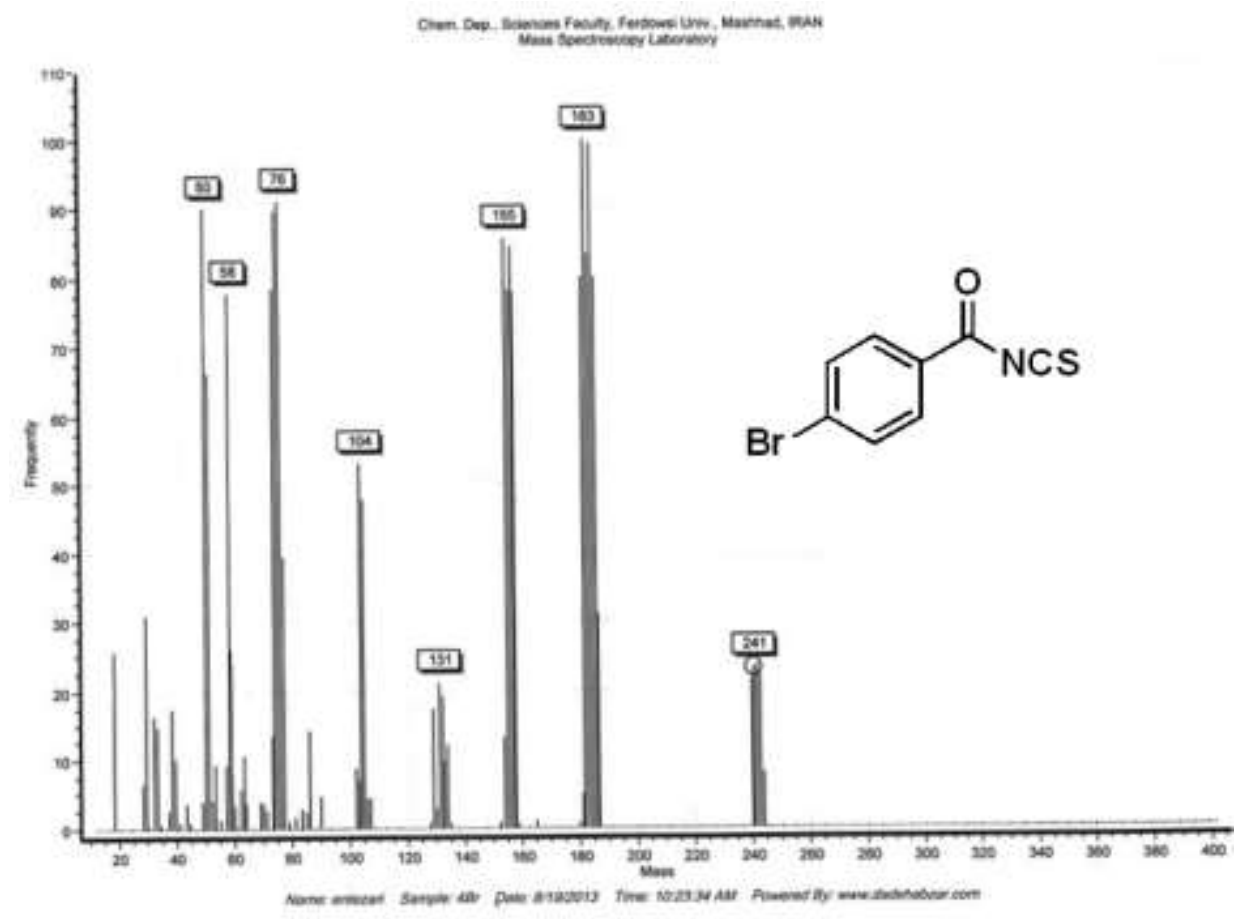

Figure S7-D: Mass spectrum of 4-bromobenzoyl isothiocyanate (Table 2, entry7)

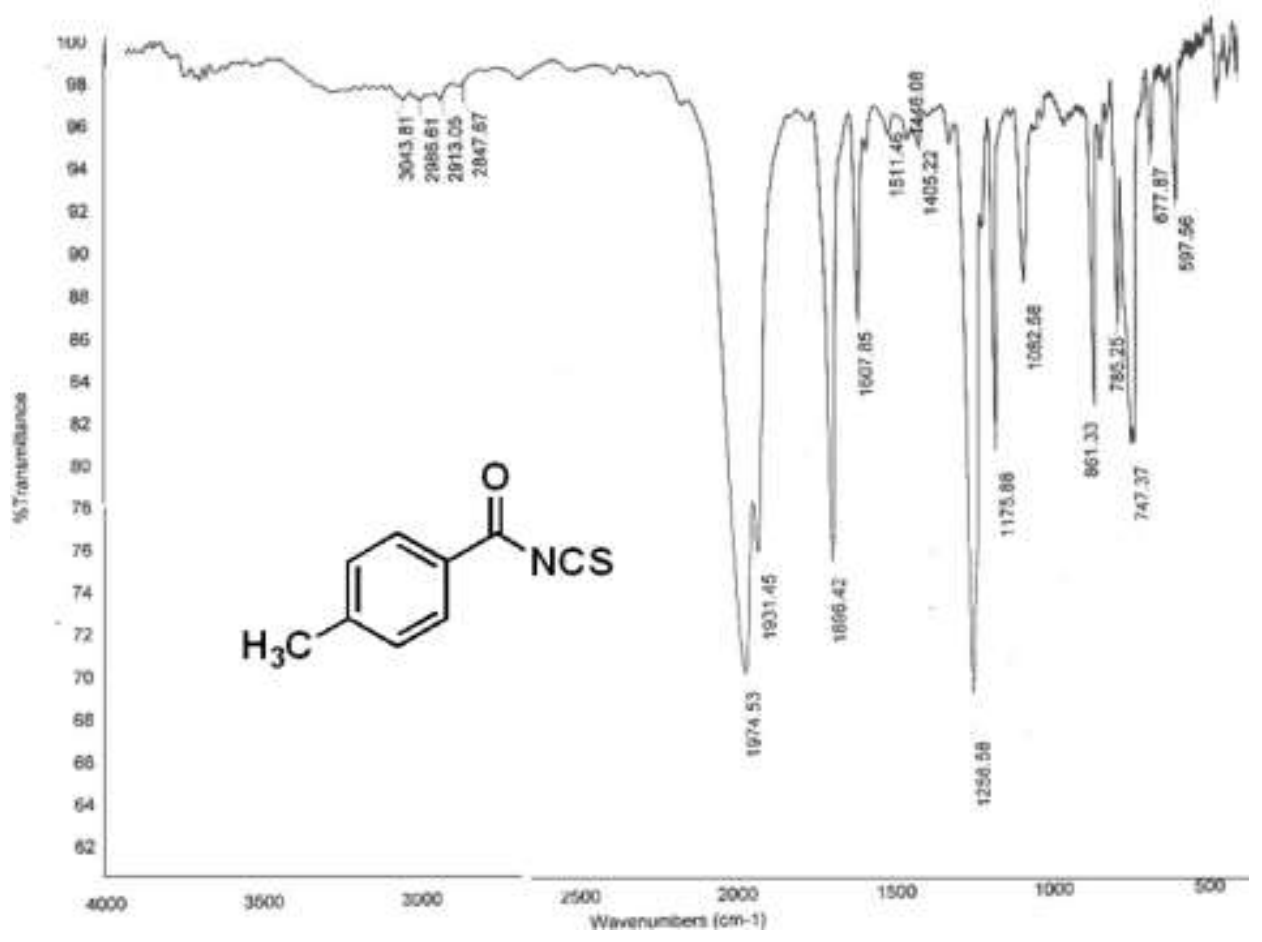

Figure S8-A: FT-IR (neat) spectrum of 4-methylbenzoyl isothiocyanate (Table 2, entry 8) 


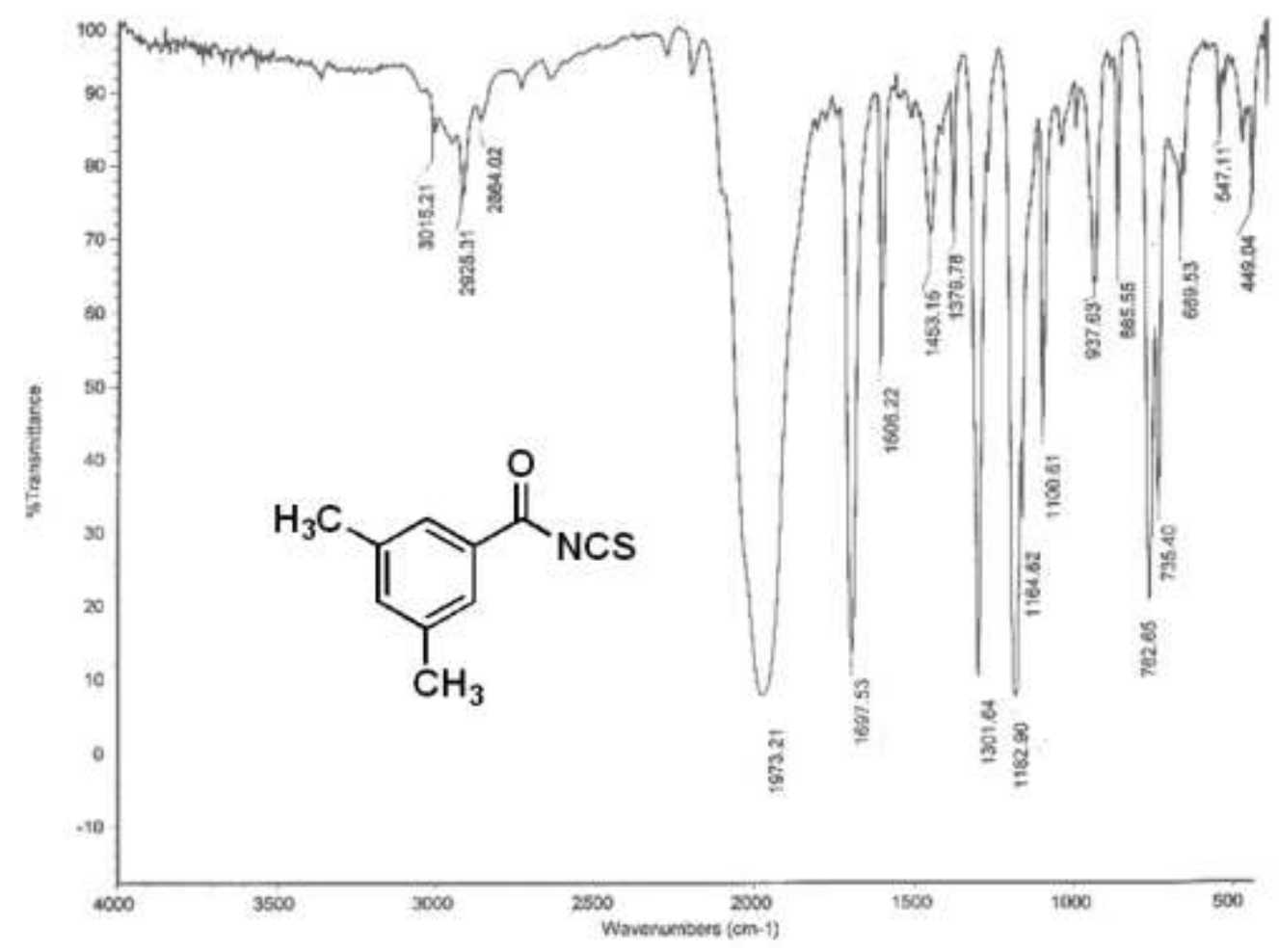

Figure S9-A: FT-IR (neat) spectrum of 3,5-dimethylbenzoyl isothiocyanate (Table 2, entry 9)

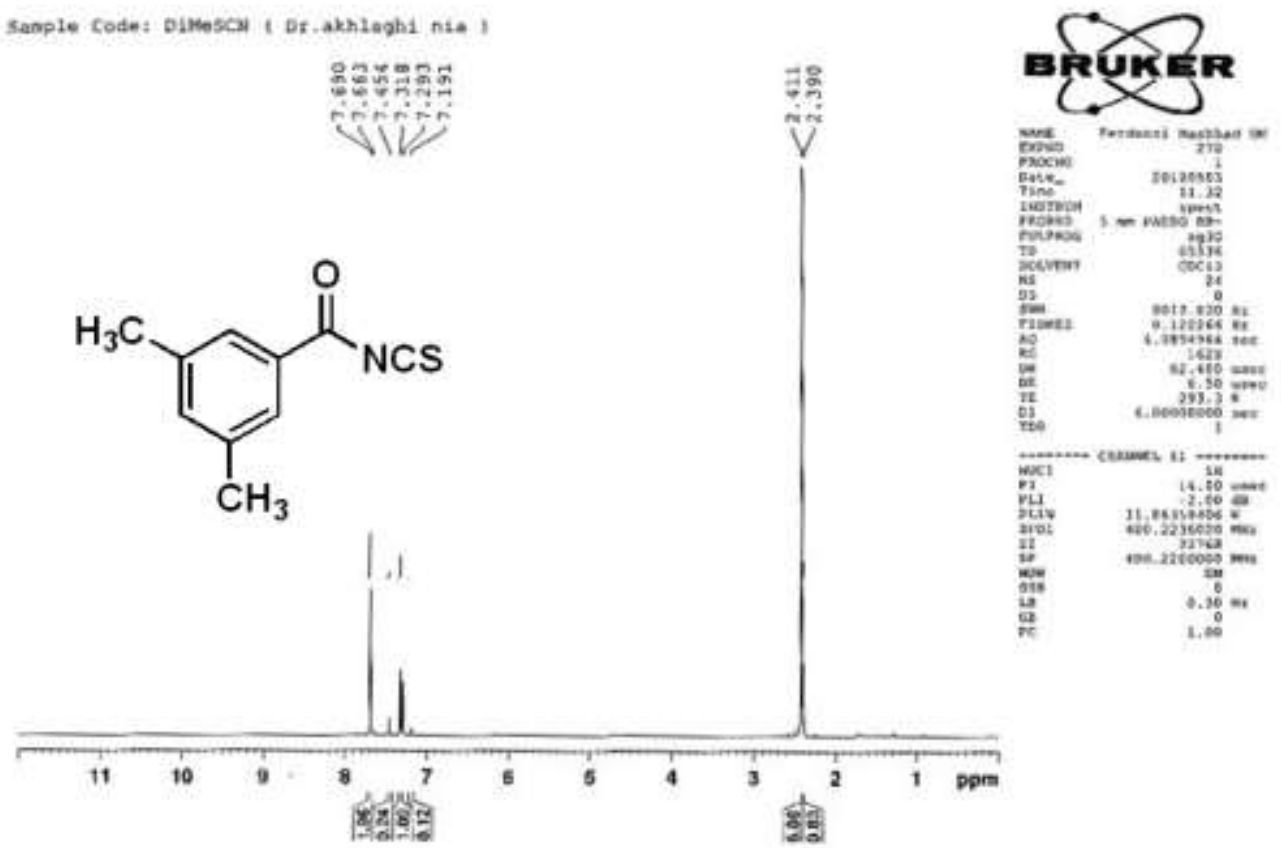

Figure S9-B: ${ }^{1} \mathrm{H}$ NMR $\left(400 \mathrm{MHz}, \mathrm{CDCl}_{3}\right.$ ) spectrum of 3,5-dimethylbenzoyl isothiocyanate- (Table 2, entry 9) 


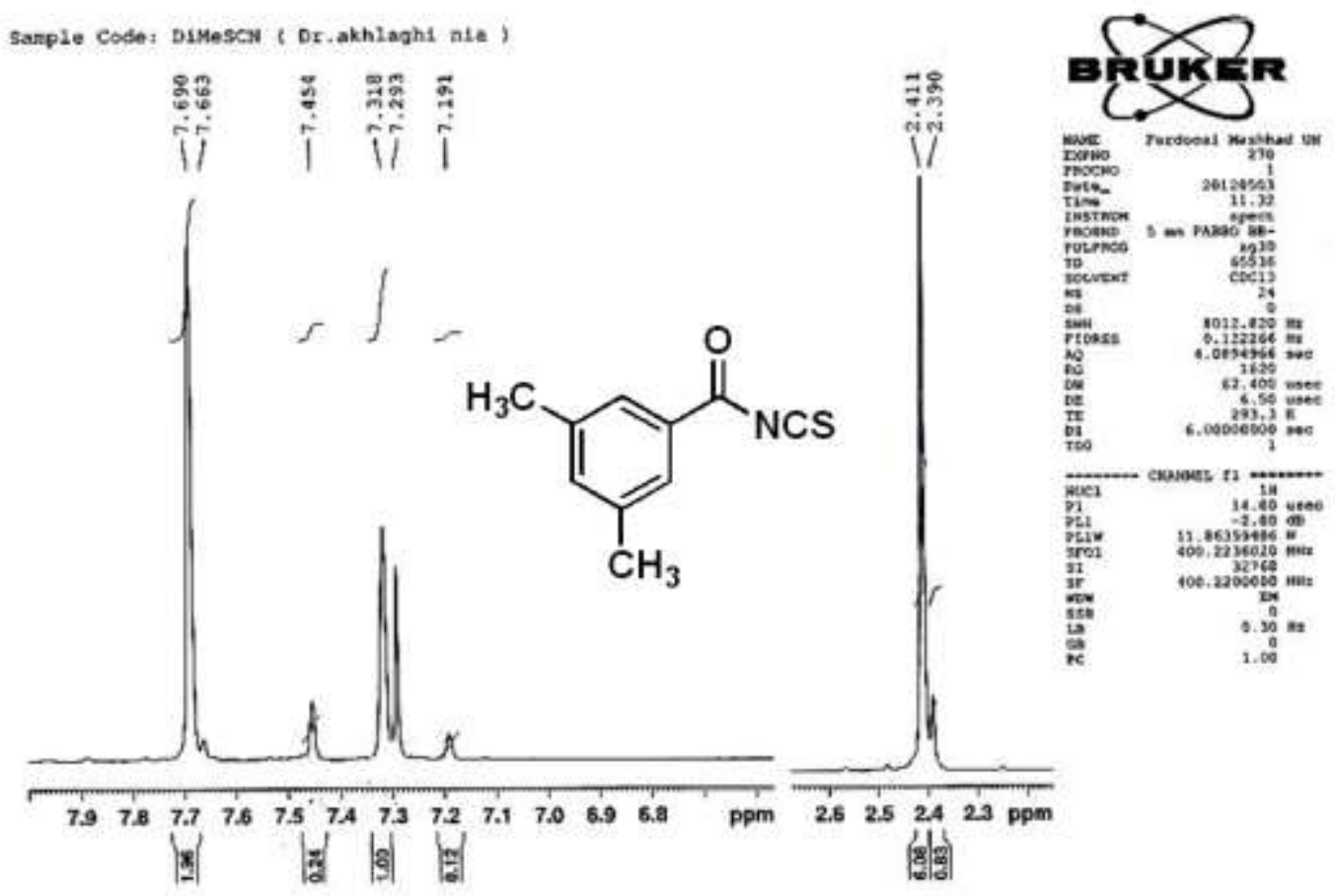

Figure S9-B $\mathbf{a}:{ }^{1} \mathrm{H}$ NMR (400 MHz, $\mathrm{CDCl}_{3}$ ) spectrum of 3,5-dimethylbenzoyl isothiocyanate (Table 2, entry 9)

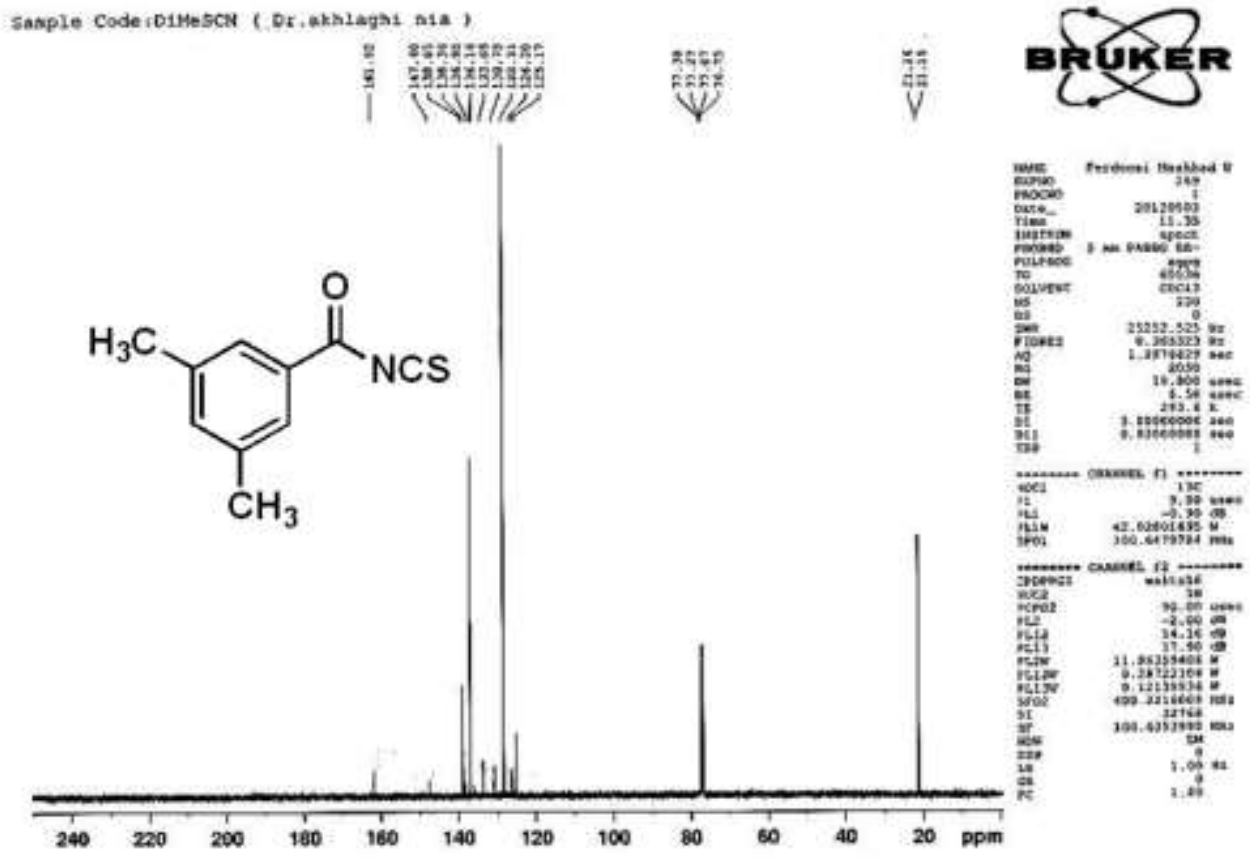

Figure S9-C: ${ }^{13} \mathrm{C}$ NMR (100 MHz, $\left.\mathrm{CDCl}_{3}\right)$ spectrum of 3,5-dimethylbenzoyl isothiocyanate (Table 2, entry 9) 


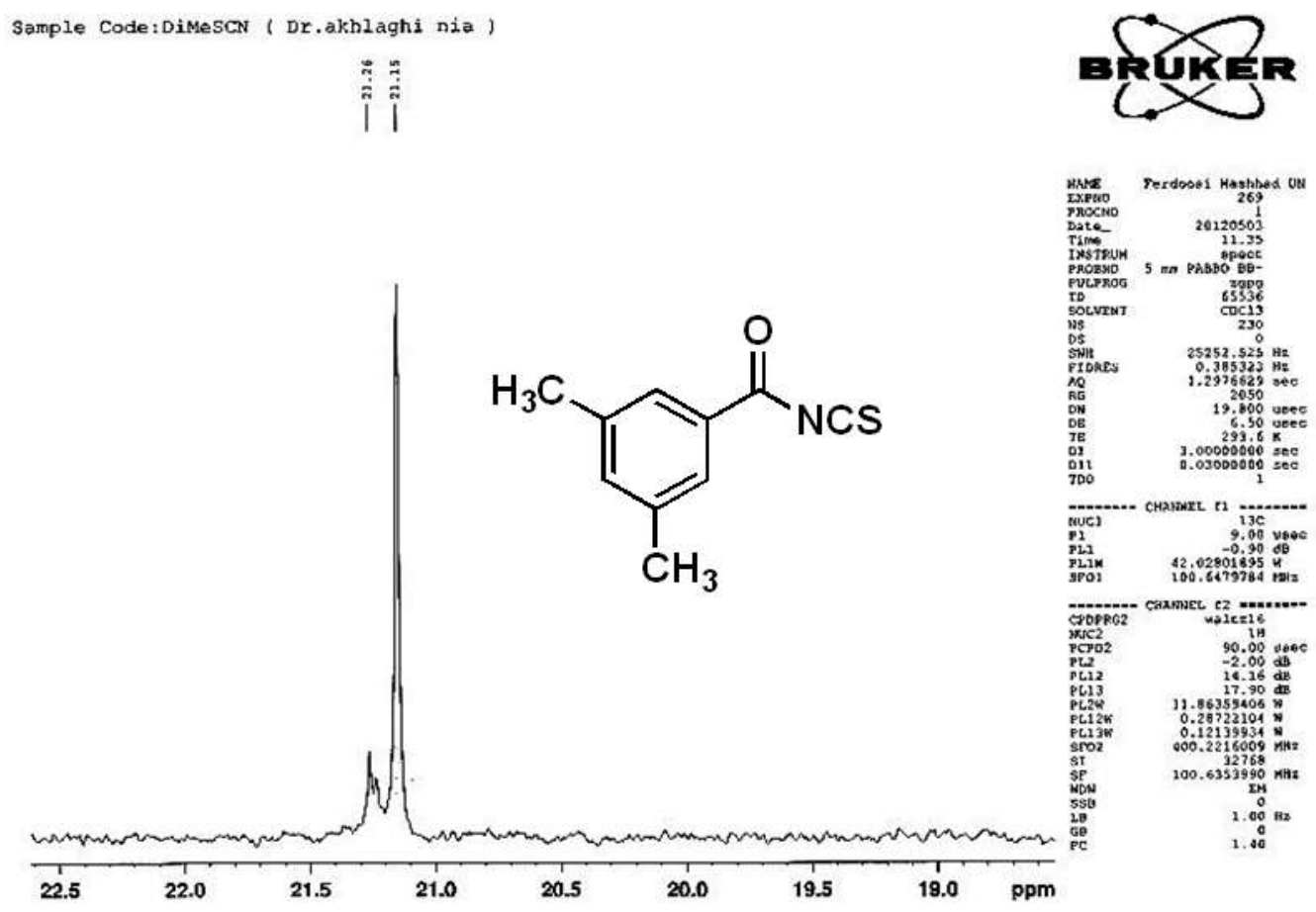

Figure S9- $\mathbf{C}_{\mathbf{a}}:{ }^{13} \mathrm{C}$ NMR (100 MHz, $\left.\mathrm{CDCl}_{3}\right)$ spectrum of 3,5-dimethylbenzoyl isothiocyanate (Table 2 , entry 9)

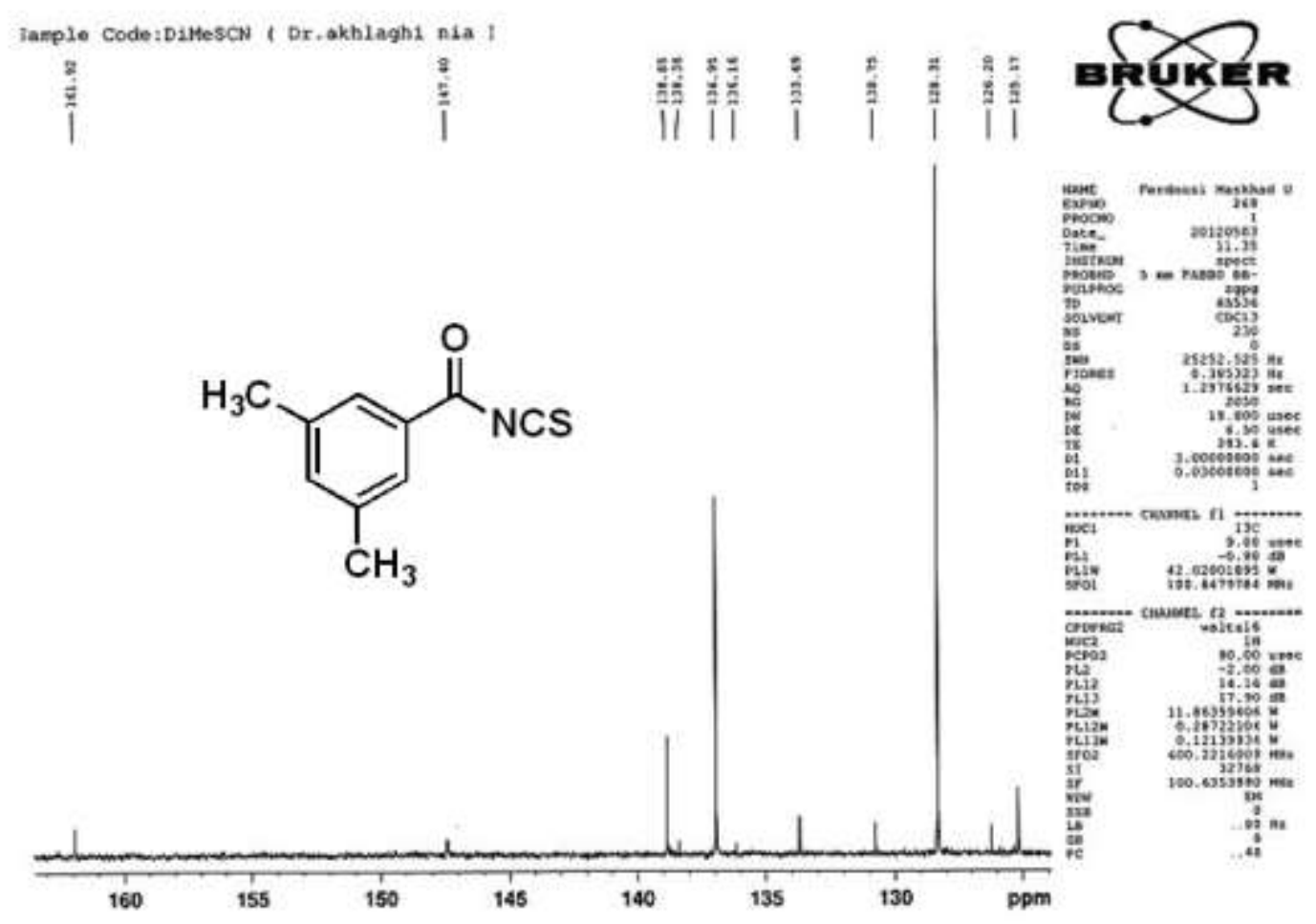

Figure S9- $\mathbf{C}_{\mathbf{b}}:{ }^{13} \mathrm{C}$ NMR (100 MHz, $\mathrm{CDCl}_{3}$ ) spectrum of 3,5-dimethylbenzoyl isothiocyanate (Table 2,entry 9) 


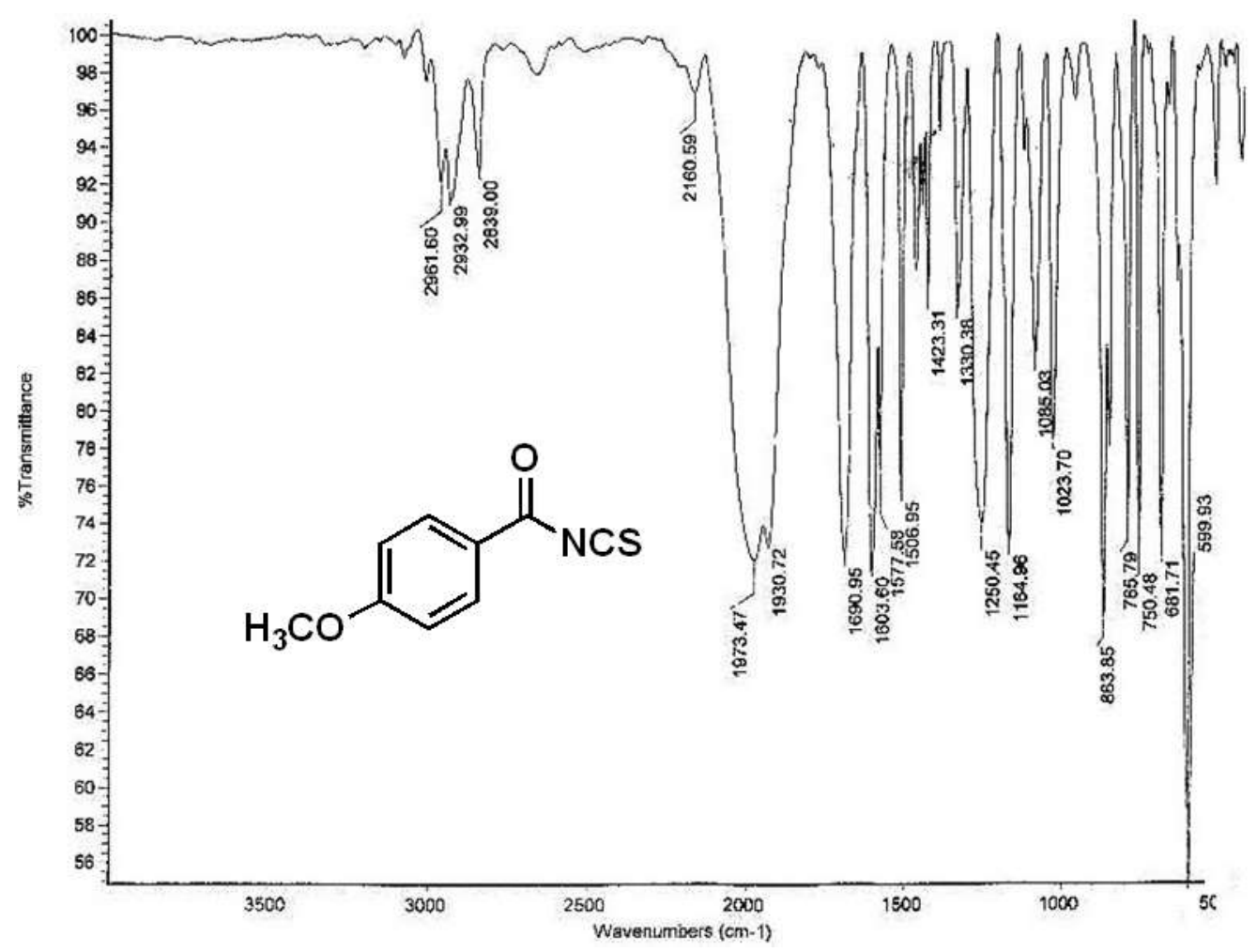

Figure S10-A: FT-IR (neat) spectrum of 4-methoxybenzoyl isothiocyanate (Table 2, entry10)

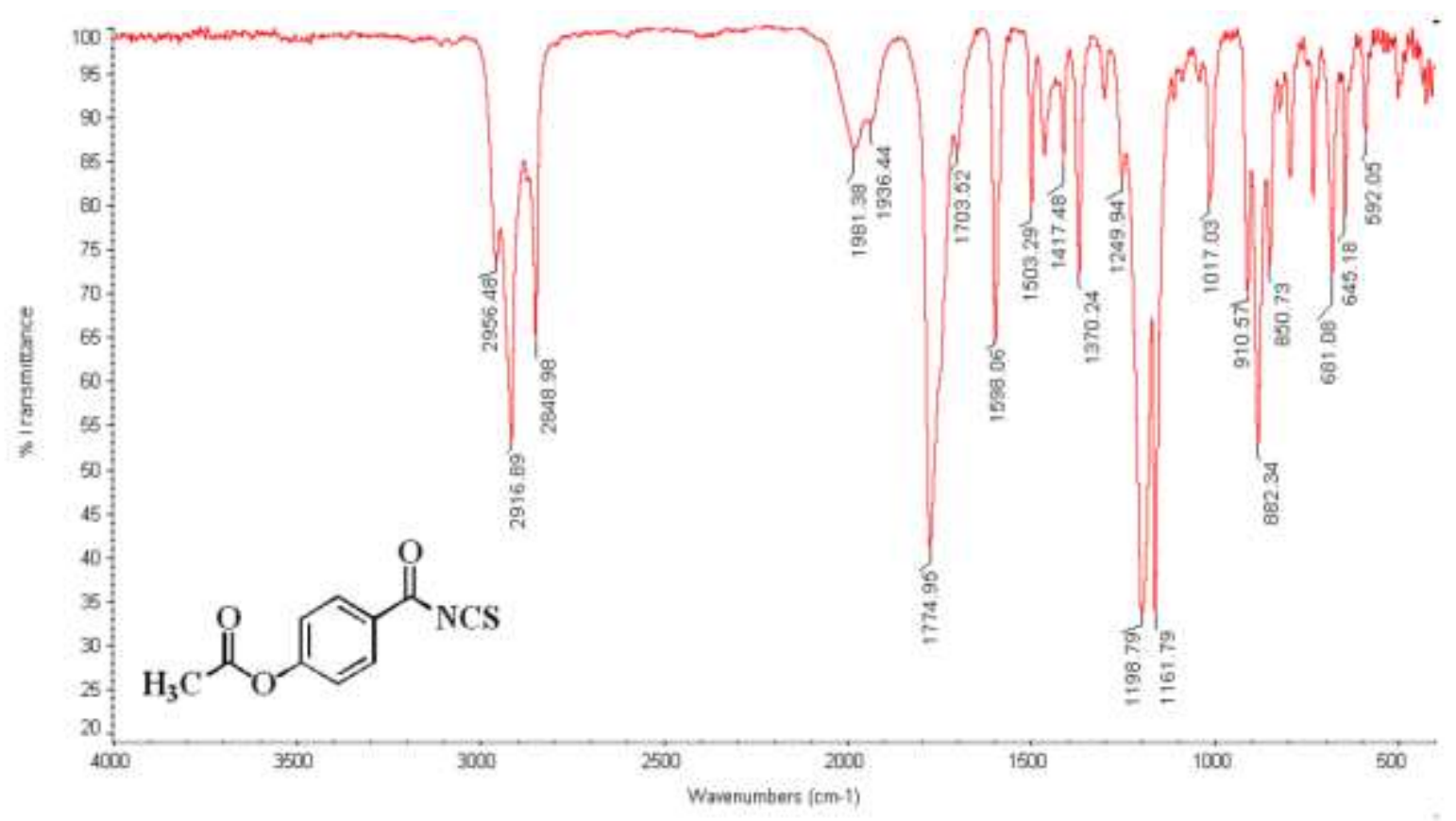

Figure S11-A: FT-IR (neat) spectrum of 4-(isothiocyanatocarbonyl) phenyl acetate (Table 2, entry 11) 


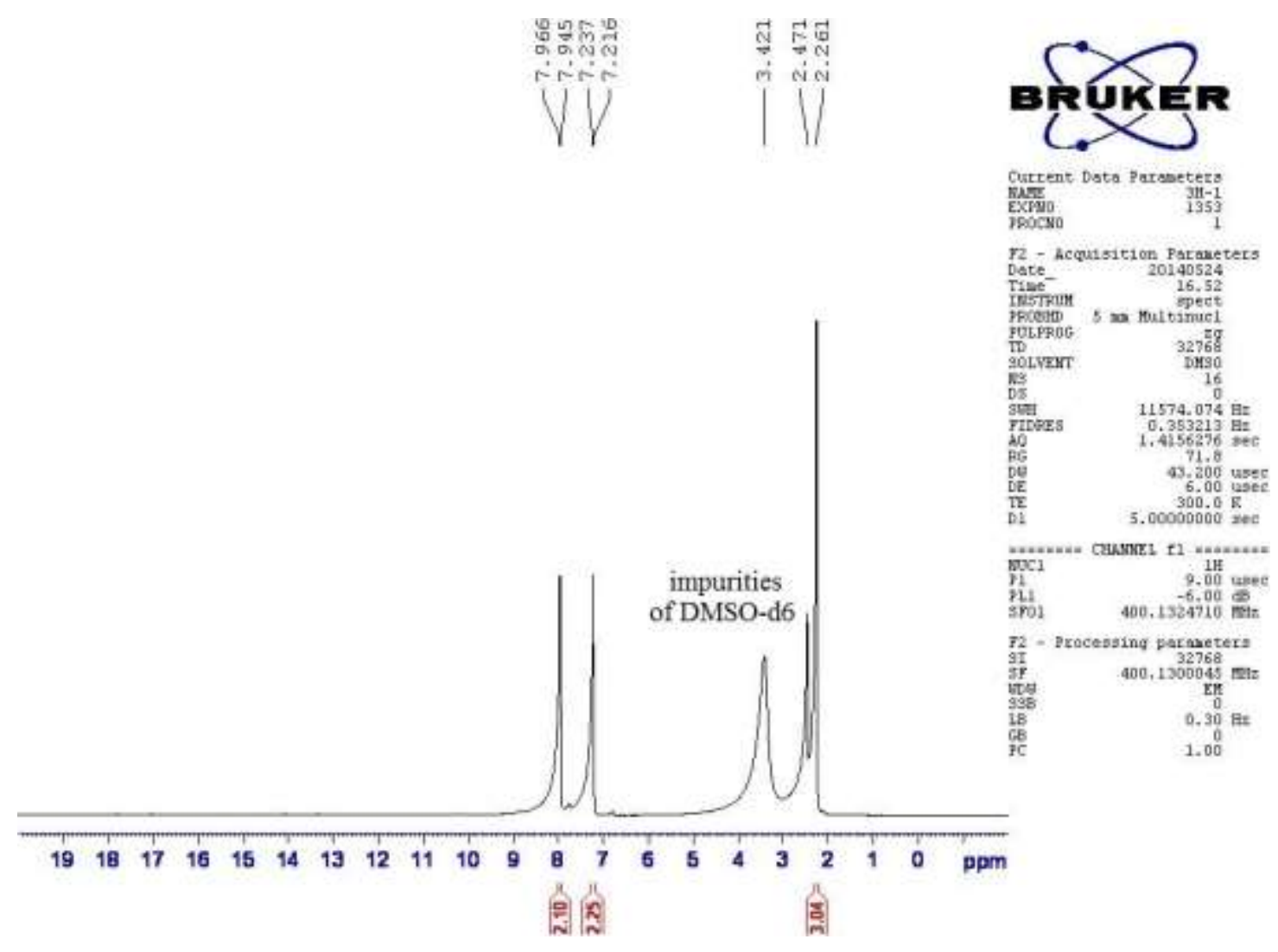

Figure S11-B: ${ }^{1} \mathrm{H}$ NMR (400 MHz, DMSO) spectrum of 4-(isothiocyanatocarbonyl) phenyl acetate (Table 2, entry 11)

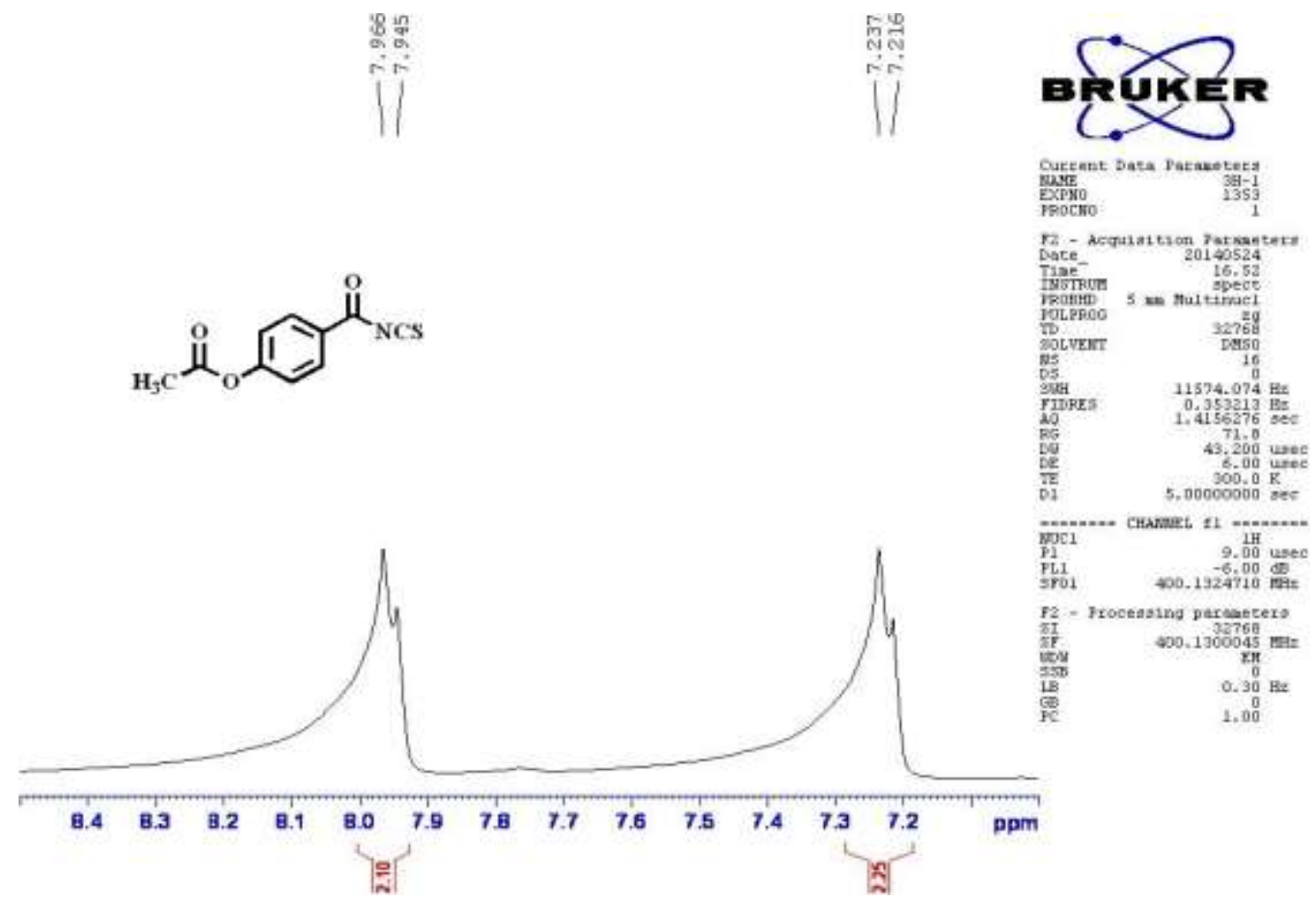

Figure S11-B $\mathbf{a}:{ }^{1} \mathrm{H}$ NMR (400 MHz, DMSO) spectrum of 4-(isothiocyanatocarbonyl) phenyl acetate (Table 2, entry 11) 


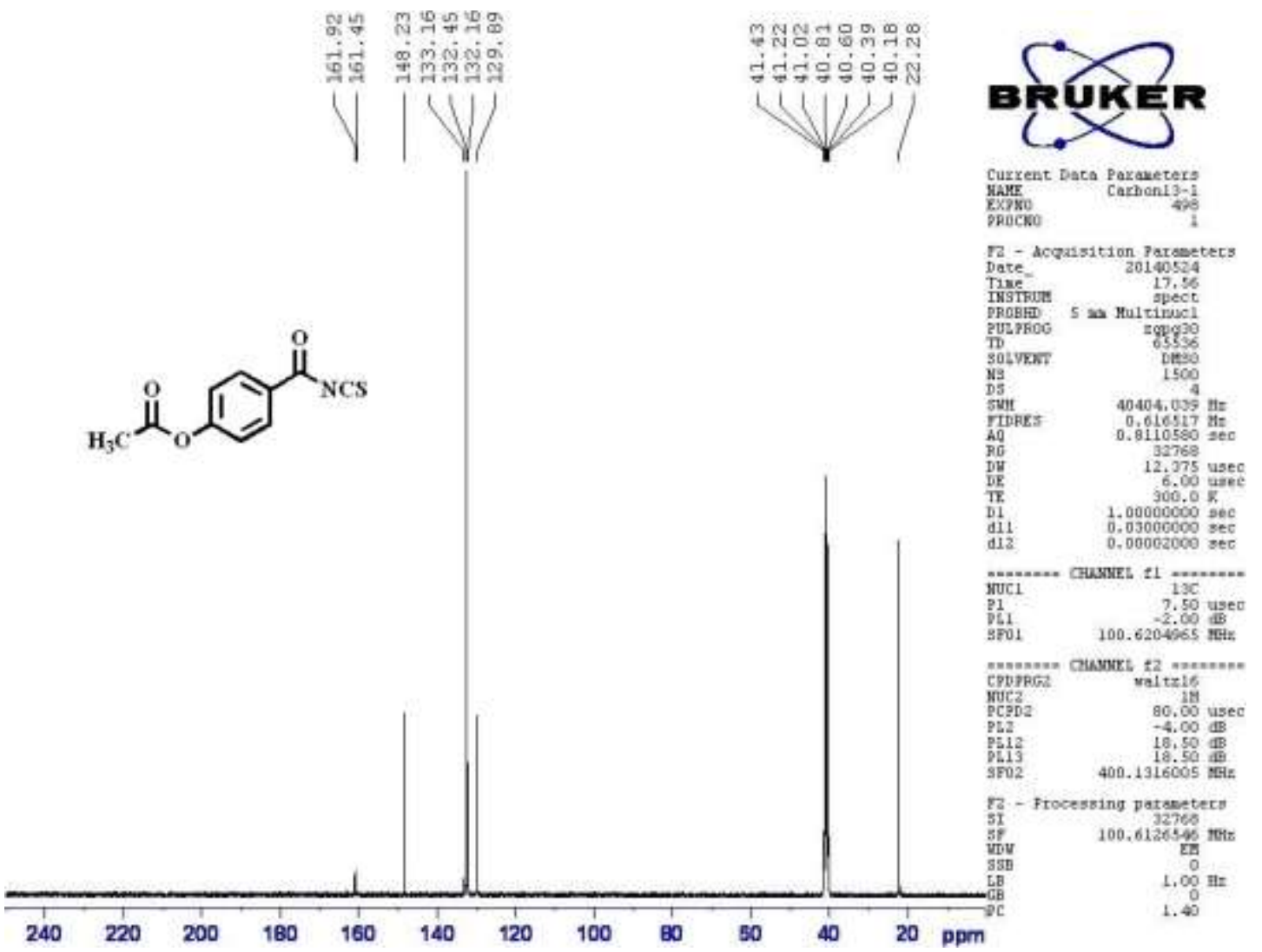

Figure S11-C: ${ }^{13} \mathrm{C}$ NMR (100 MHz, DMSO) spectrum of 4-(isothiocyanatocarbonyl) phenyl acetate (Table 2, entry 11)

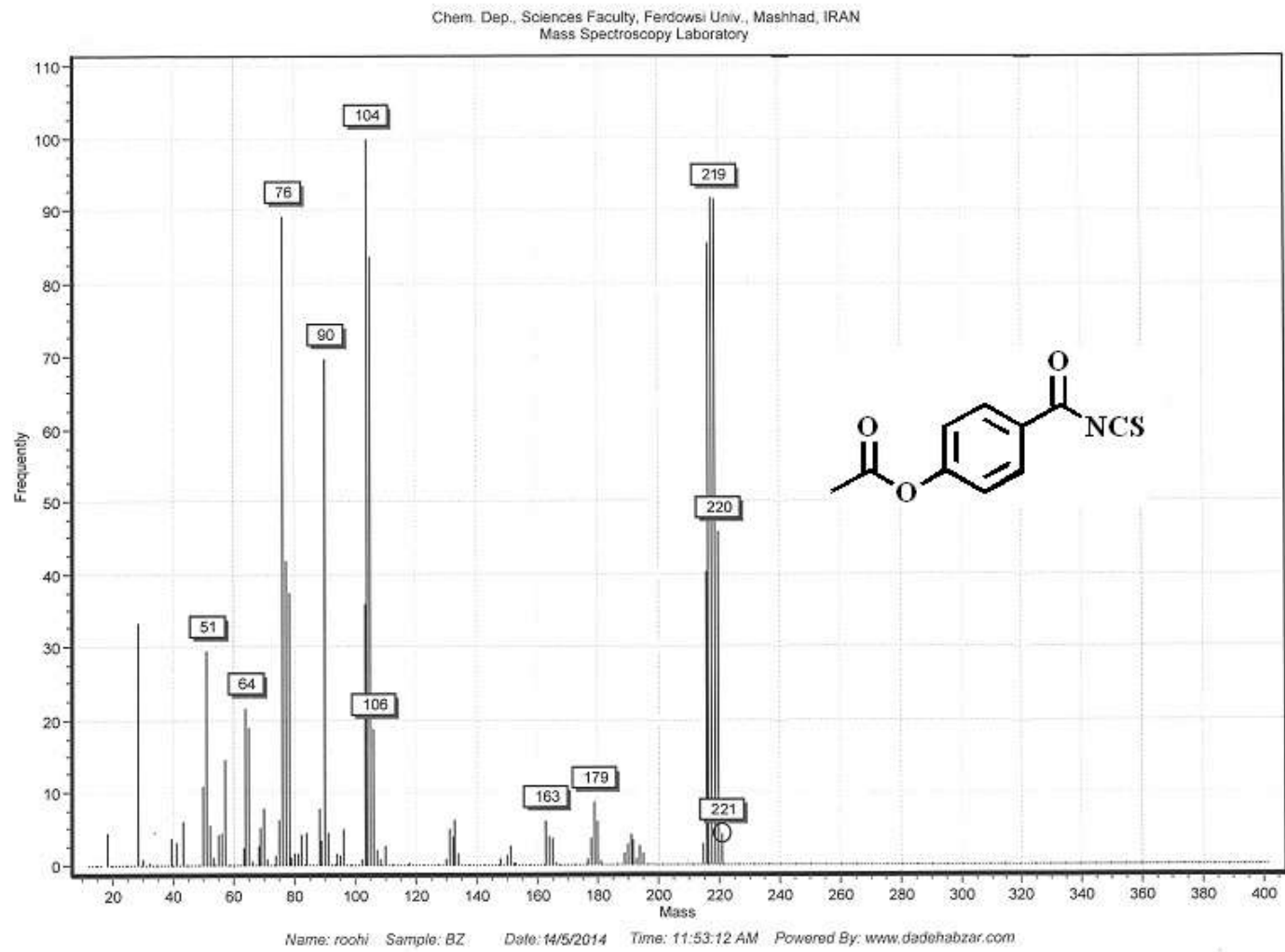

Figure S11-D: Mass spectrum of 4-(isothiocyanatocarbonyl) phenyl acetate (Table 2, entry 19) (Table 2, entry 11 ) 


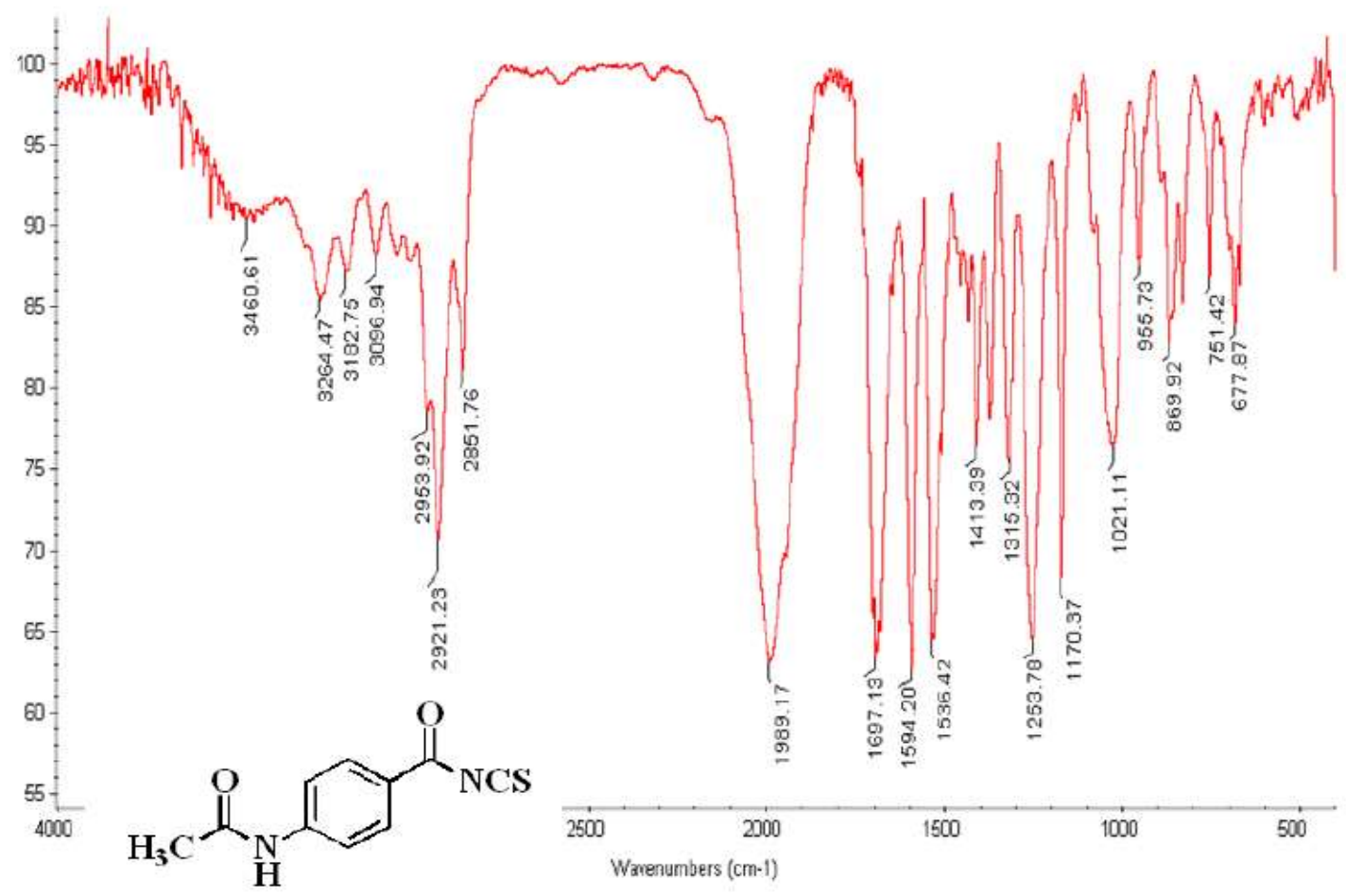

Figure S12-A: FT-IR (neat) spectrum of 4-acetamidobenzoyl isothiocyanate (Table 2, entry 12)

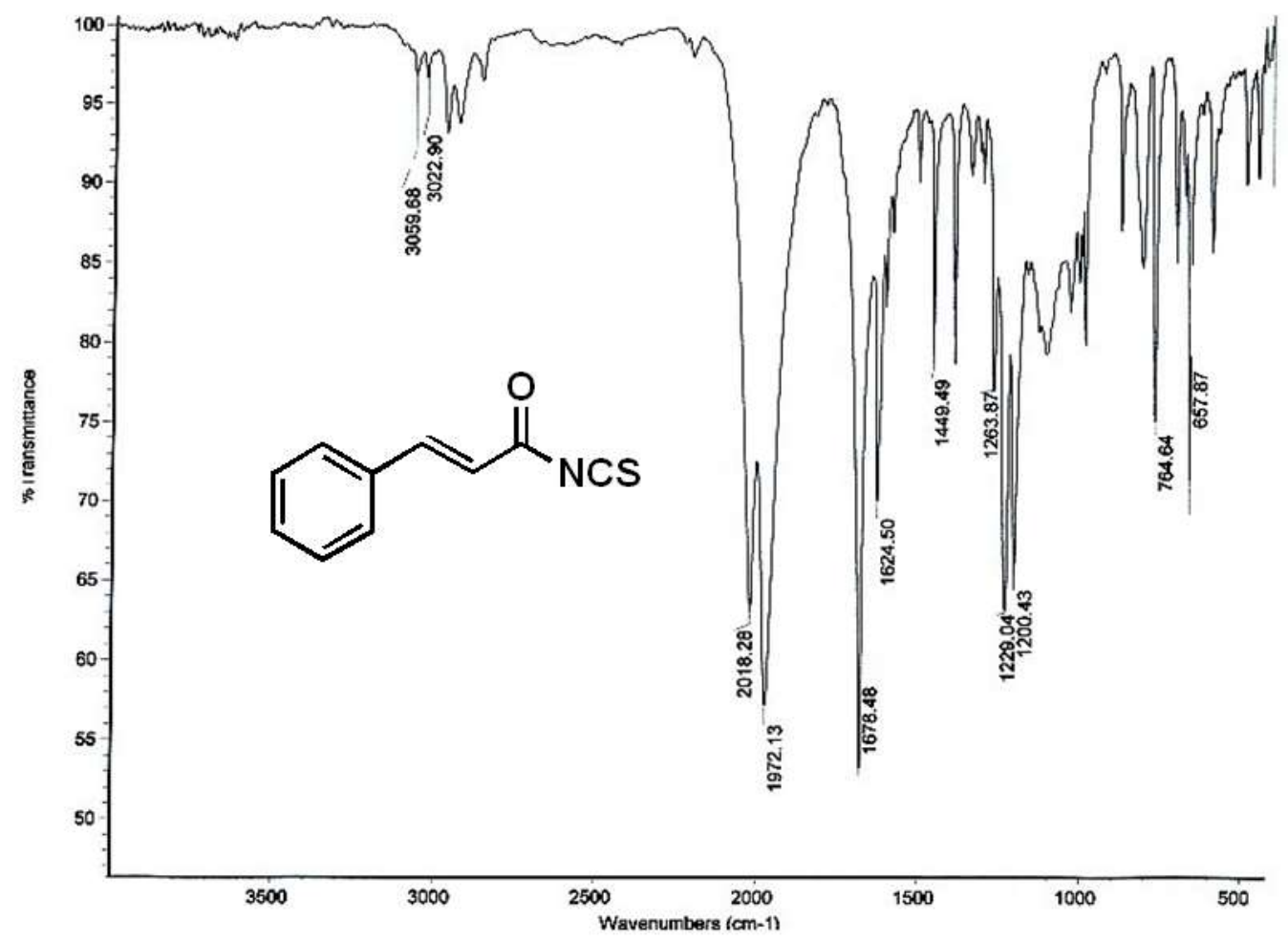

Figure S13-A: FT-IR (KBr) spectrum of cinnamoyl isothiocyanate (Table 2, entry 13) 


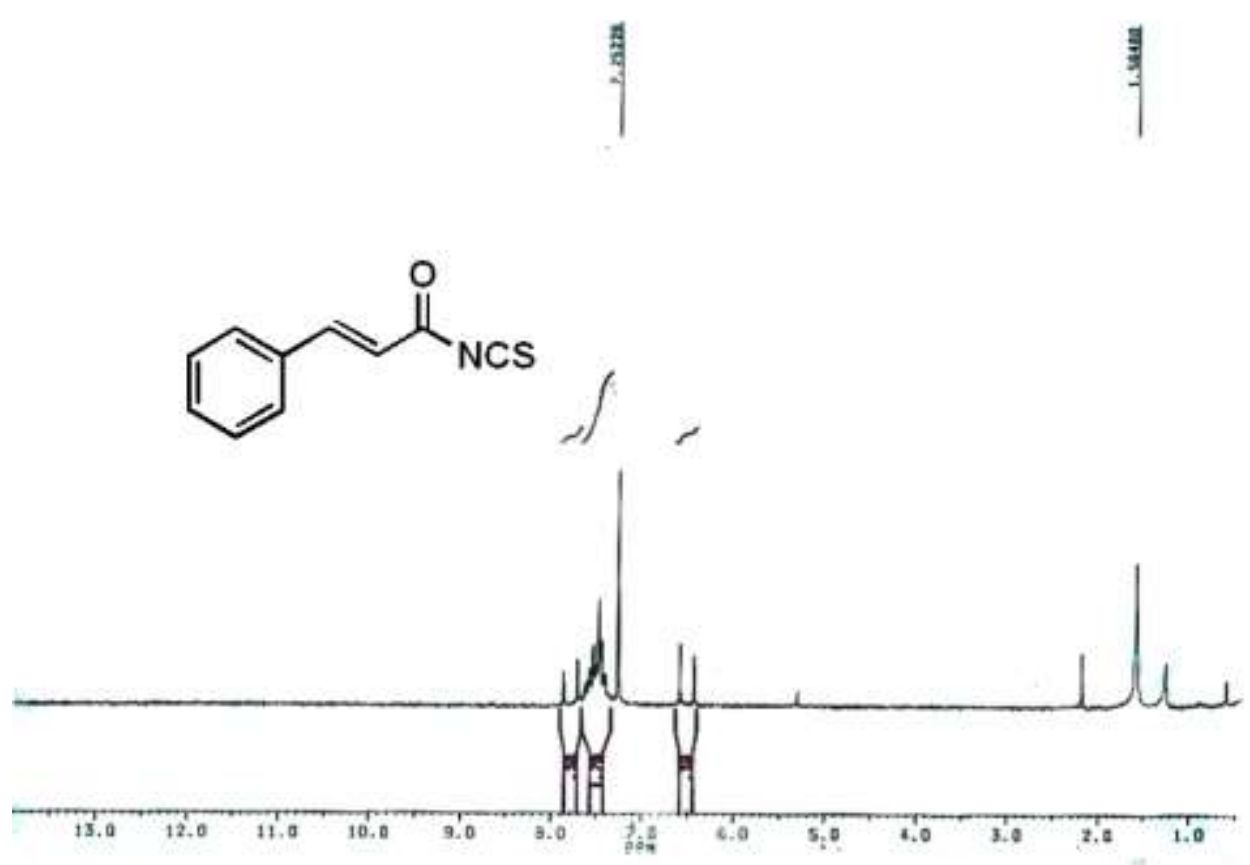

Figure S13-B: ${ }^{1} \mathrm{H}$ NMR $\left(100 \mathrm{MHz}, \mathrm{CDCl}_{3}\right.$ ) spectrum of cinnamoyl isothiocyanate (Table 2, entry 13)

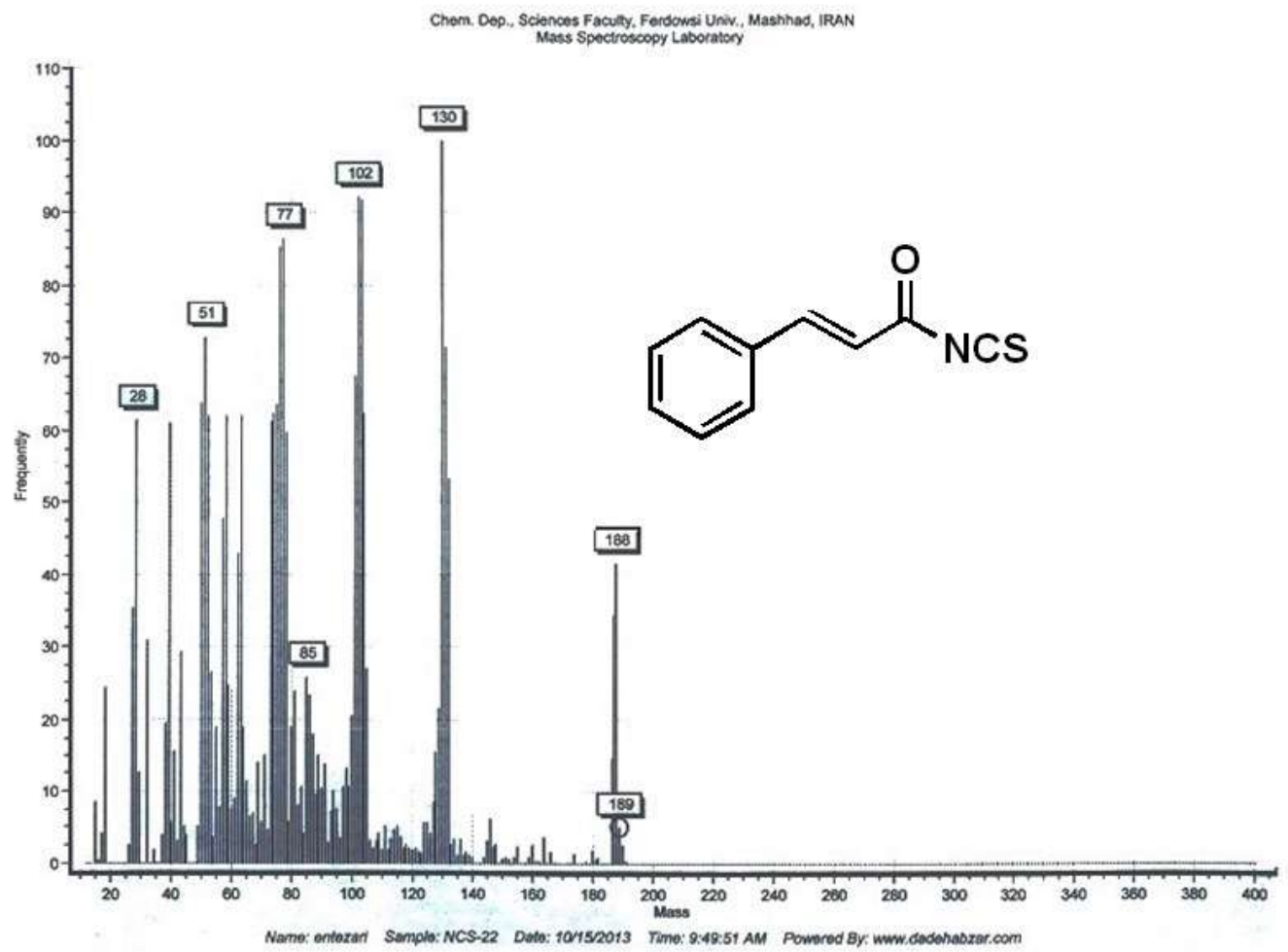

Figure S13-C: Mass spectrum of cinnamoyl isothiocyanate (Table 2, entry13) 


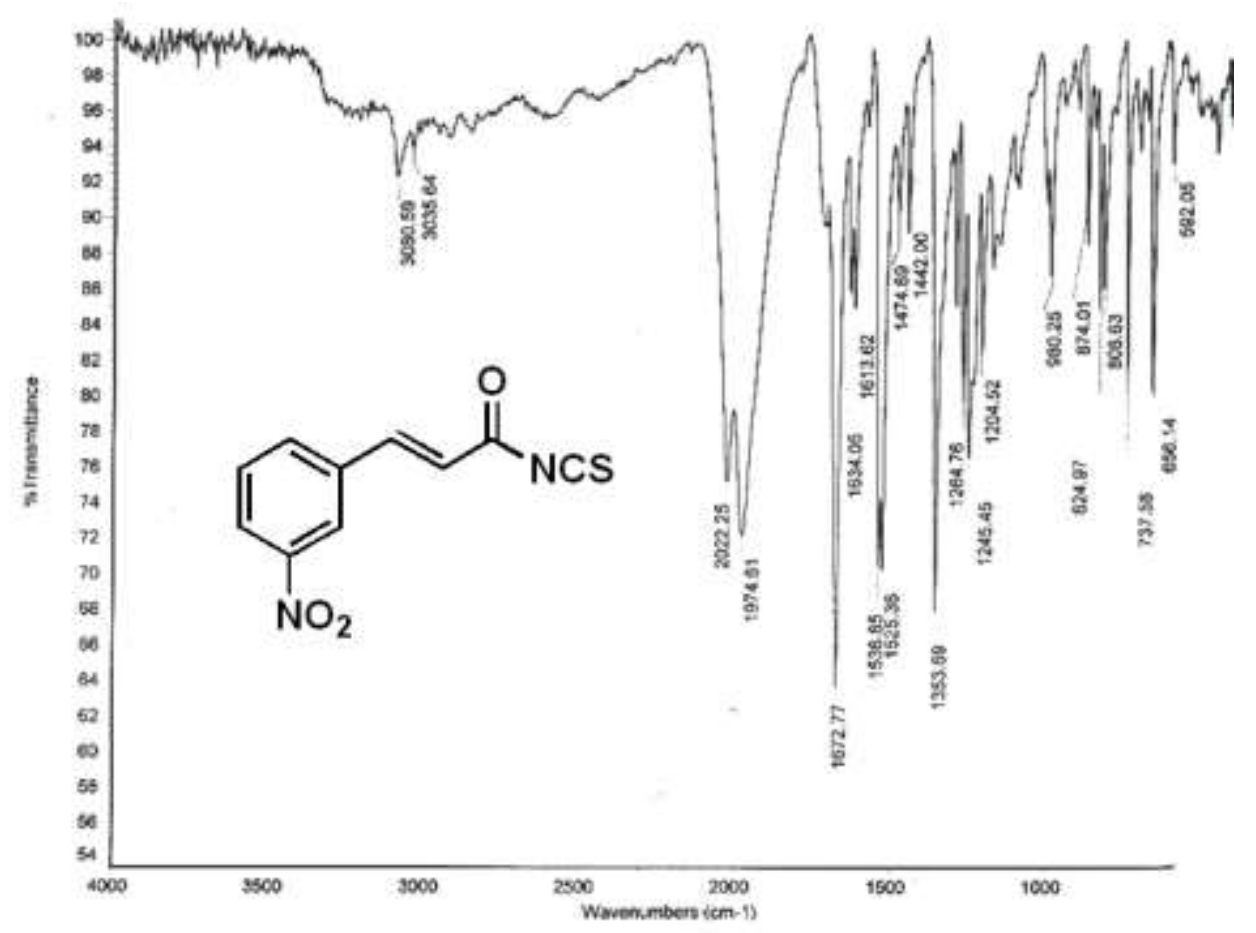

Figure S14-A: FT-IR (KBr) spectrum of (E)-3-(3-nitrophenyl) acryloyl isothiocyanate (Table 2, entry14)

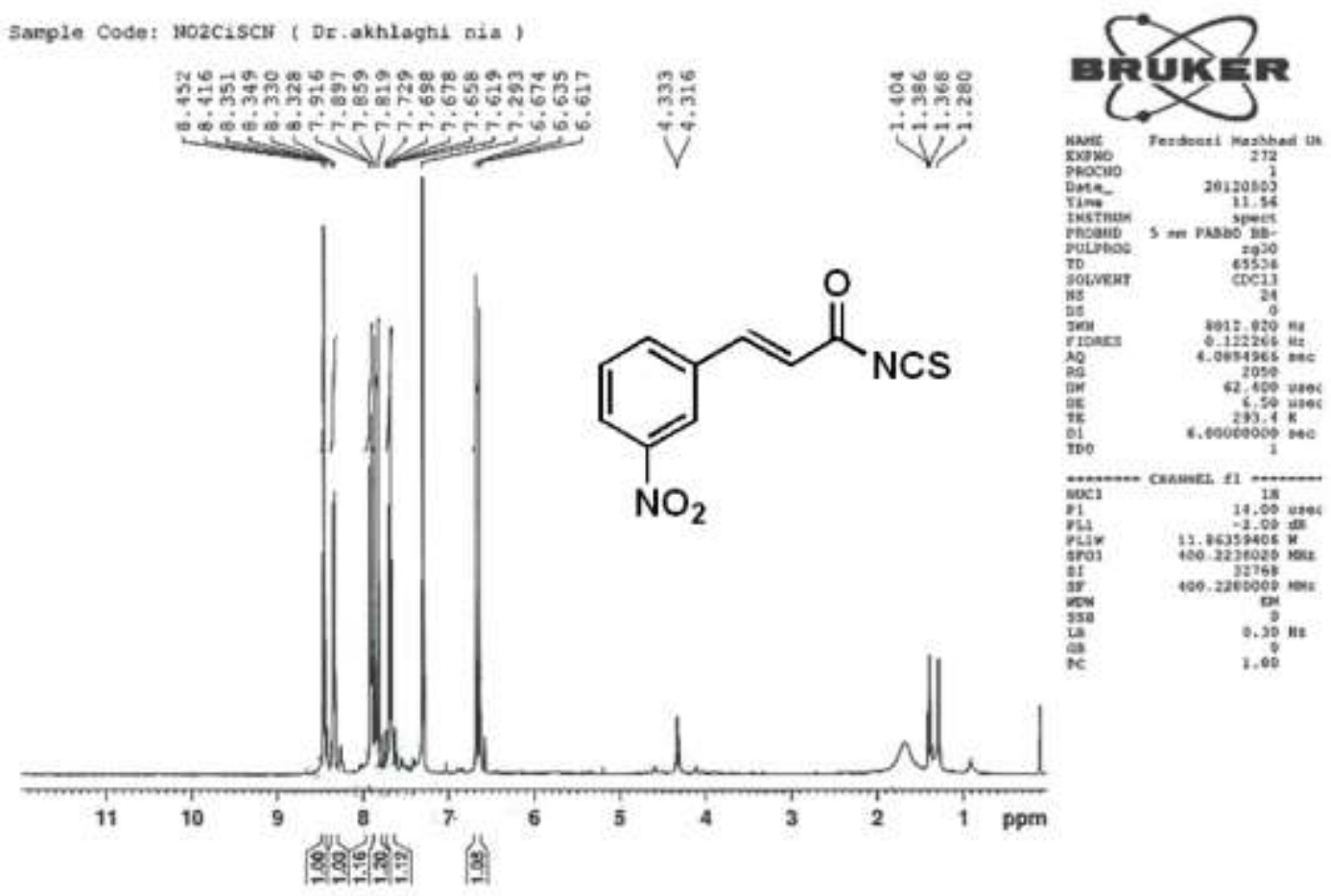

Figure S14-B: ${ }^{1} \mathrm{H}$ NMR $\left(400 \mathrm{MHz}, \mathrm{CDCl}_{3}\right.$ ) spectrum of $(E)$-3-(3-nitrophenyl)acryloyl isothiocyanate (Table 2, entry14) 


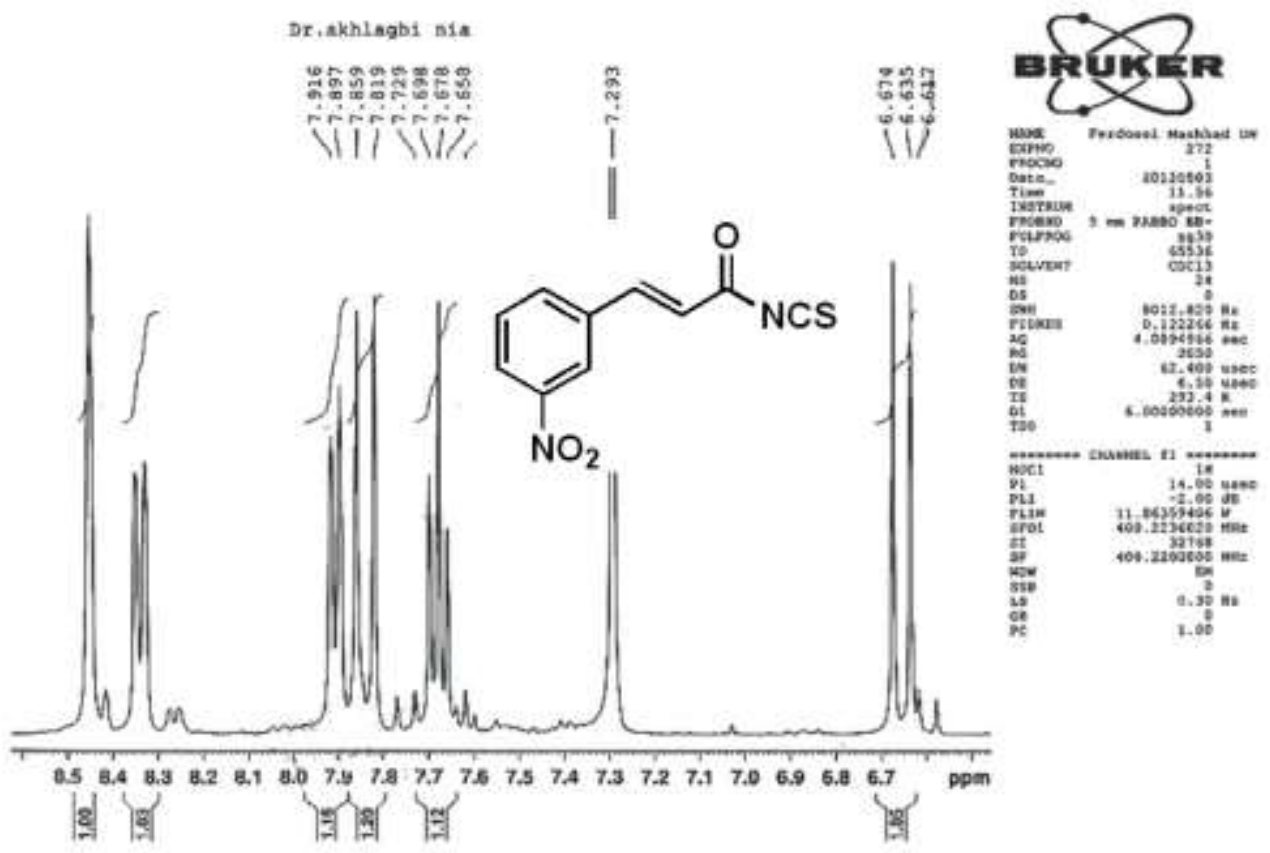

Figure S14-B $\mathbf{a}_{\mathbf{a}}:{ }^{1} \mathrm{H}$ NMR (400 MHz, $\mathrm{CDCl}_{3}$ ) spectrum of (E)-3-(3-nitrophenyl)acryloyl isothiocyanate (Table 2, entry 14)

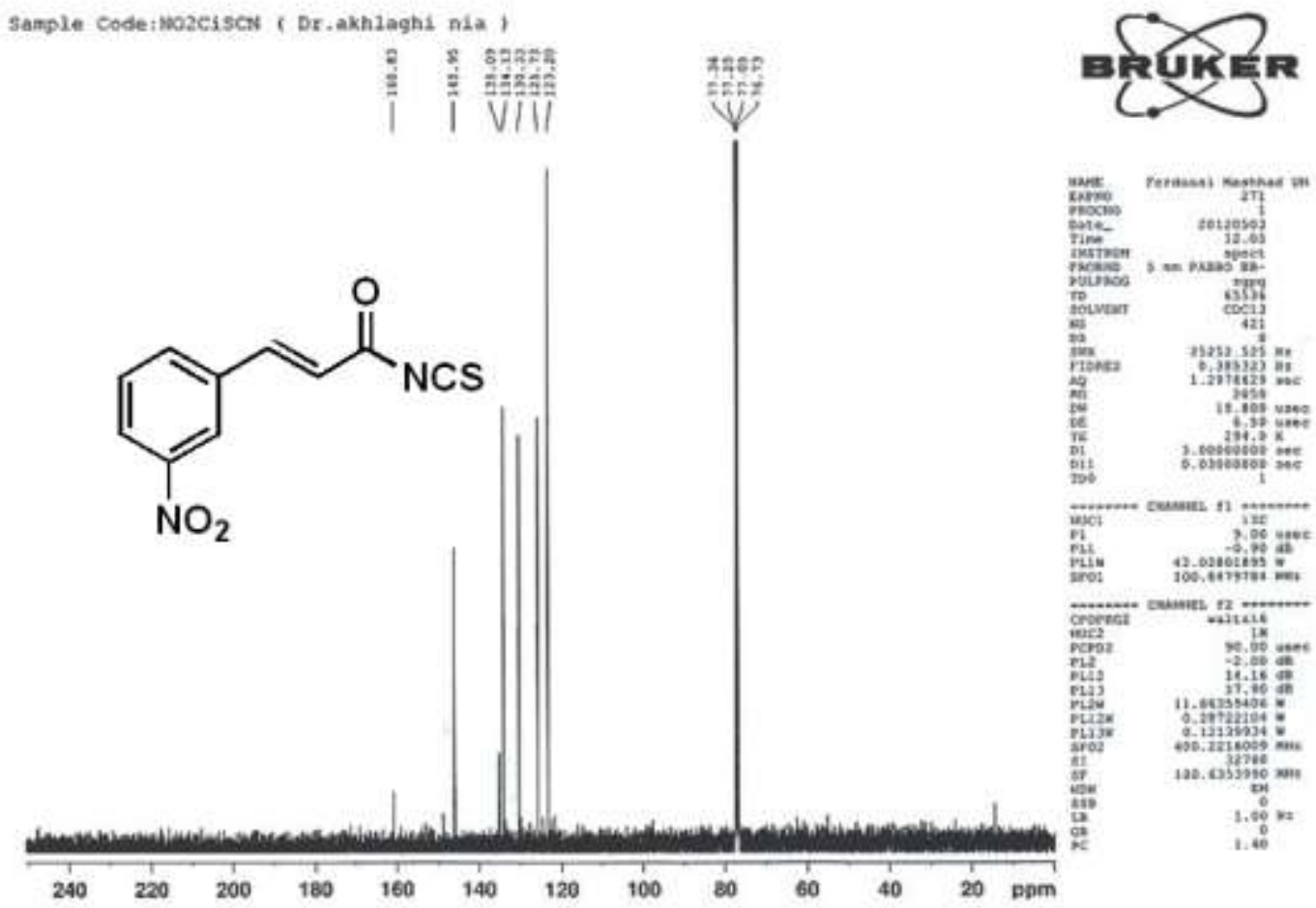

Figure S14-C: ${ }^{13} \mathrm{C}$ NMR (100 MHz, $\mathrm{CDCl}_{3}$ ) spectrum of (E)-3-(3-nitrophenyl)acryloyl isothiocyanate (Table 2,entry14) 


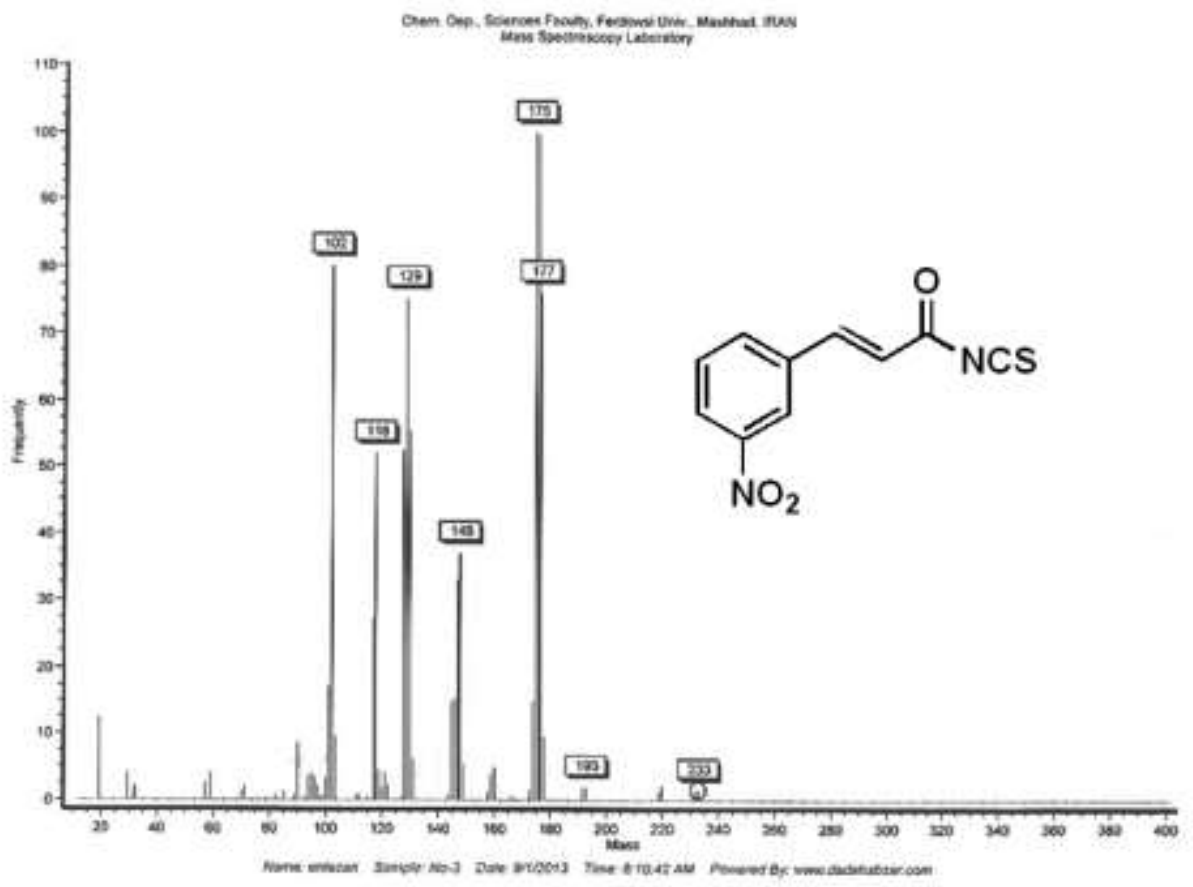

Figure S14-D: Mass spectrum of (E)-3-(3-nitrophenyl)acryloyl isothiocyanate (Table 2, entry 14)

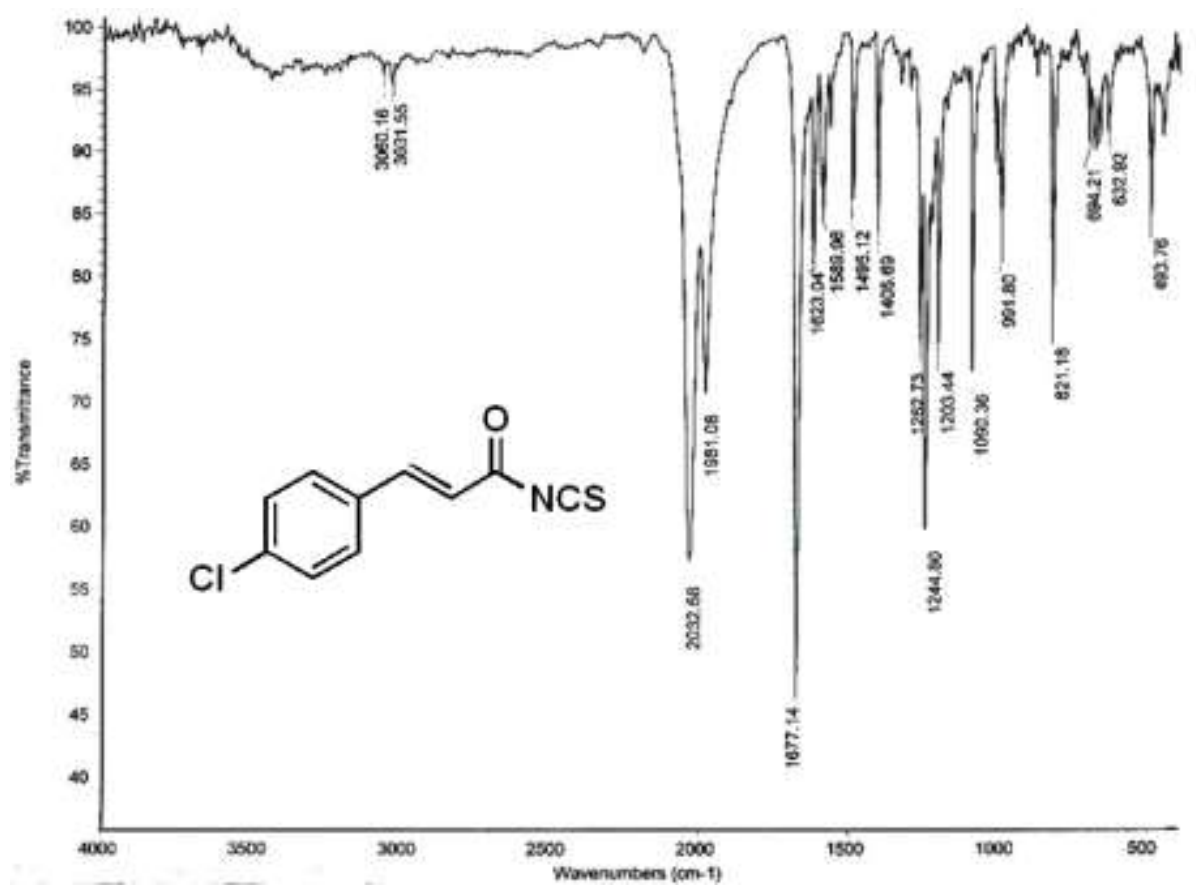

Figure S15-A: FT-IR (KBr) spectrum of (E)-3-(4-chlorophenyl)acryloyl isothiocyanate (Table 2, entry 15$)$ 


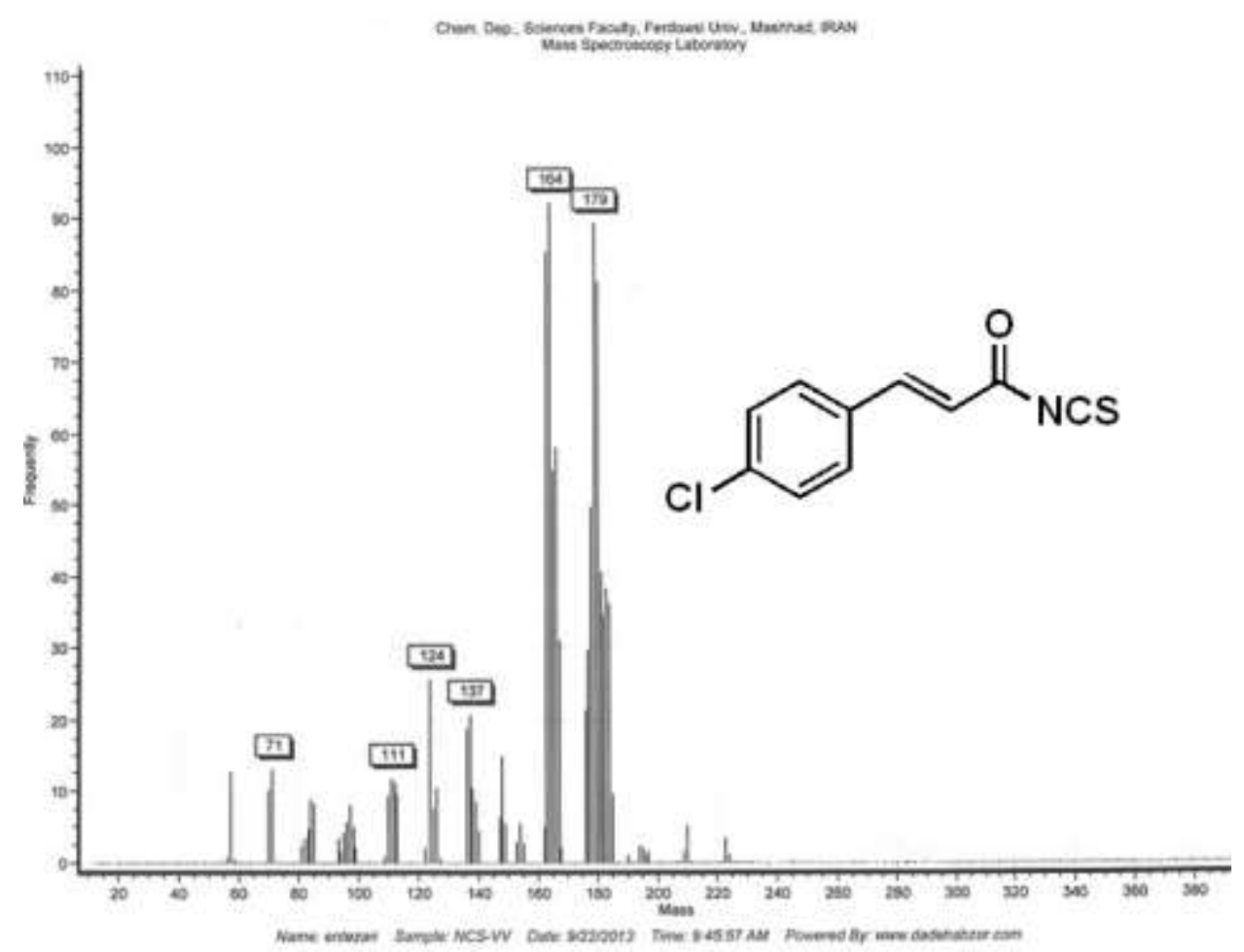

Figure S15-B: Mass spectrum of (E)-3-(4-chlorophenyl)acryloyl isothiocyanate (Table 2, entry 15)

Bager 300 Summarize Results

Date : $26 / 10 / 2013$ at $12: 14: 25$

Method Name : NCHS

Method Filename : Copy of Copy of N C B S-bkp .mth

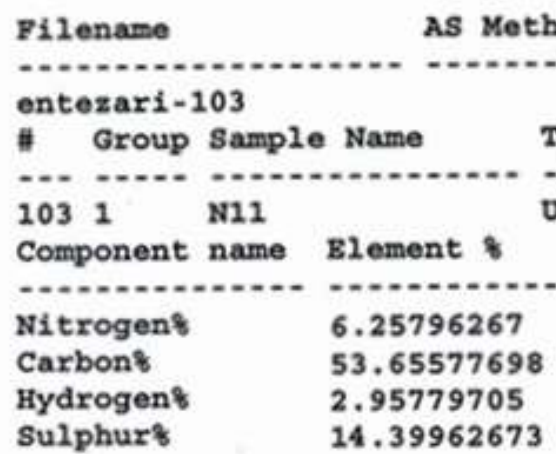

vial

Type Weig. Pro.F -..

UNK $\quad 0.335 \quad 6.25 \quad \mathrm{C}_{10} \mathrm{H}_{6} \mathrm{CINOS}$

1 Sample(s) in Group No : 1

Component Name Average

$\begin{array}{ll}\text { Nitrogen8 } & \mathbf{6 . 2 5 7 9 6 2 6 7} \\ \text { Carbon8 } & \mathbf{5 3 . 6 5 5 7 7 6 9 8} \\ \text { Hydrogen8 } & \mathbf{2 . 9 5 7 7 9 7 0 5} \\ \text { Sulphur8 } & 14.39962673\end{array}$

\begin{tabular}{|l|c|}
\hline Nitrogen $\%$ & 6.26 \\
\hline Carbon $\%$ & 53.70 \\
\hline Hydrogen \% & 2.70 \\
\hline Sulphur \% & 14.34 \\
\hline
\end{tabular}<smiles>O=C(/C=C/c1ccc(Cl)cc1)N=S</smiles>

Sulphur: $\quad 14.39962673$

Figure S15-C: Elemental analysis data of (E)-3-(4-chlorophenyl) acryloyl isothiocyanate (Table 2, entry 15) 


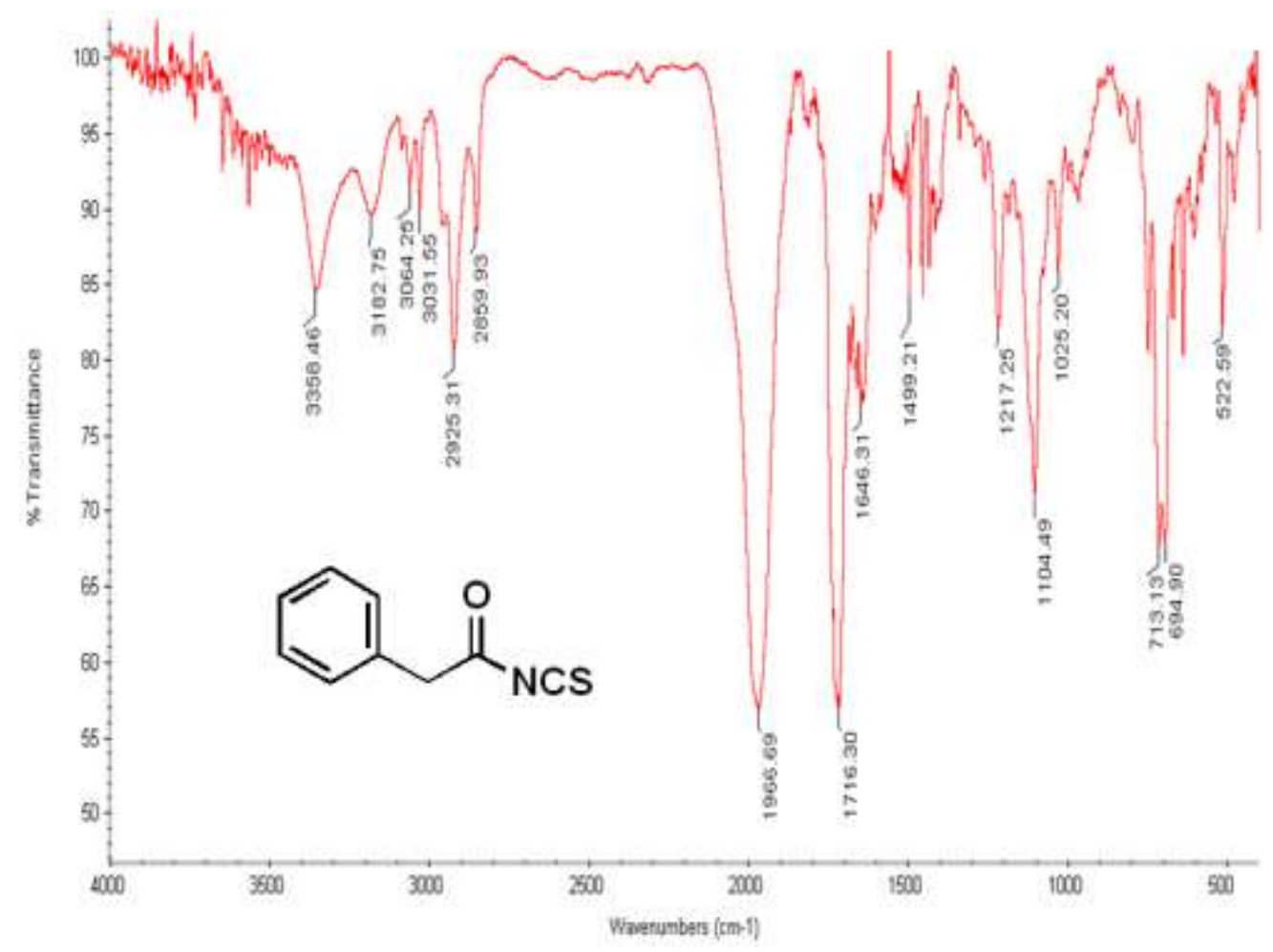

Figure S16-A: FT-IR (neat) spectrum of 2-phenylacetyl isothiocyanate (Table 2, entry 16)

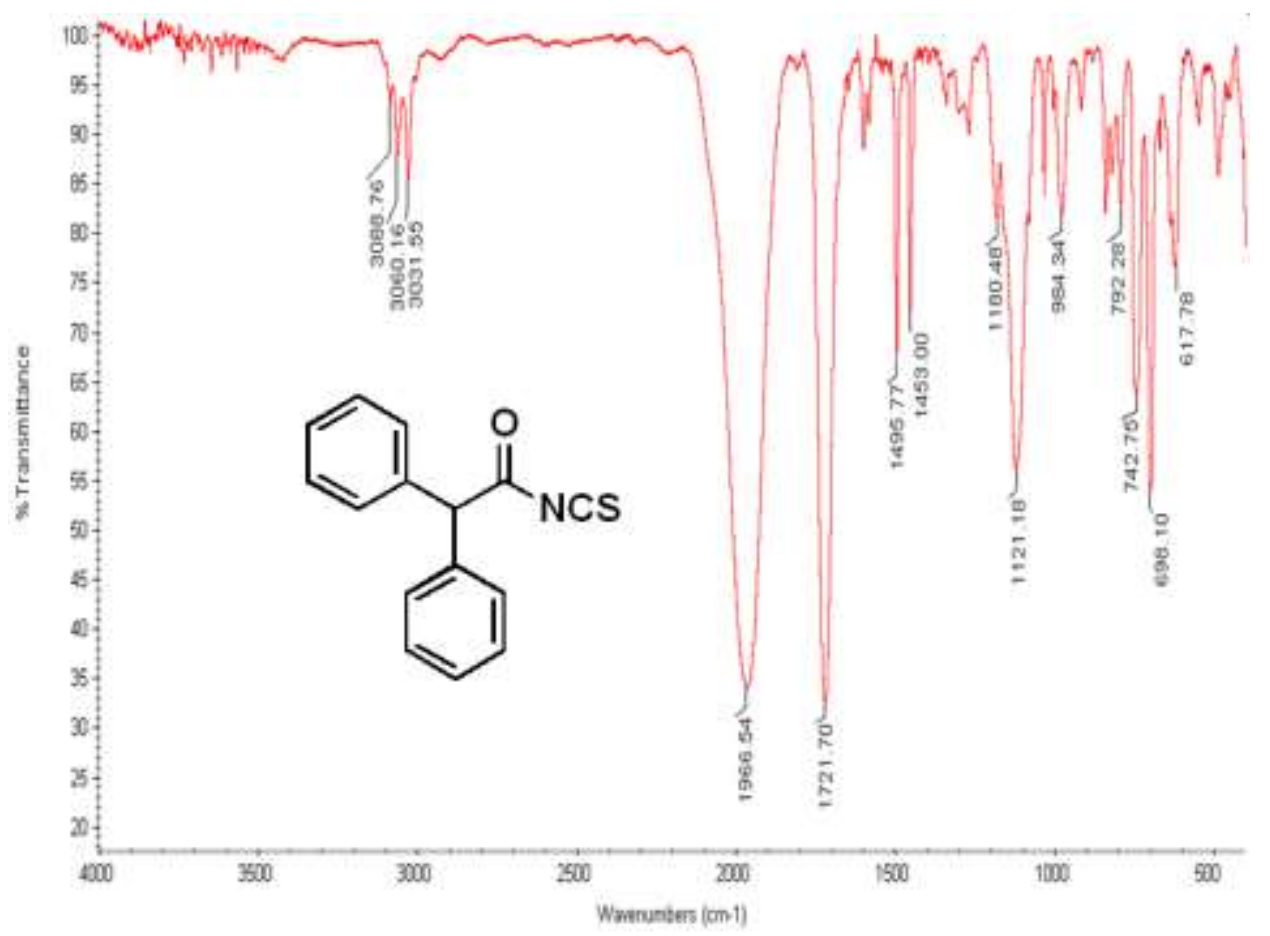

Figure S17-A: FT-IR (neat) spectrum of 2,2-diphenylethanoyl isothiocyanate (Table 2, entry 17) 


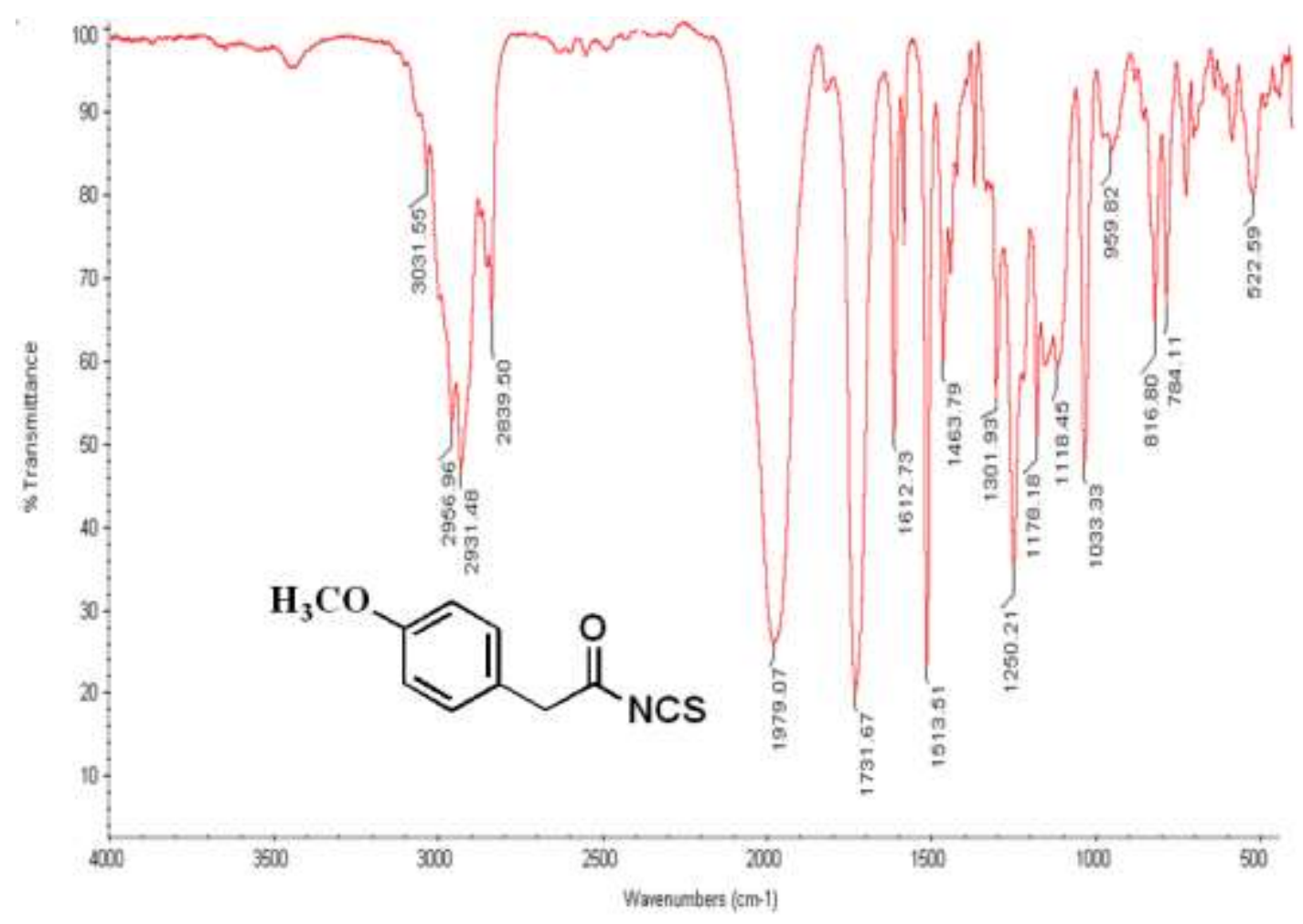

Figure S18-A: FT-IR (neat) spectrum of 2-(4-methoxyphenyl)ethanoyl isothiocyanate (Table 2, entry18)

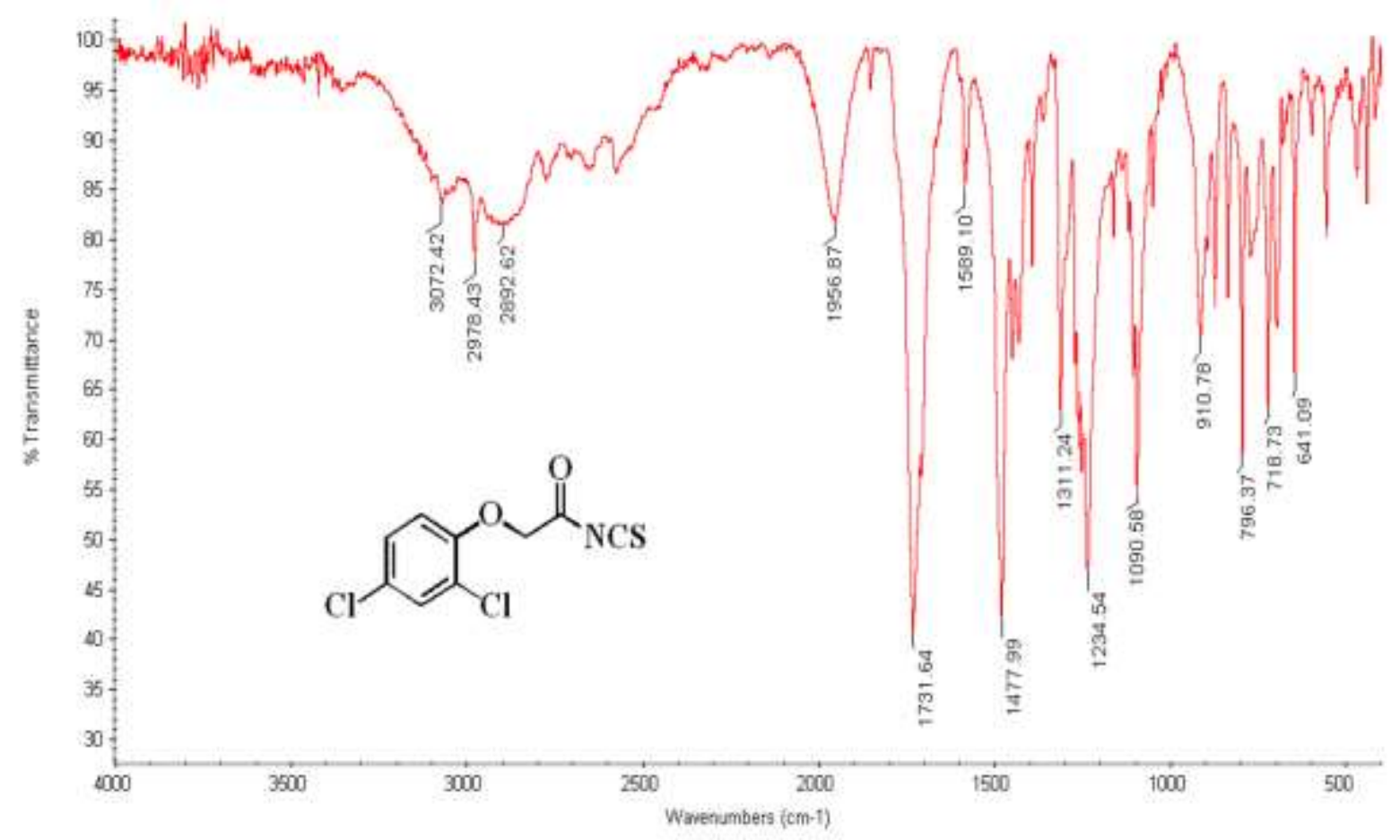

Figure S19-A: FT-IR (neat) spectrum of 2-(2,4-dichlorophenoxy) ethanoyl isothiocyanate (Table 2, entry19) 


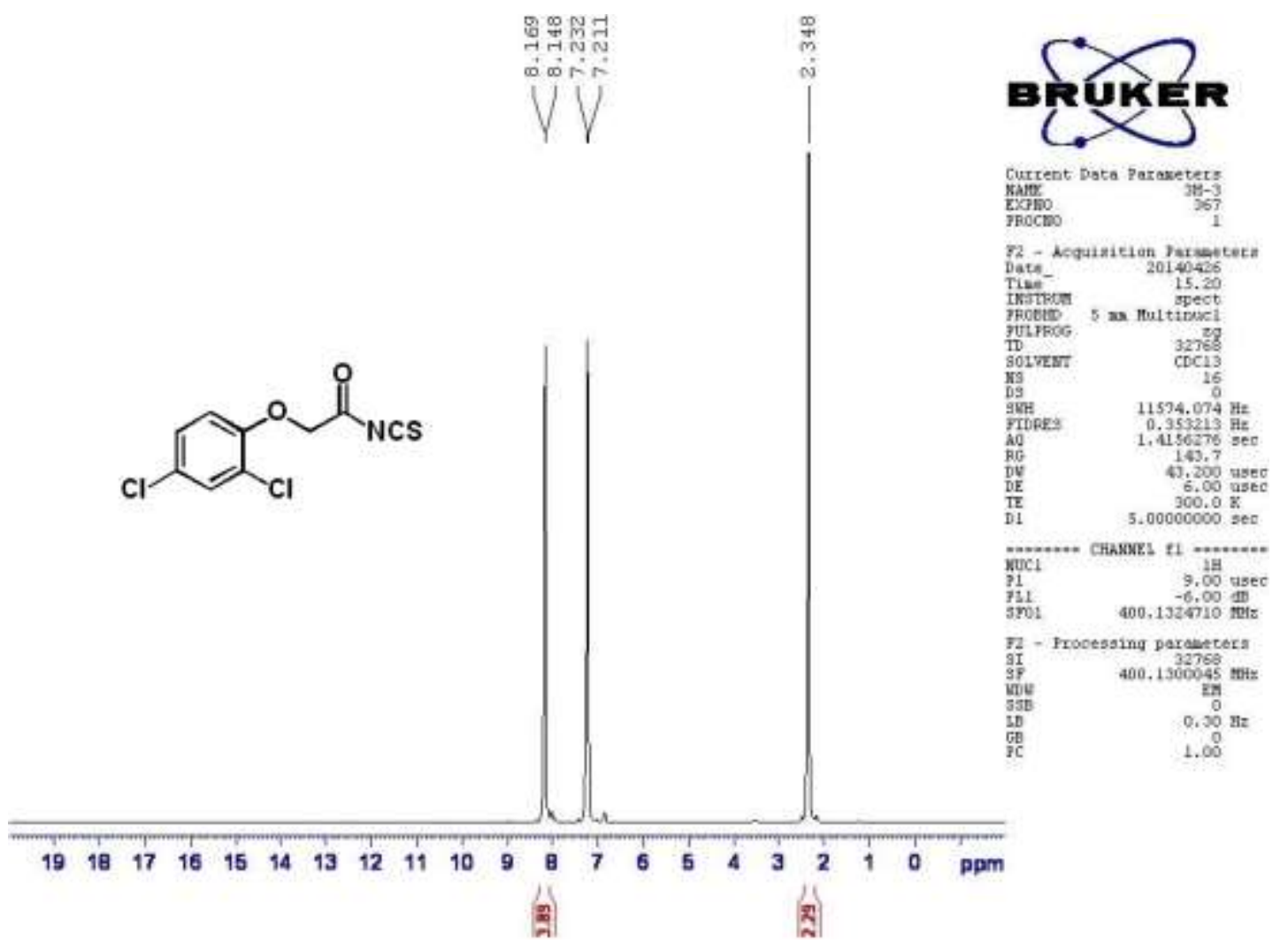

Figure S19-B: ${ }^{1} \mathrm{H}$ NMR (400 MHz, $\mathrm{CDCl}_{3}$ ) spectrum of 2-(2,4-dichlorophenoxy) ethanoyl isothiocyanate (Table 2, entry 19)

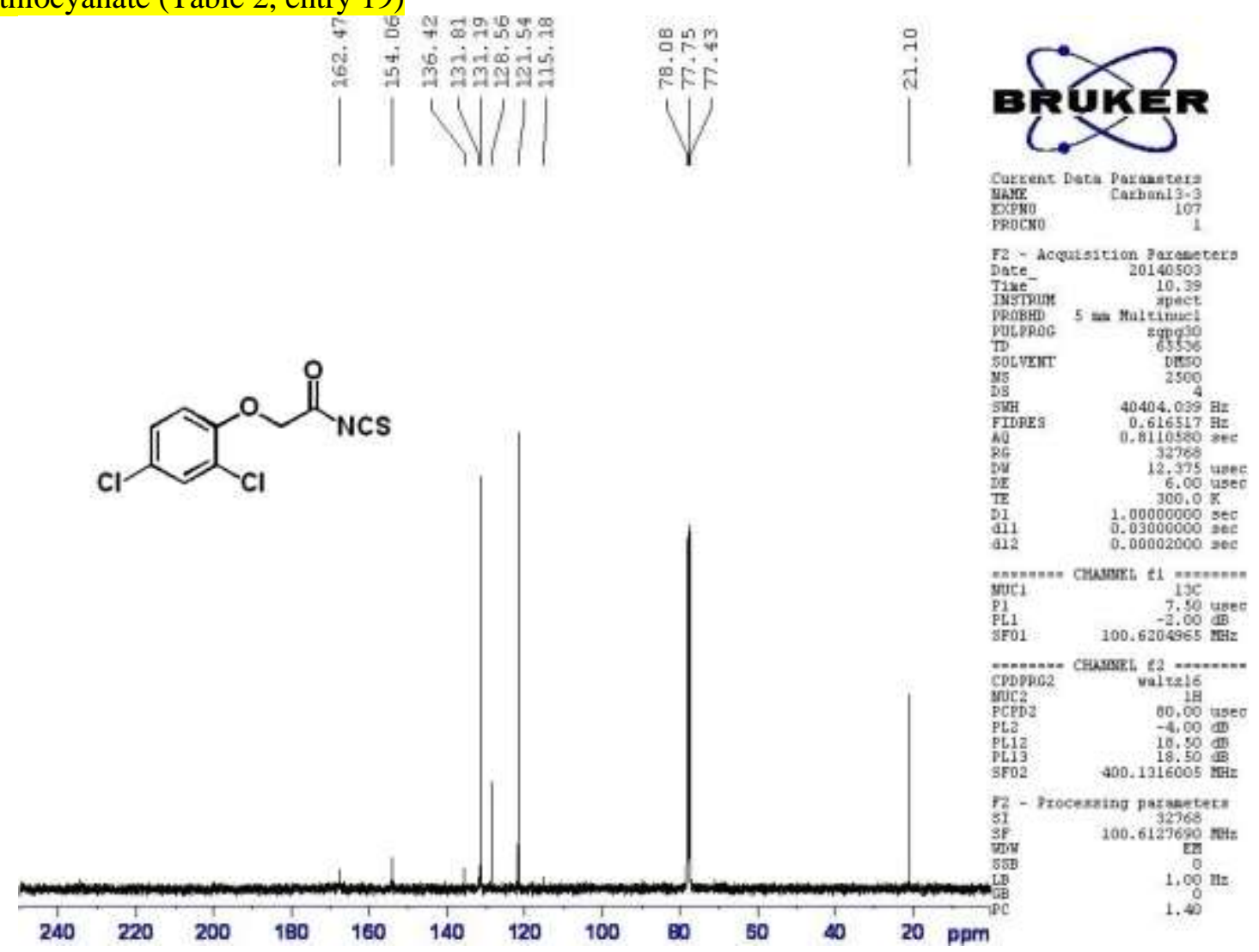

Figure S19-C: ${ }^{13} \mathrm{C}$ NMR (100 MHz, $\left.\mathrm{CDCl}_{3}\right)$ spectrum of 2-(2,4-dichlorophenoxy) ethanoyl isothiocyanate (Table 2, entry 19) 


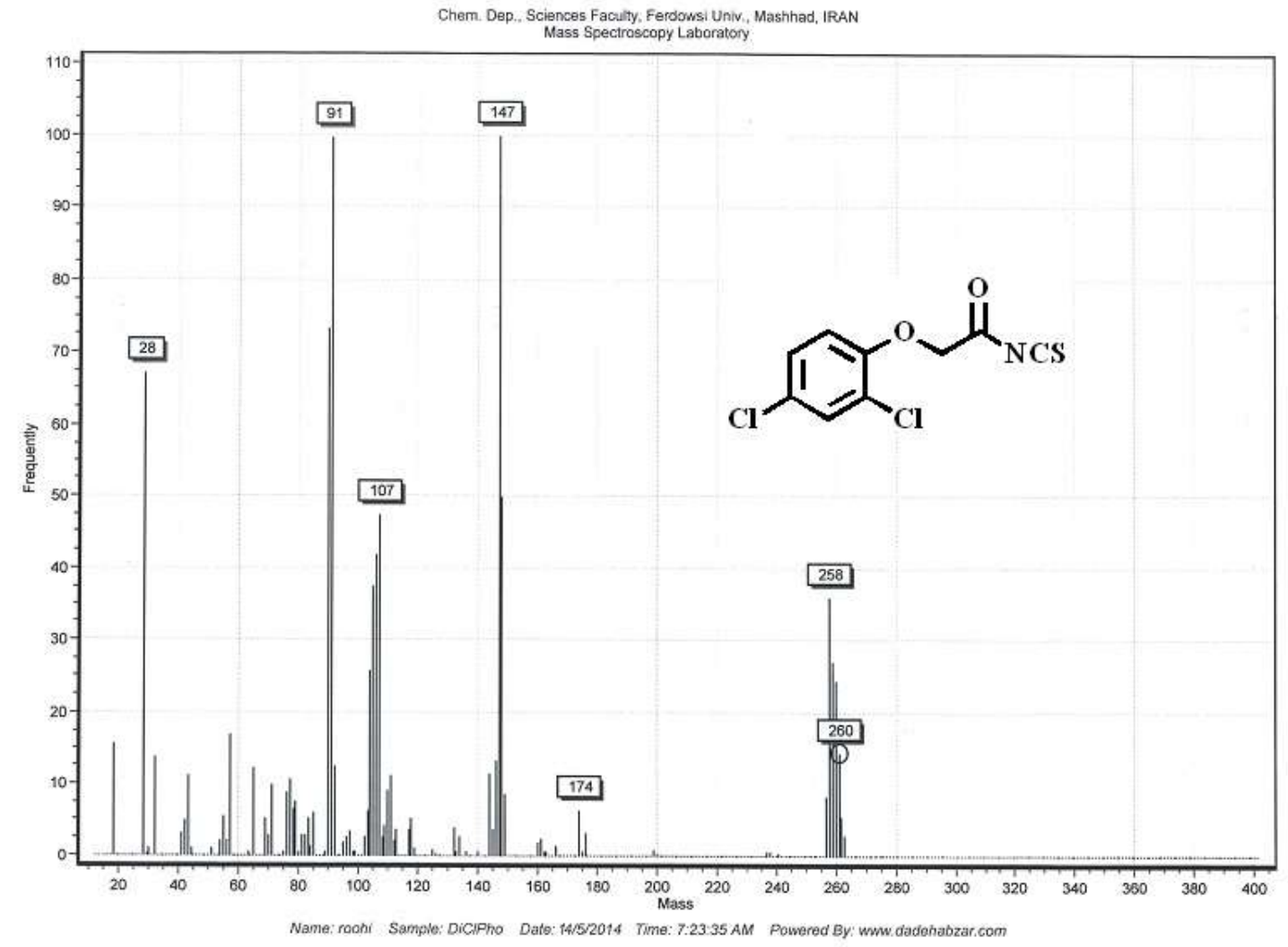

Figure S19-D: Mass spectrum of 2-(2,4-dichlorophenoxy) ethanoyl isothiocyanate (Table 2, entry 19)

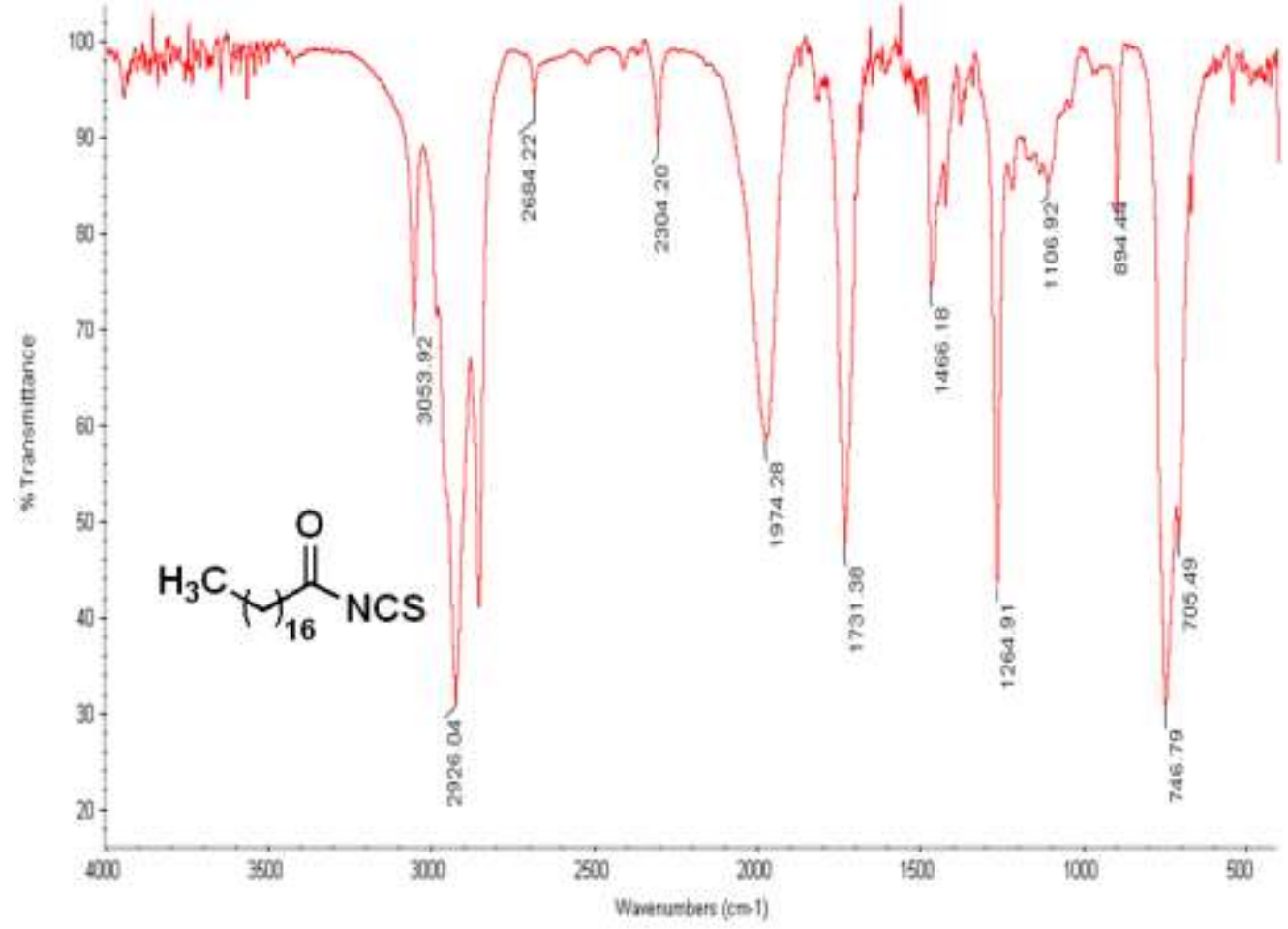

Figure S20-A： FT-IR (neat) spectrum of Stearoyl isothiocyanate (Table 2, entry 20) 